\title{
Storyline Concerns and Word Order Typology in East and West Africa
}

\section{Robert E. Longacre}

\section{STUDIES \\ in \\ in}

AFRICAN LINGUISTICS

SUPPLEMENT 10

Published by the Department of Linguistics

and the James S. Coleman African Studies Center

University of California, Los Angeles 
Studies in African Linguistics

Supplement 10

\section{Storyline Concerns and Word Order Typology in East and West Africa}




\section{Storyline Concerns and Word Order Typology in East and West Africa}

Robert E. Longacre

University of Texas at Arlington

The James S. Coleman African Studies Center and

The Department of Linguistics

University of California at Los Angeles

1990 


\section{CONTENTS}

INTRODUCTION

1. Discourse Typology

2. Storyline Analysis

3. Word Order Typologies

4. Peak as a Cumulative Development

5. Miscellaneous Concerns

1. SOME SOV LANGUAGES OF ETHIOPIA 11

1. Koorete (Omotic)

2. Afar (Cushitic)

3. Gimira (Omotic)

3.1. The grammaticalization of finals 21

3.2. The storyline scheme 22

3.2.1. Storyline verbs 24

3.2.2. Non-storyline events 28

3.2.3. Background activity $\quad 29$

3.2.4. Setting $\quad 32$

3.2.5. Irrealis information 33

3.2.6. Cohesion $\quad 34$

3.2.7. Performative clauses $\quad 35$

3.3. Rank-shifting of gerunds $\quad 35$

3.4. The storyline scheme and constituency structure 36

3.4.1. Sentence structure $\quad 37$

3.4.2. Paragraph structure 41

3.5. Peak marking features 44

4. Kambaata (Cushitic) 44

4.1. Kambaata compared with other languages 45

4.2. The storyline scheme (more comparisons) 46

4.3. Peak-marking features $\quad 49$

5. Haddiya (Cushitic) 50

5.1. The storyline scheme (upper bands) 50

5.2. Possible diachronic storyline developments 53

5.3. The storyline scheme (lower bands) 54 
6. Amharic(Ethio-Semitic) 56

6.1. The storyline scheme (upper bands) 56

6.2. Rank-shifting of gerunds $\quad 59$

6.3. The storyline scheme (lower bands) 60

6.4. Peak-marking features $\quad 62$

7. Silti (Ethio-Semitic) 62

2. SOME LANGUAGES OF SUDAN 64

1. Toposa (Eastern Nilotic) 65

2. Sabaot (Southern Nilotic) 66

$\begin{array}{ll}\text { 2.1. The storyline scheme } & 67\end{array}$

2.2. The secondary storyline $\quad 69$

2.3. Background activities/states $\quad 71$

$\begin{array}{ll}\text { 2.4. Flashback } & 72\end{array}$

2.5. Setting and author comment $\quad 74$

$\begin{array}{ll}\text { 2.6. Peak-marking features } & 74\end{array}$

3. Murle (East Sudanic) 75

3.1. The storyline scheme $\quad 75$

3.2. An extended example $\quad 77$

$\begin{array}{ll}\text { 3.3. Perfectives as peak } & 78\end{array}$

4. Luwo (Northern Nilotic) $\quad 79$

4.1. $U$ - verbs versus a-verbs $\quad 79$

4.2. $U$ - verbs versus maa verbs $\quad 80$

4.3. Ake verbs $\quad 80$

4.4. The resultant storyline scheme 81

4.5. $U$-verbs as a consecutive tense $\quad 82$

4.6. The storyline scheme and constituency structure 83

5. Anywak (Northern Nilotic) 87

5.1. Indefinite and definite verbs $\quad 87$

5.2. Consecutive clauses (compared with medial clauses in SOV $\begin{array}{ll}\text { languages) } & 88\end{array}$

5.3. Storyline scheme elements 90

5.3.1. Secondary storyline 90

5.3.2. Promoted indefinite forms 91

5.3.3. Lower storyline scheme elements 91

6. Avokaya (East Sudanic) 91

6.1. Avokaya as a weak SOV structure $\quad 91$

6.2. The storyline scheme and its parameters 92

$\begin{array}{ll}\text { 6.3. The status of speech verbs } & 94\end{array}$

6.4. Primary and secondary storylines 95

$\begin{array}{ll}\text { 6.5. The cohesive band } & 97\end{array}$

7. Jur-Mödö (East Sudanic) 99

7.1. Problems in rank-scheme analysis 99 
4. Ewe (standard dialect of Gbe, Kwa Niger-Congo) 154

5. Mwaghavul (Western Chadic) 155

6. Bassa (Kru Niger-Congo) 157

6.1. Connectives as necessary to the storyline and background activities

6.2. Extended exemplification 158

7. Juba Arabic 160

8. Nawdm (Gur Niger-Congo) 162

8.1. The folktale 162

8.2. The historical account 164

9. Gangam or Dye (Gur Niger-Congo) 166

9.1. Storyline constructions 166

9.2. Other storyline scheme bands 169

9.3. Storyline rank and constituency structure 169

SUMMARY: SOME CONCLUSIONS AND COMPARISONS 
7.2. Ranking $\mathrm{V}$ versus $k \mathrm{~V}$

$\begin{array}{ll}\text { 7.3. The storyline scheme } & 102\end{array}$

7.4. Promoters 107

8. Summary

8.1. Storyline typology crisscrossing other classifications 108

8.2. Narrative tense versus consecutive tense

3. OTHER LANGUAGES WHICH HAVE A CONSECUTIVE TENSE

1. Mündü (Eastern Niger-Congo) 111

1.1. Storyline scheme elements $\quad 112$

1.2. The storyline scheme 114

1.3. Auxiliary verbs and storyline scheme ranking 115

1.4. The secondary storyline and flashback 119

1.5. Storyline scheme ranking and constituency structure 119

2. Nzema (Kwa Niger-Congo) 125

2.1. Storyline scheme elements 125

2.2. The storyline scheme 127

3. Obolo (Lower Cross Group Niger-Congo) 129

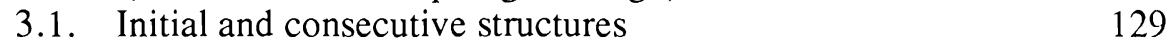

3.2. Exemplification 131

4. Tem, also called Kotokoli (Central Gur Niger-Congo) 133

4.1. The perfective and the consecutive 133

4.2. Other uses of the consecutive tense 134

4.3. Storyline scheme features 135

5. Yom or Pila-Pila (Gur Niger-Congo) 135

5.1. The perfect and the consecutive as storyline tenses 136

$\begin{array}{ll}\text { 5.2. Storyline tenses at peak } & 137\end{array}$

5.3. Perfect and consecutive off the storyline 137

5.4. The continuative 139

6. Belanda Viri (Eastern Niger-Congo) 140

6.1. Storyline form plus uninflected verb clause $\quad 140$

6.2. "Coordinated" clauses as consecutive 140

6.3. Non-storyline elements 141

6.4. Ideophones 142

4. LANGUAgES WITHOUT A CONSECUTIVE TENSE 144

1. Izi (Kwa Niger-Congo) 144

1.1. Grammaticalization of a former consecutive tense 146

1.2. The narrative past on the storyline 146

$\begin{array}{ll}\text { 1.3. Auxiliaries plus the sequential as storyline } & 147\end{array}$

2. Mumuye (Adamawa Niger-Congo) 149

3. Jju or Kaje (Benue-Congo Niger-Congo) 152 


\section{INTRODUCTION}

This volume considers data from some forty African languages on the East and West sides of the continent in an effort to answer the question, "How do languages of different word order typologies tell a story?" The evidence suggests that the ordering of constituents on the clause level, i.e. subject, verb, and object/complement, often determines differences in the mechanics of story telling. Furthermore, in some (perhaps all) languages, storyline clauses are the most typical and diagnostic of the word order typology itself, perhaps because the story (anecdote) is the most basic form of monologue discourse. Thus, a language of VSO typology in narrative may be SVO in expository or descriptive discourse and, in secondary lines of development, even in narrative. This is clearly seen especially in the languages which are cited in Chapter 2.

Our sampling of African languages in regard to storytelling considers first of all certain languages of Ethiopia which are classic SOV chaining languages. Here a main concern for storyline analysis has to do with the evaluation of the status of final (independent) verbs as opposed to the status of medials (variously called coverbs, gerunds, or participles), i.e. storyline concerns have to face head-on several crucial features of SOV chaining languages (cf. Papua New Guinea, much of South America, Korean, Japanese, and Turkish). On examination, however, certain VSO languages of Sudan and some SVO languages of both East and West Africa are found to chain from a special initial verb (and clause) plus consecutive verbs (and clauses) of somewhat different structure. Here a main concern of storyline analysis is the status of the initials versus that of the consecutives in regard to storyline weight. At this point a mirror image relationship of right-chaining SOV languages to left-chaining VSO and SVO languages begins to emerge. This suggests a further typological distinction among the world's languages, i.e. right-chaining languages, left-chaining languages, and co-ranking (or non-chaining) languages. These concerns are the main thrust of this volume.

In the balance of this Introduction I endeavor to lay a groundwork for the following chapters in regard to (1) discourse typology, (2) storyline analysis in narrative, (3) word order typologies, and (4) cumulative development in narrative, plus a few miscellaneous concerns.

\section{Discourse Typology}

Discourse analysis implies a typology of discourse. Mainlines of development differ radically from discourse type to discourse type. In narrative discourse the 
mainline is a storyline which is carried by clauses whose verbs are maximally dynamic, i.e. high in "transitivity" as defined, for example, by Hopper and Thompson [1980]. Storyline verbs are of various sorts, but action, motion, and speech verbs all have in common the fact that they represent punctiliar, sequential, and (usually) volitional happenings in the past. The line of procedure in a procedural discourse is similar in many ways to a storyline, but while its mainline verbs are punctiliar, sequential, and (usually) volitional, they are not set in past time so much as in lapsed time: a series of actions to be performed (or which were performed) under certain cultural constraints and for certain goals. Narrative and procedural discourse also differ in respect to agent-orientation in the former and goal-orientation in the latter, i.e. it does not matter who performs these procedures provided that the proceed towards the stated end.

Other discourse types are even more radically different. In hortatory discourse there is a line of exhortation (persuasion) carried by command forms which are often subtly mitigated. The line of exhortation/persuasion is accompanied by other elements such as the authority or credentials of the speaker, the situation or problem out of which the exhortation springs, and motivation (promise or warnings) to act on the exhortation.

Expository (explanatory or descriptive) discourse has a line of exposition. Its mainline, in contrast to that of other discourse types, is static with a preference for 'be' verbs and other statives as used in equative, existential, and descriptive clauses. Supportive material can involve dynamic verbs employed by way of illustration and anecdote.

An awareness of this broad typology is essential for text analysis. The clause types and verb types that occur in one sort of discourse versus another differ radically not in regard to statistical count only, but structurally in regard to distribution in mainline versus supportive materials. In fact, the verb system (tense, aspect, and mood) of a language can be profitably viewed as a set of subsystems appropriate to each discourse type which is, in turn, characterized by the cluster of verb forms which it exploits. Noun phrases and kindred elements (pronouns, pronominal affixes, and zero anaphora) also are used differently according to the major discourse types in which they are found. Thus, sentence and paragraph structures can differ so markedly in, for example, narrative and procedural discourse versus hortatory and expository, as to give the impression of two sets of grammar at work in the same language, e.g. in certain languages of Papua New Guinea and of northern South America.

\section{Storyline Analysis}

The importance of storyline analysis is twofold, (a) both in respect to the distinguishing of the storyline itself and (b) in respect to distinguishing other strands of narrative development which encode various degrees of departure from the storyline. 
Putting matters this way involves two assumptions. (1) First of all, it is assumed that in most languages clauses that advance the progress of a narrative are distinguished in some more or less consistent fashion from clauses that do not. Often storyline clauses require a distinct verb form, i.e. some tense, aspect, or combination of the two. At any rate, storyline clauses represent happenings as punctiliar, sequential, and (most often) voluntary. The formal distinguishing of the storyline needs sometimes to be supplemented by a semantic distinction, e.g. barring 'be' verbs and statives from the storyline even if they happen to have the required form. (2) Secondly, storyline clauses, except in the most rudimentary, stripped-down kind of narrative, are accompanied by clauses which report other sorts of information and which may be ranked in order of progressive degrees of departure from the storyline.

In developing and illustrating these assumptions I shall procede in two stages. First of all, I shall illustrate briefly some of the more fundamental distinctions. This will culminate in a tentative scheme (Diagram I) which will be illustrated via English (for a more adequate treatment of English, see Longacre [1989a] and Longacre [1989b]). Secondly, I shall procede to present and discuss a more adequate scheme which is both an a priori theoretical and an empirical construct (Diagram II) and which has proven basic to discourse analysis in the languages embraced in this project and comes from a previous sampling of languages from around the world [Longacre 1989a].

A tentative scheme can be posited as follows: If we rank Storyline clauses as (1), we also find (2) clauses which report Backgrounded Events which are considered to be preparatory to or resulting from those which are reported on the storyline; (3) clauses which report Backgrounded Activities which are overlapping rather than sequential and durative rather than punctiliar; (4) Setting clauses (the when and where of the story, the circumstances, introduction of participants, background explanation) which have 'be' verbs, whether existential/locational or copulative/descriptive, or other stative verbs; (5) Irrealis clauses (modals, conditionals, and most negatives) that present an alternative world to the world given in the storyline; (6) Author Intrusions (performatives, evaluation, and morals); and (7) Cohesive clauses (adverbial) which refer back to previous parts of the storyline, either by reporting a new but script-predictable event or by an anaphoric reference to the former event.

In regard to this ranking, the following remarks apply to verb forms: (A) Since it is assumed that verbs are central to their clauses, the ranking of the latter in regard to the storyline of narrative in a language is also a ranking of verb forms (aspects, tenses, and moods) with reference to narrative. (B) Clauses without verbs, i.e. nominal clauses, can occur in setting. (C) The scheme especially classifies independent verbs in main clauses. Adverbial clauses, relative clauses, and most verbals are demoted. Thus a verb which, if independent, would have been on the storyline may be demoted to (2) when it occurs in an adverbial clause, relative clause, or as a verbal, but not simply cohesive as in (7). (D) Some languages have a 
special pluperfect form, which determines a variant of (2) above. More often, languages do not have such a form.

I summarize this ranking in Diagram I. The accompanying tabulation illustrates such forms in English. The sentences within the tabulation are not arranged in a narrative sequence, but rather in the order of the bands given in Diagram I. All the sentences in the tabulation are to be regarded, however, as from the same narrative. Where only a part of a sentence is illustrative of a given rank, that part of the sentence is underlined.

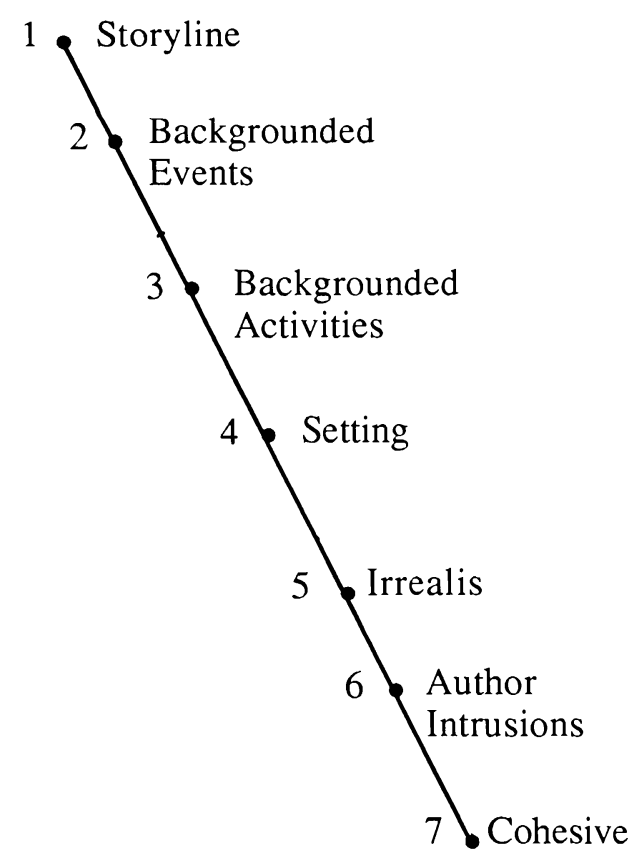

1. We climbed over the wall...The guard yelled out a warning.

2. Jumping up and grabbing the edge, I managed to pull myself up. Then I tossed down the rope which Harry had brought.

3. All the time the two "decoys" were making their way around to the other side of the property.

4. It was a small, somewhat bombed-out little town in Normandy, three weeks after D-day...The wall was about seven-foot high and made of crumbly old masonry.

5. If it had only been two hours earlier, all this wouldn't have happened.

6. I remember that wall, and I defy anyone who thinks he could have got over it noiselessly.

7. About as soon as we got over the wall, the hue and cry of the chase began.

\section{Diagram I}

\section{Tabulation I}

The rank scheme, while illustrative of some of the more basic distinctions which are encountered, nevertheless needs further distinctions and enrichment. To begin with, in English itself, storyline verbs seem to constitute a band which is internally ranked according to case grammar (classification of verb) considerations. Thus, Subject as Agent presumably outranks Subject as Experiencer and Subject as Patient, giving us a classification into Actions, Cognitive Events, and Contingencies, as seen in "We climbed over the wall" vs. "We sensed immediately that something was wrong" vs. "We got caught in a thunderstorm." Motions, those predicates in which Agent is conferential with Patient, may rank somewhat lower than Actions proper. In a story, motion verbs move participants on, off, or across 
the stage preparatory to their participation in actions. In English, furthermore, cognitive events, such as illustrated above, must be distinguished from cognitive states included under 3 in Diagram I: "We knew all along that something was wrong." Finally, a verb ranking scheme in any language, including English, typically has devices to promote to higher bands as well as devices which demote, e.g. subordination. Thus, punctiliar adverbs (immediately, suddenly, all at once, at that moment) can promote material from Bands 3-5 to Band 1: "Suddenly we were pitching hay as if our lives depended on it," "All at once we were back in the old grove, doing the same old activities, talking the same old way," "At that moment, we were no longer strangers."

To range farther afield than English, however, we must recognize that the simple distinction Storyline vs. Background Events is not adequate to explain the considerable divergence of form which characterizes narrative around the world. To begin with, many languages not only have a storyline but a category of pivotal events/actions which, when taken together constitute a tolerably good abstract of the story, while the pivotal events plus the main storyline forms yield a somewhat fuller abstract. The pivotal events are marked in some fashion which may or may not be formally similar to the marking of the main storyline. On the other hand, there may be a kind of secondary storyline, again formally distinct from the main storyline, with secondary events/actions which are preparatory to, resultant from, or in some way ancillary to those of the main storyline. But even this is not all, for some languages have a further kind of verb/clause reserved for the marking of routine, script-predictable actions, especially when they occur in a running sequence in the story. This further category is a kind of tertiary storyline. To all the above can be added the reporting of actions/events in adverbial or subordinated clauses, a kind of suppressed action/event in which grammatical subordination indicates demotion in the rank scheme. Finally, flashbacks can be reported (although this is apparently not a language universal); the English pluperfect is a good example as any of the narrative functions of such as tense. All this constitutes a gradient scale of actions/events from pivotal, to main, to secondary, to tertiary (routine), to suppressed, to flashback. While it strains credulity to expect to find all these distinctions morphologically marked in one language, yet one may plot verb/clause distinctions against the scheme for a given language, which may distinguish several of the above with bundling of contiguous (or near contiguous) etic distinctions into one morphological category, e.g. bundling secondary and tertiary, or suppressed and flashback.

I offer Diagram II as an etic rank scheme formulation that is partly empirical (it reflects work on a number of languages around the world and was tested after its formulation on the languages reported in this project) and partly a priori, i.e. it is based on careful reasoning about how a story moves forward and how it is embellished by various non-storyline materials. I believe that the present volume has established the overall workability of this enlarged scheme as a theoretical 
construct, related in many ways to the well-known Hopper \& Thompson [1980] categories of transitivity.

This scheme, once that it is used to index the verb forms and clause types of a given language, can give way to a rank scheme or storyline scheme responding to the morphosyntactic realities of that language. Then-and here is the ultimate payoff-it can be used to guide constituent analysis in that language. Within a narrative paragraph, sentences whose main verbs are storyline should be the dominant sentences in the constituent structure of the paragraph and other sentences whose main verbs rank lower should be ancillary. In turn, relatively high ranking ancillary sentences have in turn lower ranking ancillary sentences that are even less prominent in the paragraph structure. If a language has highly complex sentences with heavy embedding as, for example, Gimira in this volume, then the considerations of relative ranking of other than main verbs can afford similar guidelines for the internal analysis of sentences.

$1^{\prime}$. Pivotal storyline (augmentation of 1 )

1. Primary storyline $(\mathrm{S} / \mathrm{Ag}>\mathrm{S} / \mathrm{Ex}>\mathrm{S} / \mathrm{P})$

2. Secondary storyline

3. Routine (script-predictable) action sequences

4. Backgrounded actions/events

5. Backgrounded activitity (durative)

6. Setting (exposition)

7. Irrealis (negatives \& modals)

8. Evaluations (author intrusions)

9. Cohesive \& thematic

Note: Flashback, as an ill-defined category, can group with (2) or (4); as a well-defined morphosyntactic category, it can be added after (5).

Diagram II. Etic bands of salience in narrative

\section{Word Order Typologies}

In assuming these word order typologies I am speaking here of surface structures and of contemporary languages. It may, indeed, be strongly challenged as to whether deep structure order as opposed to surface structure order is a tenable distinctive. Wallace Chafe's arguments that linearization belongs to the surface carry with me considerable weight. I therefore dismiss such concerns as whether Amharic (surface structure SOV) is basically VSO or not [Bach 1970] and side with Hudson [1972] that this is not really a question rightly put. I also dismiss Creidler 
and Creidler's [1983] suggestion that Nilotic (currently VSO for some languages and SVO for others) is basically SVO.

I also downgrade here considerations of language history, i.e. I want to know what a language is typologically in its present structure regardless of its past history. I cannot, however, entirely dismiss such considerations because past word order arrangements can leave historical traces in present-day language. While to the student of discourse tell-tale morphological traces of past word orders do not materially affect text analysis (which is primarily interested in correlations with constituent order within the clause), nevertheless anomalies may occur which are more relevant to his work. Thus, Amharic which is today SOV by analogy with surrounding Cushitic and Omotic languages was assuredly VSO at an earlier stage, as can be seen by comparison with Ge'ez (a now extinct liturgical language related to Amharic) and comparison with classical Arabic and Biblical Hebrew. But a peculiar trace of the original VSO order is seen in the subordination of clauses with the prefixes $b a \ddot{-}-, k \ddot{a}-$, and lä- on the verbs. In most languages a subordination of a clause will either occur clause-initial (in VSO and SVO structures) or clause-final, often a verb suffix (in SOV structures). But in Amharic's development from a VSO to SOV the preposed element has shifted along with the verb to which it is procliticized so that the subordinator occupies a rather anomalous position on the verb in a SOV clause. This can be regarded as partly normalized by (1) the further development of elements postposed to the verb so that subordinators which bracket the verb, such as bä...gize 'when', have developed and (2) by the overall consideration that it is the verb that is regularly marked so as to distinguish medial verbs (in medial clauses) from final verbs (in final clauses) in typical SOV chaining languages such as Amharic has become.

It therefore seems to me that historical considerations of the past word order typology of a language (especially arguments based on morphological structures or features of the noun phrase) need not greatly affect the analysis of contemporary text in that language. I therefore dismiss as largely irrelevant Talmy Givón's contention that Niger-Congo languages and, for that matter, Nilotic were all once SOV at an earlier reconstructed common stage. Certainly, in discourse structure these languages do not act at all like the contemporary SOV languages of Ethiopia.

Thus, Creidler and Creidler [1983] contrast topic-comment structure in Nandi, a VSO Nilotic language, with such structure in (Kenya) Luo, a SVO Nilotic language. Even if we were to grant that both these Nilotic languages are SVO in their deep structure or that historically all of them came from SOV (as Givon contends), it is documentable that they currently have different discourse structures in terms of topic-comment relations, and very probably in respect to other facets of discourse structure as well.

A basic goal, therefore, of this volume is to consider how and to what degree distinctions in contemporary word-order typology at the clause level affect discourse structure. 


\section{Peak as a Cumulative Development}

Most texts are not given at a uniform level of tension throughout their development. Rather there is a cumulative sort of development, so that the text is, so to speak, "going somewhere". In a story the moments of special interest are (1) the inciting incident (without which there would not be a story), (2) the climax of tension and confrontation, i.e. the nouement, and (3) the release or resolution, i.e. the denouement. These are the notional, or deep structure parts of a story that are candidates for special surface structure marking. The reasoning here is simple: (a) a story can only give so much detail and elaboration; (b) the same level of detail and elaboration, if maintained throughout a story, would result in a feeling of tedium or distraction on the part of the hearer/reader; (c) therefore, relative fulness of detail or elaboration is reserved (in a well-formed story) for the great moments of the story as listed above.

Nevertheless, not all the moments of a story that are candidates for special marking will necessarily emerge with such marking in the surface structure. The inciting incident, while frequently underscored in some fashion, can in some stories be given tersely and without much elaboration. Climax of tension and denouement are more likely to be specially marked. Often, however, only one is elaborated. Thus, climax of tension can be marked and denouement treated as simply a further episode. Or, conversely, denouement can be marked and the climax of tension as simply a preceding episode. In some stories both may be marked. When special surface marking or elaboration characterizes a climax or denouement we call that portion of a story its "peak". When both are so marked a story has peak and peak 1 .

I have in several previous publications [1981, 1983, 1985] listed and discussed ways in which the peak of a story is indicated and will not recapitulate in detail all that material here. First of all, it is necessary to distinguish a didactic or thematic peak from an action peak. The former involves the stopping of action while a crucial monologue or dialogue takes place. In the ensuing monologue or dialogue the main themes of a story are presented. Action peaks are cumulative in reference to the plot of the story. Essentially, action peaks are indicated on one of three ways. In the discussion below I will simply refer to action peaks as "peak" and make no further reference to didactic/thematic peaks.

A number of peak-marking devices can be grouped under the rubric augmented sequence. Here the routine storyline, consisting of sequential and punctiliar events/actions shifts to a different velocity: (1) there may be a fast-moving series of actions; (2) component actions not normally mentioned may be portrayed, e.g. how a man shifts his body weight and moves various muscles and grabs some surface edge in rising out of a chair to confront someone; (3) paraphrase of action may be employed so that what is essentially one action is portayed as if several actions were involved, e.g. "he tore it, he ripped it up from end to end, he methodically destroyed it." Notice that in (1) above there is a genuine quickening of the pulse of the eventline, while (2) and (3) are more like speeding the camera and catching 
more detail at the peak of a movie. Either way, however, the overall result is likely to be a higher ratio of verbs to nouns than is found in more routine narration.

Augmented sequence at peak is likely to affect the sentence structure. If a story has been told in rather short, terse Hemingway-style sentences, it may suddenly launch out into one or more long run-on sentences at peak. If, on the contrary, a story has employed sentences of medium to long structure in routine narration, it may shift into a series of terse sentences at peak. Here the shift in sentence length is an iconic reflection of augmented sequence.

A further number of peak-marking devices can be grouped together under the rubric immediacy. Here the story teller tries to transport his audience more directly into the world of the story by such strategems as the following: (1) There may be a shift in tense or aspect. Thus, in an Indoeuropean language there can be a shift from past tense story telling to the historical present. (2) There may be a shift in person. Here, for example, a story which has been told in the third person can shift to the first person plural. (3) A story which has not had much dialogue can run-in dialogue at peak, or a story which has had dialogue routinely throughout the story can shift to drama, i.e. reported speech without formulas of quotation but given simply in the order of alternating speakers. The converse development, elimination of dialogue at peak, can best be understood above under augmented sequence, where a fast moving action line is incompatible with verbal exchanges except those of the most rudimentary variety. (4) "Extra" background and setting can be added. This is also iconic of reality. At times of great crisis, sometimes little physical details of a situation will impress themselves upon a person, as in Walt Whitman's association of lilacs blooming in the dooryard with the assassination of President Lincoln. (5) Onamatopoeia, ideophones, four-letter words, and such devices can also be employed here to mark peak or may be statistically more common at peak. (6) Asyndeton, i.e. lack of connectives, is not uncommon at this point. It is as if the narrator is too busy to perform all the niceties of normal surface cohesion, so conjunctives and other sequence signals are dropped or used less frequently.

Finally, we find at peak a maximum interlacing of participant reference. To begin with, there is often a crowded stage at peak. If it is a sea story, all hands are on deck. This convergence of participant references puts a burden on the resources of the language for normal routine participant tracking. There is likely to be more use of noun and pronoun at peak and less resort to more implicit methods of participant tracking. There may be rapid change of focus from one participant to another. There may even be special devices appropriate to representing a confrontation.

Peak-marking will, as a whole, be a subordinate concern within this volume. It is not noted in respect to all the languages here. 


\section{Miscellaneous Concerns}

In the following chapters I consider, in order, the SOV languages of Ethiopia (Chapter 1), then certain Sudanic languages, especially Nilotic (Chapter 2). In the course of the latter chapter, the concept of the "consecutive tense" is introduced and illustrated, and the mirror image parallelism of right-chaining SOV languages to left-chaining VSO and SVO languages is established. In Chapter 3 there is further attention to other (non-Sudanic) languages with a consecutive tense, and in Chapter 4 , to languages without such a consecutive tense, thus concluding our three-way exemplification of storyline consideration in right-chaining, left-chaining, and coranking languages.

Before closing this introduction, I want to acknowledge the cooperation of the following organizations in facilitating this research project: The Bible Society of Ethiopia, The Sudan Interior Mission, The Mekane Yesus Evangelical Church of Ethiopia, The Summer Institute of Linguistics, and the Nigerian Bible Translation Trust. These organizations provided facilities for text analysis workshops in various African countries and provided individual linguist-translators who cooperated in the project. My thanks to all the latter for their patience with me in my efforts to wrestle with problems of text analysis in languages with which I had had no previous experience. The good things which turned up are largely their discoveries, and whatever errors and misconceptions are found here are mine. I acknowledge individual contributions in various places in this volume, which could almost be considered to be multiply authored.

For concerns clustering around the privileges and rights of my colleagues, both African and expatriates, I do not accompany this volume with a volume of texts. I, furthermore, look forward to the time when many of my colleagues who have collected research data on languages cited in this volume will publish research results in their own right. Not only do the data underlying this volume deserve longer and more explicit treatment, but there is also a considerable amount of preliminary writeup on participant reference in narrative discourse and on hortatory discourse which needs to see the light of publication.

I also acknowledge a summer stipend from my home university, the University of Texas at Arlington. This stipend has facilitated my writing of this report volume and made possible a delightful summer (1985) spent in working over the field notes and preliminary write-ups which we brought with us from our June-December 1984 research on the African continent. Finally, I acknowledge on-field support funding from the Town North Presbyterian Church (PCA), Richardson, Texas, and a grant from the Griset Foundation to subsidize the publication of this volume.

Robert E. Longacre Arlington, 1987 


\section{CHAPTER I}

\section{SOME SOV LANGUAGES OF ETHIOPIA}

The Cushitic, Omotic, and Semitic languages of Ethiopia are SOV languages which chain clauses in strings so that (1) final clauses have special fully-inflected verbs and (2) non-final clauses have verbs that are not fully inflected but are variously called "gerunds", "participles", and "coverbs" by different investigators [Bender 1976, Bender et al. 1976]. There is some tendency to develop switch reference systems to keep track of same versus different subject from clause to clause. In over all typology these languages are similar to Korean and Japanese, languages of Papua New Guinea, and languages of northern South America, as well as to certain languages of the southwestern part of the United States.

It is important to note at the outset that we should not equate a medial clause plus a final clause in such languages with a subordinate clause followed by a main clause in IE structures. Where English or some such language says, "We killed a cow, butchered it, and disposed of the meat," with three coordinated verbs all of the same structure, a chaining structure such as we describe here makes the last verb the only fully inflected structure while the other two verbs 'killed' and 'butchered' are not fully inflected. To translate the string as 'having killed the cow, and having butchered it, we disposed of the meat' gives, to be sure, a distinctive structure to the last verb in English but resorts to a somewhat unnatural and stilted construction that ill reflects the naturalness of the medial verb $-1+$ medial verb + final verb sequence in a chaining language.

Languages of this sort may have (1) several sorts of gerunds (as I will call them following the usage of my colleagues in this project) as medials. They may also have (2) subordinated verbs in adverbial clauses with subordinating morphemes (whether particles or affixes) more on the pattern of IE subordinated clauses.

How is a story told in such languages? It will be told in a series of sentences each one ending in a final verb and (most often) preceded by one or more gerunds and/or subordinated clauses. The sentence strings will be of varying length, depending on the language, the style of the individual storyteller, and the placement of the sentence within the story. In respect to the latter we again distinguish between routine narration and narration at peak. Narration at peak can involve resort to a somewhat longer sentence than usual, so that an on-rush of activity is given in one pell-mell string. Or, at least in one Amharic text, a series of short sentences each with only a final verb can occur at peak. While the factors governing the latter choice (a series of short sentences each with only one [necessarily] final verb) over 
against the former (packing one sentence with a long series of gerunds culminating in a final verb) are as yet obscure, both seem to be equally effective as gear-shift mechanisms in marking the transition to peak.

As far as the storyline status of gerunds and finals go, there are three hypothetical possibilities regarding their mutual ranking. Assuming that the whole sentence is not off the storyline, we could find $\mathbf{A}, \mathbf{B}$, or $\mathbf{C}$ :

A. Only the final verb is storyline; preceding verbs indicate backgrounded actions or happenings, backgrounded (ongoing) activities, or some element still lower, according to the rank scheme which is presented in the Introduction.

B. The final verb is a routinely added element which either is grammaticalized or is in process of being grammaticalized. Verbs meaning 'do', 'be', or 'say' are likely to occur in this function. In such circumstances it is the preceding gerunds which are storyline, or perhaps one particular privileged kind of gerund.

C. Both the final verb and the unmarked gerunds which are directly dependent on it are storyline (while gerunds are off the line if they depend upon off-the-line final verbs).

Of the three possibilities sketched above, $\mathbf{C}$ is possibly the commonest alternative, but $\mathbf{A}$ appears to be documentable in our sample of Ethiopian languages, and a structure approximating $\mathbf{B}$ is also found. In subsections of this chapter I discuss Koorete which illustrates $\mathbf{A}$ above, then Afar, which approximates B, and finally various other languages, Gimira, Kambaata, Haddiyah, Amharic, and Silti, all of which illustrate alternative $\mathbf{C}$. Among these languages, Gimira will be given the most detailed attention.

\section{Koorete (Omotic)}

For Koorete, Carolyn Ford posits that the storyline can be divided into primary and secondary events. Primary events are indicated by final verbs which have person-number markers, are completive stems, and have an -o suffix. Secondary events have the completive stem, and have an $-i$ suffix. Ford comments, "Secondary Event clauses preceding Primary Event clauses may function as prerequisite to Primary Events; stimulus or grounds for Primary Event; synonym or qualifier of Primary Event." These are illustrated as follows:

(1) Secondary events that are prerequisite to the primary event (a brief indication of each context is given):

(1) [A mother has just cooked some meat.]

koc'c' $\underline{i}$ serdi ibaardo taking-out cutting-up she-tasted
'She took it out, cut it up, and tasted it.' 
(2) [Two girls have just found a knife that they can use in food preparation.]

soro maša 'etti 'uc'od'd'o

knife sword taking they-chopped-up
'They took the big knife and chopped it up.'

(3) [same context as above]

'esa boordi 'ummudo

it baking they-ate

'They baked it and ate it.'

(2) Secondary events as stimulus or grounds for the Primary event.

(4) [A hyena has been waiting in the back of the house to eat two girls who have just entered. On being warned by a rat, the girls flee.]

$\varnothing \quad k a t \underline{i} \quad d^{\prime}$ 'eeddiko 'ugeede 'ewots'ts'o

(the hyena) awaiting failing-to-gain-objective after-them he ran

'Waiting for them it failed to get them and ran after them.'

[The function of the -ko suffix is not understood at present; it occurs on a handful of medial verb forms of different rankings.]

(3) Secondary event as, in effect, a paraphrase or qualifier of the Primary event. A frequent construction here is a quotation followed by a quotation formula whose verb 'say' is marked for Secondary event with all this followed by a 'say' verb marked as for Primary event. This gives a paraphrase-amplification of the sort, "He said (Primary)," i.e. "The words that he said (Secondary) were..." (but in the opposite ordering of constituents).

(5) [Two sisters are talking in the house of the python. When he finds out that the older sister wants some inset food, he replies as follows:]

"gonceke ba gonce waya bewayte." hidi "eydo like-inset-food not inset-food up-there see! saying he-said

'He said "See, up there is something like inset food which isn't inset food."'

In regard to all the above examples, Ford argues that only the clause with the final verb is primary storyline, while the preceding clause(s) with $-i$ marked medial verb is secondary storyline. Note above in (1) that taking out and cutting up are necessary preliminaries to tasting some meat that is cooking; taking the knife in (2) 
is preliminary to chopping up the food [presumably this is not the familiar specification of instrument as so generally found in West Africa]; and in (3), baking the bread is preliminary to eating it. In (4), waiting for the girls and failing to get them, is the grounds-stimulus for the hyena's running after them. In (5), we have a clear instance of the secondary form used not to indicate an event separate from that referred to by the primary form but with the secondary used an as amplification paraphrase of the primary, where the amplification precedes what it amplifies.

This distinction of primary versus secondary forms is basic to storytelling in Koorete but other forms of final verbs and medial verbs also occur. I mention the following verb forms from Ford's outline write-up. Each verb form determines the rank status of its clause.

Final verbs with the suffix -icca or with-iya...-ecca close a series of routine script-predictable activities that are tertiary in respect to the storyline. The suffix iya goes on a pre-final verb followed by the verb 'be' + -ecca.

(6) [The rat has warned the girls that the hyena is waiting for them and that they should quickly grind their grain, take it, and go away, which they proceed to do.]

hine bed'iila gac'c' $\underline{i}$ 'etti $d^{\prime}$ 'addi 'uhangicca

so then their-flour grinding taking leaving they-go

'So then they ground their flour, took it, and went away.'

Here the final verb is a continuative stem + -icca. It ends a series of $-i$ marked medial verbs (secondaries) of the same sort illustrated above with final primaries. The whole series thus marked represents a text-conditioned script-predictable sequence of actions set back from the main storylines (secondaries + a primary).

(7) [The two sisters, at a different place in the story, are entertained by an unseen guest to whom is passed the younger sister's desire to have a fire to warm herself by, which fire the unseen host proceeds to give them.]

tama handi kasiya 'uyecca

(to)-fire going warming-themselves they-were

'They went to the fire and stayed there warming themselves.'

Here the secondary verb marked with $-i$ is followed by a close-knit pair of verbs, the first ending with -iya and the second, the verb 'be', with -ecca. Here the scriptpredictable sequence of going to the fire and warming oneself ends with a 'be' verb.

Setting in Koorete stories is frequently given in relative clauses. A setting may, however, be given in a main clause by using -iya on one of a pair of closely-knit 
verbs the second member of which is a form of 'be' (but not with the -ecca suffix of (7)).

(8) [When an angry husband, coming to beat his wife for not coming at his call, arrives at the house, he encounters the following situation:]

haya gerara we iya yesesa

here people-with lying-down (she) is-in-the-state-of.

'She is lying down with the other people.'

Non-events and negative situations employ a negative existential verb baasso.

(9) [The family and neighbors, one by one, have tasted the hyena's food and fallen dead.]

$\begin{array}{lll}\text { yena iupana } & \text { 'ekkesi } & \text { baasso } \\ \text { therefore their-plight-news } & \text { who-takes } & \text { there-is-not. }\end{array}$

'So then, there was no one to report what had happened to them.'

Here iupana 'ekkesi is a relative clause followed by the existential negative.

We see from the above examples that independent (final) verbs of varying rank occur in the four following circumstances: (1) A primary storyline with attached secondaries is indicated by a final completive verb in -o. (2) A tertiary storyline is indicated by a final verb with -icca or -iya...ecca, with attached secondaries. (3) Setting, while usually given in relative clause, can be given in an independent sentence with -iya + the verb 'be'. (4) Irrealis, here negative, employs a relative clause with an existential negative ("there was no one who could X"). We see in these distinctions among final verbs indications of ranks 1,2, 4, and 5 in my scheme which is presented in the Introduction.

Further elements, also roughly following the posited rank sequence, occur as medials rather than finals. Here there is considerable variety of suffixation all of which I will not attempt to present here.

Backgrounded activities are expressed by medials that distinguish reiteration versus duration (doing something again and again versus a prolonged activity) by suffixing a medial with $-i$, with further suffixes $-/+-s i+-d i$. If $-s i$ is present, duration is indicated; without -si reiteration is indicated. Ford also posits a pretransitional, promoted background activity indicated by -eniya (ka). Here, the medial so marked is followed by a primary verb that indicates a major transition point in the story ("On X having happened, then Y!"). Some of these medials are indicated in the rather complex example below: 
(10) [The two sisters have asked their unseen guest to manifest himself, but they get the shock of their lives when he does:]

yeyko 'epina mululu hissidi 'ehood'd'eniyaka

it's like-that waist (onomatopoeic sound saying as-he-was-descending like running water)

"wuyi 'aba bo 'uwani" hissidiko d'addi 'udoondo (scream) what (kind of) animal saying leaving they-jumped

'The (python's) waist made a flowing sound as it came down and the girls screamed, "What kind of an animal is that?!" and jumped away.'

In this example $-s i+-d i$ on hissidi 'saying' marks the whole stretch yeyko to hissidi as a background activity (the sound made by the python's body coming down from the overhead within the house). The suffix -eniyaka on its verb marks pretransitional major background (they find out who their guest is and their former gratitude and confidence is turned to fear). The verb hissidiko marks another background activity (what they kept crying out in fear as the sound continued). The verb $d^{\prime}$ 'addi is a secondary, and 'udoondo is the primary.

Overt cohesion in Koorete stories is supplied not only by conjunctions (several of which are illustrated above), but by medials suffixed in various ways and resembling adverbial clauses in English. I give one such example here:

(11) [The father and the mother discard their proposed dinner, which was really only the man's cape rolled in blood and smelling and tasting accordingly.]

yona maad"ineni "miisuko" hissidi yetolko "umaasso so-then it-being-and "cow-it-is" saying that-hyena they-milked.

'So, that being the situation, they decided that the hyena was the cow and milked it.'

Here the one-word clause maad'ineni alludes summarily to the preceding situation which the rest of the story builds from.

The above material, taken from Carolyn Ford's outline with a minimum of reinterpretation, is more tantalizing than complete. It serves to introduce us to some general features of Cushitic and Omotic by way of illustrating several kinds of final verbs and several kinds of medials with indication of their ranking relative to the storyline. The main point to be gleaned from the above is, however, that the data support well Ford's contention regarding the privileged rank of the final 
primary verb, the forms with the person-number markers, completive stems, and suffix $-o$. While some of the examples can easily suggest parallel examples in other Ethiopian languages, what is peculiar about Koorete is that the storyline prominence of the final verb over the medial seems to hold throughout the available data.

\section{Afar (Cushitic)}

Afar folktales 1 [Bliese \& Genat 1985] illustrates a somewhat typical SOV structure (cf. Ferguson in Bender et al. [1976:71-2, 75]) in which medial verbs ("perfect participles" in Bliese [1981]) are on the storyline and final verbs in the perfect are also on the storyline--subject to the following complications: (1) storyline perfects may be followed by still another perfect which consists of the verb 'say' and which functions as a disclaimer of responsibility; and (2) the medial or final may be a compound verb whose last element (a form of the verb 'put' or 'say') is grammaticialized as an auxiliary while the lexical weight is in the preceding element.

Some basic and relevant features of Afar grammar are (a) the distinction of the perfect final verb in e from the imperfect final in $a$, and (b) the contrasting medial forms, i.e. the participles, with eh marking the perfect participle and with $u k / a k$ marking the imperfect participle. A further complication here is that the perfect participle can, in certain contextual situations function as a final.

Setting aside for the moment ways of marking pivotal action/events, I first note here the structures which mark the routine storyline. In order of increasing complexity these elements are as follows:

(1) As already mentioned, the storyline may be carried by a string of perfect participles ending with a final perfect verb.

(2) The above structure may be modified by appending after the final perfect still another final which consists of a form of the form 'say', e.g. iyyen 'they say' or yan 'say'. The verb 'say' here is not compounded with what precedes, but rather, as a sentence terminator, marks unwitnessed or reported (equivalent, therefore, to a disclaimer of responsibility). As a terminator the final verb 'say' is not storyline. Storyline status belongs rather to the preceding elements.

Both of the above, i.e. (1) and (2), may alternate in the same text. Thus, in a story "A Lion, A Wolf, and a Jackal" ten sentence final forms are pattern (1) above, while eight sentence final forms are pattern (2). ${ }^{2}$

${ }^{1}$ There is an obvious need here to investigate other sorts of stories and non-narrative discourse in Afar.

${ }^{2}$ Needless to say, accounting for this variation is a further unsolved problem in the text analysis of Afar. 
(3) In what Bliese and Genat call an "expanded style" the form of "say' may be reduced to an enclitic form, -yen 'they say', which is added directly to the final verb in the perfect aspect. In such a construction, suffixal -ii may be added to the perfect participles as well, but this feature is not obligatory. At any rate, the story continues to be carried by the participles and the final perfect regardless of the suffixal/enclitic additions.

The description of the elements which mark the pivotal storyline actions/events requires an understanding of compound verbs in Afar. Compound verbs consist of a stem form (actually the imperative form) whose last consonant is doubled (with suffix a) plus an auxiliary element which is a form of iyye 'say' for intransitive verbs and a form of hee 'put' for transitive verbs (sug 'be' with medial verbs which represent activities is considered below). Bliese [1981:146] gives a few illustrative forms:
fak-ka hay-'t-e
open compd put-you/she-perf.
'you/she opened'

He notes here that this is more emphatic than simply
fak-' $t$-e
'you/she opened'

For an example with the auxiliary element 'say', note
in'dix-xa in-'t-e
'you/she said'
say-compd say-you/she perf.

Such compound forms, formerly called by Bliese "emphatic", are now seen to be markers of the pivotal storyline when in the perfect aspect within a story or where occurring as a perfect participle depending on a perfect.

What is of some interest here is the possibility that such compound verbs reflect old medial-final combinations in which the stem with the doubled consonant is the old medial and the form of 'say', 'put', or 'be' is the old final. The whole unit is now so frozen that it can and usually does function as a medial, i.e. a participle, in the present-day structure.

Bliese and Genat also note the use of a further pivotal form that is restricted to the peak in narratives, i.e. the use of a perfect participle as a final. They term such forms "emphatic perfects".

Compound verb and emphatic perfects (rare at best) mark pivotal events so that a compilation of the clauses which contain these forms yields an abstract of the story. I quote here a paragraph from Bliese and Genat: 
(12) "In a story about a frog and an elephant, the introduction about the elephant stepping on and killing the frog's father, and the frog seeking justice has no compound verbs. Then follows the challenge of the frog to the elephant which is a pivotal event marked by the compound verb gexxi yeeh 'going hesaid' when he goes to make an appointment to fight. This is followed by three more compound verbs telling of the frog's and elephant's arrival at the appointed pond: ookommu iyyeh...warayya iyyeh...katayya 'yeeh 'preceding (frog) said... going-forward he said...(the elephant) following said.' The elephant puts his head in the pond to drink. The frog ilaalisak suggu 'yeeh 'watching was (compound) he-said' and jumps into the elephant's trunk. The elephant pleads, but the frog says, 'When males fight all is equal.' The next verb is a compound, 'He stopped up his breath' eyseddi heeh before the final 'killed him'. Again the six compound verbs mark pivotal events among the 24 independent verbs of the narrative."

The "emphatic perfects" which Bliese and Genat also mention as marking pivotal events occur in pivotal events at the peak of a story (climax of tension or denouement). Thus, in regard to the "Elephant and Frog" story referred to above, Bliese and Genat also assert:

"We had the story of the frog and elephant retold to check the verbal endings, and the sentence 'When males fight all is equal' was closed with iyyeh 'he said'. The sequence was broken with the next sentence beginning, 'Then he stopped his breath.'. The 'he said' emphatic perfect was the only occurrence of this form in the story."

It is instructive to note, in reference to the two quotations from Bliese and Genat, the variation which is indicated in the two tellings of the same story. In the first telling of the text the sentence, "'When males fight all is equal," he said,' is simply treated as a mainline event (see below), but in the retelling of the story it is marked with the emphatic perfect that is appropriate to a sentence in peak. This illustrates that in text analysis we are largely shut up to explaining the speaker/writer's choices ex post facto, i.e. once he has used a given grammatical form we can give a plausible reason for his choice, but we cannot predict beforehand all his choices. Admittedly, the general plot structure of a story and the etic prominence of actions over background activities and other similar considerations are reliable enough indicators that we could predict the speakers choices in, say, some $90 \%$ of the time. Nevertheless, it remains that the speaker's choices are the speaker's choices, and he reserves the right to exercise his options, even to the point of on occasion telling a story poorly.

Besides compound verbs marking pivotal events and emphatic perfects marking pivotal events at peak, Bliese and Genat also mention the use of compound verbs in 
adverbial (temporal) clauses. While they still classify such usage as marking pivotal events, a problem (it seems to me) is raised by the grammatical subordination which usually demotes a verb to lower rank in the storyline scheme in most languages. (See Introduction, Diagram II). Possibly, the use of a compound verb in a subordinate clause signals that the action so indicated is pivotal in respect to the importance of the following actions and thus indirectly underscores the importance of the following action. Thus, Bliese and Genat mention the use of a clause af fakka hee waqdi 'mouth opening put when', i.e. 'when he opened his mouth' in the following context: The jackal is running with the rooster in its mouth, and the rooster tells him to call out to the dogs. On the jackal's opening his mouth, the rooster escapes. Here the subordinated compound verb marks, to be sure, a crucial action, but at the same time it may be serving to underscore the importance of what follows, i.e. the rooster's escape.

In regard to further ranks of forms in the storyline scheme which Bliese and Genat posit, I shall proceed somewhat summarily, pausing mainly to note compounding which involves the verb 'be'.

Routine script-predictable events are imperfect rather than perfect participles or may be encoded as imperfects in temporal clauses with a subordinating conjunction. Such script-predictable events are, e.g. the elephant's crying in connection with pleading for his life, the wolf limping after his leg was broken, or the jackal laughing after having caused the wolf to break his leg. As an example of the imperfect in a temporal clause we find that after the jackal seized the rooster we are told 'when he takes him in his mouth' which is predictable from the verb 'seized'.

Background activities are encoded by past continuous verbs which are imperfect participles (final -k) plus a form of yen 'be' 3 as in garaqak yene 'thieving he-was', asgaaduk yene 'slaughtering he-was', and luk yene 'having he-was'. Here this verb 'be' is still a bona fide final (perfect tense in -e) in form, but is semantically auxiliary to the preceding imperfect participle. There are similar compound verb forms with sug 'be'. Since compound verbs with consonantal doubling are considered to be pivotal, Bliese and Genat believe that expanded forms such as wagitak sugga yeeh 'was watching (watching-was-she-said)' instead of the simpler wagitak yeeh are promoted to pivotal status instead of simply marking background activity. The nominalized verb is also considered to encode background activity.

Setting is variously indicated, by relative clauses, by clauses with 'be' verbs, or by temporal and locative clauses. Irrealis constructions are negative clauses and purpose clauses - the world of what didn't happen and of the potential. Author evaluations, i.e. proverbial or hortatory material "seems more regularly to be put in the direct speech of the participants rather than as the storyteller's comment" [Bliese \& Genat 1985:8]. However, on one occasion, Bliese and Genat cite an

${ }^{3}$ According to Bliese [1981], en (1st person), y-en (3rd person), $t$-en (2nd person), is a prefixing verb and considered historically older than sug-e (1st, $3 \mathrm{rd})$, sug-t-e (2nd), a suffixing verb. Except for dialect preferences they seem to be interchangeable. 
author's quotation of a proverb which is applicable to a participant. Cohesion, i.e. repetition in one sentence of material found in another sentence, is via relative clauses and adverbial clauses with perfect aspect verbs. Sometimes the verb 'see' is implanted in such backreference constructions: "X happened. When he saw that X had happened...."

Bliese and Genat distinguish pivotal actions/events, main actions/events, and routine, i.e. script-predictable, actions/events as well as background activities, setting, collateral (irrealis), evaluation (by author), and cohesion. The overall scheme is, then, quite like that found in the Introduction. The distinction between pivotal actions/events and main actions/events has to do with securing an abstract of the story, i.e. the clauses marked as pivotal when assembled constitute a tolerable abstract of the story which can be rounded out by addition of the main actions/events, then by the routine actions/events, and on down through materials of lower rank.

\section{Gimira (Omotic)}

Gimira (data from Mary Breeze) is representative of what is possibly the more usual structure in Ethiopian SOV languages, viz. the final verb and at least one sort of gerund which directly depends on the final, are equally of storyline status (or equally off the line if the final verb is off the line). Gimira has not only several sorts of finals (tense-aspect distinctions) but also several sorts of gerunds as well. While this is apparently typical of Cushitic and Omotic, it is not necessarily typical of Ethiopian Semitic (cf. Amharic below, where there is formally only one type of gerund). In Gimira the grammaticalization of finals has not proceeded to the extent that we find in Afar. What we may find, however, in other Cushitic/Omotic languages in this respect must await further study of the various languages.

3.1. The grammaticalization of finals. In regard to the grammaticalization of finals, we find this mainly in regard to verb forms used for background activities (but see also under 3.2.4 below). Here a gerund occurs in construction with a final such as yist 'exist', and pes 'spend time' 4 and other like auxiliaries. The imperfective form may occur medially by simply reducing the final form of the auxiliary to a gerund. Thus

$\begin{array}{lll}\text { opta } & \text { koya } & \text { ta } \\ \text { walktue }\end{array}$

occurs as well as a construction in which the final auxiliary yistue is reduced to a medial form:

${ }^{4}$ Gimira has five tone levels numbered from low $\left({ }^{1}\right)$ to high $\left({ }^{5}\right)$. 
$\begin{array}{lll}\text { opta } & \text { koya } & \text { yista } \\ \text { walking } & \text { searching } & \text { being }\end{array}$

Both are roughly equivalent to the English 'I was walking around and searching', but one is a final and one is a medial, which embodies a formal distinction with no close parallel in English.

In Afar the verb 'say' as a disclaimer of first-hand reporting occurs on almost every sentence in a folktale and therefore becomes in essence a sentence-level marker of unwitnessed, whatever its grammatical form (free 'yyen, or bound -yen); in Gimira, however, the corresponding form mastue 'it was said' occurs only once at the end of the entire folktale. It does not therefore, undergo grammaticalization in Gimira, as in Afar.

3.2. The storyline scheme. Mary Breeze has worked out a careful storyline rank scheme for Gimira; the scheme includes not only main verb forms but also gerunds. Of course, what is classified here is not simply verbs as such but the clauses which terminate in given verb forms, whether main or gerund.

I present here Breeze's rank scheme with the following modifications: (1) Breeze has presented two ranking schemes, one for main verbs and one for gerunds. I have arranged the two in parallel columns, since this parallelism is implicit in her scheme. (2) I rotate her flashback band from following backgrounded activity to preceding it so as to keep the various action type events together. ${ }^{5}$ (3) I shift purpose clauses in her scheme to irrealis, since things purposed haven't happened yet. (4) Her subordinated clauses which introduce new information and are therefore not merely functioning as a backreference to the previous sentence pose a more considerable problem. Breeze's ranking of these clauses had put them between the imperfective gerunds (background activity) and the stative gerunds (setting), but this seems to me to be too low. When such subordinated clauses refer to an action, the action so referred to is presumably demoted in the rank scheme (by virtue of the grammatical subordination), but it

5I ignore her "pivotal backgrounded event" because she has no category of "backgrounded event", as such, from which pivotal backgrounded events can be selected. I therefore have only backgrounded activities in Band 3. 


\begin{tabular}{|c|c|c|}
\hline Bands & Main clauses & With gerunds/dependents \\
\hline $\begin{array}{l}\text { 1. Storyline } \\
\text { actions }\end{array}$ & $\begin{array}{l}\text { Pivotal (style I): } \\
-e^{3} \rightarrow a^{4} \\
\text { Main style I: }-e^{3} \text { past } \\
\text { Main Style II: } \\
-e^{3} \rightarrow a^{4} \text { (discourse medial) } \\
-e^{3} / a^{2} \text { (discourse final) }\end{array}$ & $\begin{array}{l}\text { Indicator of denouement } \\
\text { unmarked gerund }+-a m+S R \\
\text { Main: unmarked gerund } \\
\text { Secondary: } \\
\text { unmarked gerund + SR }\end{array}$ \\
\hline $\begin{array}{l}\text { 2. Non-storyline } \\
\text { actions }\end{array}$ & $\begin{array}{l}\text { Flashback: } \\
\text { Present Perfect, Pluperfect }\end{array}$ & $\begin{array}{l}\text { Routine, script predictable: } \\
\text { Pres. Perf. gerund + SR } \\
\text { Demoted (backgrounded) } \\
\text { action/event: } \\
\left.\begin{array}{c}\text { subordinate } \\
\text { verbs } \\
\text { infinitive }\end{array}\right\}+\begin{array}{c}\text { post- } \\
\text { positions }\end{array}\end{array}$ \\
\hline $\begin{array}{l}\text { 3. Background } \\
\text { Activities }\end{array}$ & Periphrastic Imperfective & $\underset{\|}{\text { Imperfective gerund }}$ \\
\hline 4. Setting & $\begin{array}{l}\text { Depictive/ambient verbs } \\
\text { forms of yist- } 3 \text { 'be' } \\
\text { Nom. clause + stative suffix }\end{array}$ & $\begin{array}{l}\text { Gerund forms of the same } \\
\text { Stative gerunds }\end{array}$ \\
\hline 5. Irrealis & Negative Verbs & $\begin{array}{l}\text { Negative gerunds } \\
\text { Purpose clauses }\end{array}$ \\
\hline 6. Cohesion & Sequence signals & $\begin{array}{l}\text { Subordinate clauses in back } \\
\text { reference }\end{array}$ \\
\hline & Performative statements & \\
\hline
\end{tabular}

Diagram I. Rank scheme for Gimira (adapted from Breeze) 
nevertheless reports an action. Possibly, going by Breeze's original ranking, we can consider them to be demoted to somewhere around Band 3. But since I have permuted her Band 3 relative to 2, these subordinated structures might better be put into Band 2 on the right side along with the gerunds found there.

3.2.1. Storyline verbs. Storyline verbs in Gimira vary acconding to two alternative styles: (1) Simple past-tense action verbs, which Breeze describes as the past root of the verb, a person-number marker, and the completive marker $-e^{3}$, occur. She further distinguishes formal versus informal paragraph marking, with $-e^{3}$ found on every storyline main verb in the former, but only paragraph final in the latter.6 (2) An alternative storyline structure for folktales substitutes ("after the participants have been established") for the person-number marker, a suffix $-a^{4}$ which Breeze suggests "may be related to the coordinate marker $-a^{4}$ usually added to nominal phrases." This, in effect, suggests a discourse given in a sort of run-on "and a... and a...and a..." style such as is found in certain oral forms of storytelling in English. For the discourse final verb in this style, Gimira may employ an -a suffix but more frequently reverts to the regular simple past with the personnumber marker and $-\mathrm{e}^{3}$ of the completive.

Of some interest here is the fact that in the first style indicated above, pivotal events can be indicated by resorting to the suffix $-a^{4}$ as found routinely in the second style. Breeze states "a native speaker's comment was that in oral storytelling, these verbs serve to catch the attention of the listeners and to seek their approval to continue the story."

For exemplification, I choose a few examples from Breeze's outline write-up.

(13) [This exemplifies style (1) above with simple past action verbs marked for number and person and further marked with $-\mathrm{e}^{3}$ 'completive' in paragraph final.]

mat' woyn bod koya hank'en

one day road seeking went-3f.

ušam c'ira soy yaken.

then clay good found-3f.

yiška kesa budn gomene.

digging taking-out outside piled-3f-comp.

'One day she went off seeking (i.e., to find clay from which to make pots). Then she found some good clay. She dug it out and piled it up.'

${ }^{6}$ The actual statement is, "In more informal paragraphing, $-e^{3}$ is often dropped, except on the final verb of the paragraph, or quotation, and on the more important "events'." In that quotations involved embedding and paragraphs are like to reflect a climactic development, I interpret all this to mean simply paragraph final. 
(14) [This exemplifies style (2) above.]

mat'n gok'n ša'k'an hamagi ata ${ }^{4}$

one day forest-L going arrived.

ša'k'an yisi hamagi atnagušnnisa

forest-L he-S going arrived-he-when

dawu bai surk'nsi yistn bek' $a^{4} \ldots$

antelope old-S having-slept being-SR saw ...

[End of discourse:

karti hank'ue

returning went-3 m.comp

mastue.]

said-3.m. comp.

'One day he journeyed and arrived at a forest. When he had journeyed and arrived there, he saw an old antelope that was asleep...he returned and went home, so they say.'

Another example, which I will not give here, also illustrates style (2) above. It ends the first sentence with $c^{\text {' }} \mathrm{ega} \mathrm{a}^{4}$ 'called', the second with yit ' $\mathrm{a}^{4}$ 'stood', the third with ata $^{4}$ 'arrived' and the whole discourse with hayk ' $\mathrm{a}^{4}$ 'died' and masta ${ }^{2}$ 'it was said'. Here, rather than a sequence of two finals (both completive) as in (14), we have the closure with $-\mathrm{a}^{2}$ on the last verb and no use of the verb 'say'.

For the marking of a pivotal event in style (1) above, consider the following:

...gazat yicend. ušnis ba

...bet made-3 pl. that- $\varnothing$ 3.Ref.

gažatnu gešn, boč boč buknagi

betting after a-little-while fighting

panc' $i$ ba gam ernsi

leopard-S 3.Ref. weakness having-known

donti woc' $\mathrm{a}^{4}$

getting-up ran

'...they made a bet. After betting they were fighting for a while, and the leopard, knowing his weakness, got up and ran off.' 
In regard to (15), it is important to take account of the fact that the whole tale is told in style (1), i.e. with simple past tense forms such as yicend 'they made' above. In such a story the occasional resort to a verb marked with $-a^{4}$ indicates an action/event signaled out for special prominence ["pivotal event"].

The corresponding gerund forms are indicated on the right side of Diagram I. The unmarked gerund (which does, however, take person-number markers $-i^{5}$ and $\left.a^{4}\right)^{7}$ is primarily a storyline form that occurs in medial rather than in final position. It assumes the same subject as the verb on which it depends. Rank-shifting of such gerunds so that they come to depend on something other than a storyline form takes them off the storyline. This is discussed below in $\$ 3.3$.

Unmarked gerunds which are dependent on storyline finals are exemplified in (13) above. In that example, koya 'seeking' occurs before the main verb hank'en 'she went', and yiška 'digging' and kesa 'taking ou' occur before the main clause budngomeme 'she piled it outside'.

The gerund with a further affix and a switch reference marker (SR) indicates a category of pivotal action/event at peak. Before describing this construction it is necessary, however, to consider the more usual role of the unmarked gerund plus the SR marker. Breeze considers that such a gerund marked for SR ranks lower in the structure of a sentence (and hence in the rank scheme) than does the same gerund without the SR marker. This is because the gerund + SR regularly refers to the non-thematic participant and is therefore somewhat parenthetical. Consider the following:

(16) ta ezni nut'nušsn opti

my older-brother our-place-at walking

sokam sokam gya'i kesn

evening-abl tea-S boiling-SR

nua banaind kaski yistue

us-with 3.Ref.-with-and playing was-3.m.

'My older brother would walk over to our place every evening, and tea being made, he would chat with us.'

Here the main verb kaski yistue is imperfective and is background activity rather than storyline. The unmarked gerund opti 'walking' which depends on kaski yistue is down-shifted (see 3.3) and is part of the description of background activity. However, the relevant points of this example are the following: (1) The clause gya ' $i$ kesn 'tea-S boiling' is marked with the SR marker $-n$ (syllabic nasal) and is somewhat parenthetical. (2) Opti 'walking' which outranks it and groups with kaski

$7_{-i} 5$ indicates 1 p.pl. inclusive, 2 pl, 3 p. masculine s. and pl.; - $a^{4}$ indicates 1 p.s., 1 p.pl exclusive, 2 p.s., 3 p. feminine s. and pl., and 3 reflexive. 
yistue is not marked for subject change even though there is a subject switch from 'older brother' to 'tea'. (3) It is rather the transition from the non-thematic participant ('tea') back to the thematic participant ('older brother') that is signaled by the use of the SR marker.

This does not hold so obviously for peak action and for dialogue, where the rapid shift from one participant to the other in vigorous interaction results in more liberal use of the SR marker. On the other hand, such moments of a story probably involve rapid shifts of thematicity from one participant to the other as well, so perhaps the thematicity constraint from the SR marker will prove to hold here as well.

Besides the unmarked gerund and the unmarked gerund $+\mathrm{SR}$, Breeze also described a further construction, i.e. a gerund $+a m^{4}+S R$ which marks a pivotal event at the peak of a story. Since it is a pivotal event at peak but involves the SR marker, it has a non-thematic participant as subject. Thus, in the following example it involves the triumph of the protagonist and the departure of the antagonist, who is the subject of the switch-reference clause. Its use here represents therefore the denouement of the conflict.

(17) [A man is up in a tree collecting honey ...]

panc'i yi tok'an yisti inč gapmk'an wognsi hammsagyis leopard-S his foot-L being tree branch-L having-sat go-Fut-Stat-he maki bak'u. Taci peški hamišidni iču. Gartn nasi esa saying waited thinking not-to-go refused Gartn man-S honey myac'a kabnsi yi apm haznm'msi myac'am dusti bees having-wrapped his face-L throwing-SR having-eaten by-bees woc'i koškan wot'i šsičamm yiam gurt' $i$ being-stung running valley descending leaving-SR by-it trembling yisti dodn wortni hank'u. being ground-L descending went.

'A leopard being under him, he just sat on the tree branch and waited thinking he would soon go. While he was thinking like this, he refused to go. Gartn wrapped the honey and the bees and threw it in its face. The bees stung him and he ran away down into the valley. After he had gone, trembling, he descended and went.'

Here the SR marker occurs twice: once on the unmarked gerund haz-n of which Gartn is subject, and also on the form šičam-m of which the leopard is subject. While the use of the SR marker in the clause of which Gartn is subject probably reflects rapid thematic interchange at peak, the use of -am suffix as well as the SR marker in the clause of which the leopard is the subject reflects the departure of the 
antagonist (non-thematic). Gartn is apparently thematic for most of this paragraph and is certainly the protagonist of the story.

Notice, then, that on the gerund side of our rank scheme there is a distinction which matches somewhat the pivotal versus regular storyline forms in the main verb. But while pivotal events in the main verb are not limited to any one part of the story, the pivotal-event-at-peak gerund has such a limitation. Notice also the use of SR marker on the gerund side serves to keep track not of subject switch as such but of subject switch plus thematicity switch.

3.2.2. Non-storyline events. Gimira constructions which belong to Band 2 of the rank scheme embrace, as I indicate, a variety of non-storyline events. Flashback, a somewhat rare category, is indicated by perfectives and pluperfects in the main verb. Flashbacks are actions but are out of consecutive order and refer to something which took place earlier. Breeze gives but one example which I will not reproduce here.

Present perfect gerunds, as opposed to the unmarked gerund, have the ending $-n s^{4}$, -ank $k^{4}$, or $-n g^{4}$ and the person-number markers $-p^{5}$ and $a^{4}$. While they are not the semantic equivalent of flashbacks, they involve use of the gerund, which is somewhat similar to that of the main verb of Band 2 in that (a) they encode routine, preliminary actions and (b) rank immediately between the storyline gerunds and the imperfective gerunds, much like flashback ranks between the storyline and background activities in main verbs.

(18) [From a story of an accidental confrontation with a leopard. At this stage of the story, the protagonist/narrator does not yet realize that the eye that he has seen is that of a leopard, but thinks it is that of a lost cow for which they have been searching.]

...ta yiam yi api sank'i
..I it-by its eye shining
yiskus s kay bak'nsa gyar gyar
was-which only having-seen forward forward
ta yi dadn hank'ue
I its side went-I

The clause with the present perfect gerund embeds a relative clause. The whole example could be rendered by a pluperfect in English: '(Guiding myself) by the shining eye which I had seen, I went steadily forward to its side.' Not all examples lend themselves to a pluperfect translation in English but perhaps a range of meaning between pluperfect and preliminary routine activity is correct. In another example, which I do not reproduce here, two merchant-thieves, most of whose goods remained unsold, having met on the road, one asked the other what he had 
with him. Here the 'having met on the road' (a quite predictable place to be if one's goods are unsold) employs a present perfect gerund and is considered by Breeze to be a script-predictable preliminary event.

When a present perfect gerund occurs with a SR marker, the clause in which it is found has a non-thematic subject referent.

(19) [A snake asks a man to take him across the river.]

nasi soye maki yiršn
man-S good-Stat saying bending-down
maki ba baris besa.
saying his neck he showed.
c'obmbaba uš nasi nasyi
snake that-man-S man-him
bark'an ba $k^{\prime}$ ark'nsn
neck-L himself wound-Perf.-SR
nasi so'n seyk'n yi kesa.
man-S water-L across him took.

"The man said, "OK," and bending down bared his neck. The snake, having wound himself around the man's neck, the man took him across the river.'

In this example: (1) the action of the snake in winding himself is a necessary preliminary action; (2) it is also script-predictable from the preceding context; and (3) it is the action of the non-thematic participant in a paragraph where the man is thematic.

3.2.3. Background activity. In the two examples below, the same verb surk" 'lie/lie down' is used plus in one case the perfective marker -ns and in the other case the perfective marker -ank'. In both cases the sense is that the animal had lain down before the protagonist came upon it and was still lying down when discovered. In both cases the protagonist is thematic, and the animal at this stage of the story is non-thematic, hence the presence of SR marker on the auxiliary.

(20) $\check{s}{ }^{\prime} k$ 'an yisi hamagi atnagušn̆nisa

forest-L he-S going he-arrived-when

dawu bai surk'nsi yistn bek'a.

antelope old having-lain being-SR he-saw.

'When he went and arrived at the forest, he saw an old antelope lying down (sleeping).' 
(21)

...ša ${ }^{‘} \quad$ dentkañ surk'ank'i

...forest middle-L having-lain

yistn

being-SR

...maka

...saying

...hank'ue

...I went.

'...lying there in the middle of the forest...saying... I went (towards it).'

Background activity (besides being encoded by a special gerund form described below) is encoded by the periphrastic imperfective forms which are described above in 3.1, i.e. by an unmarked gerund followed by a regular past tense form of yist ${ }^{3}$ 'be' or on occasion pes ${ }^{1}$ 'spend time'. Thus, in the text concerning searching for a lost cow and coming upon a leopard by mistaking its eye for the cow's (in the jungle at night), we find imperfective forms:

(22) ša'k'an ta kay eka haka

forest-L I alone there here-and

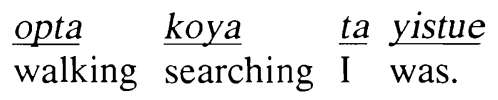

'I was alone walking here and there and searching.'

Breeze gives a similar example with 'spend time'. Here the reduplication of the gerund is iconic of the duration of the search:

(23) kang aci dyant enwu

all men-S cow that-her

koyi koyi koyi koyi pešku

searching spent-time-3m.

Background activities overlap temporally with one or more of the actions on the storyline and/or represent lapsed time between actions. Imperfect gerunds represent such background activity as encoded in a verb phrase which terminates in a medial verb form. These can be considered to be simple transformations of the corresponding main verb as already illustrated in 3.1. The peak (denouement) of the unwitting confrontation with a leopard employs a string of imperfectives as in the following partial representation of the long sentence found at that point: 
(24)

...gurta yista, wo Yero
trembling being Oh God

ta keso maka yista

me take saying being

yiam wotam wotam kay opta hank'a yista

it-by backwards-backwards only walking going being

...yiam woc" kayam karta

...by-it running only-by running

tat'n hank'ue.

to-my-place I-went.

'...trembling, saying "Oh, God, get me out of this," working my way slowly backwards from it... I ran all the way from it, and I got home.'

In this example, gurta yista 'trembling' maka yista 'sayin', and opta hank'a yista 'walking (backwards) and going' are all imperfective. The durational nature of the latter is also reinforced with the repeated wotam wotam 'backwards'. With the gerund clause yiam...karta 'ran away from it' and the main clause tat 'n hank 'ue 'I went to my place', we return to the storyline and conclude the tale. The spate of imperfectives lends suspense at peak.

There is a non-periphrastic imperfective gerund which consists of the future root of the verb + the suffix $-a g^{3}+$ person-number marker. This imperfective construction is illustrated in (14) above where it seems to refer to the durative activity of a trip which culminates in arrival as given in the sentence final verb, hamagi ata 4 'going arrived'. Here ham- 'go (fut)' is the stem, -ag is the imperfective marker, and $-i$ is the person-number marker.

The imperfective gerund with SR marker occurs with the periphrastic construction described above and again implies the non-thematicity of its subject.

(25) [cf. (20)] kang aci ba kobam kobam hank'i

men all-S his-Ref. direction direction going

dyanta anwu koyi koyi koyi koyi pešn

cow that-her searching spending-time-SR

yapstarga sidene.

not-being-found remained-she.

'All the men, each going in his direction, spent a lot of time searching for that cow, but she remained unfound.' 
Here the cow is considered to be thematic rather than the various people searching for her. Consequently, the sequence koyi koyi koyi koyi pešn 'to spend time searching', which would otherwise be simply an imperfective gerund, bears the SR marker on pešn 'to spend time'.

3.2.4. Setting. Setting, which is even further removed from the storyline than background activity, is encoded in a number of constructions all of which involve non-action verbs.

(26) yi kyanndi zolas
his dog-Pl-S strong
ic sam-3pl.compl
sumind sod yistende.

their name-Pl many was-3pl.-comp.

'His dogs were strong. They had many names.'

In the above the verb 'be' as inflected here (yistende) is no different from an action verb. This verb, however, is used in descriptive and copulative senses and, as in languages around the world, cannot be considered to be storyline even when it has the same form as a storyline verb.

$\begin{array}{lll}\text {...dodnda } & \text { tib tib } & \text { maki } \\ \text {...earth dark dark saying } \\ \text { t'ummi } & \text { šikue } \\ \text { to-get-dark } & \text { approach-3 p-compl. }\end{array}$

This example involves two ways of saying 'It was getting dark'. The main verb šikue 'approached' is an action verb, but it is not used here with an animate, volitional subject. The clause is, therefore, not an action clause. Notice, too, the preceding non-final clause, which uses 'say' in an extended sense with 'earth' as subject rather than an animate volitional being. As ambient clauses, these are setting rather than storyline.

Setting is also expressed by nominalized clauses, e.g. "She is pot one-whomakes", and nouns marked to serve as stative predicates.

Gerunds used to express setting include, e.g. any ambient or descriptive expressions that occur as gerund clauses (cf. dodnda tib tib maki 'the earth dark dark saying' in (25) above). Presumably t'ummi šikue 'darkness approached' could occur as a gerund clause as well as as a main clause.

Nouns marked by stative suffixes can occur as gerunds. With the latter, at least, the SR marker can occur in the usual function of indicating the non-thematic participant. 
A further construction which Breeze calls "imperfective gerund with SR marker" probably belongs here in setting as well. It is not the usual gerund construction described under 3.2.3., but consists of a present perfect gerund followed by the auxiliary yist 'be' + SR marker. No examples of this periphrastic gerund without SR marker are given. It is certainly not an imperfective gerund, since the latter consists of the unmarked gerund plus the auxiliary, and, equally clearly, it is not a perfective gerund, since the latter occurs without the auxiliary.

Relative clauses also figure in encoding setting, as do also subordinated clauses which give new actions and are not simply in cohesive backreference function. Probably whenever action verbs occur either in relative clauses or in subordinated clauses, they had best be considered to be demoted from the storyline to setting.

3.2.5. Irrealis information. Irrealis information is expressed in negative verbs and in purpose constructions.

nuna num wu bek'argue nu
we-S ourselves her see-neg-1 Pl. our
dora bana atargene
sheep with arrive-neg-3F.

'We ourselves did not see her. She did not come with our sheep.'

(29) ta ingušnaga dyantis yiešn koyna

my friend-deitic-gen cow-O him-for to-look-for(INF)

donta ša'k'an ta hank'ue.

getting-up forest-L I go-3.m.-comp.

'Getting up, I went to the forest to look for my friend's cow for him.'

In regard to negative gerunds, Breeze leaves most such gerunds in the irrealis band, but promotes to storyline status those that are in close relationship with a main verb of storyline status.
(30) ta šikagušn
bam dyant wus esaraga
I approached-I-when she cow she not-being
nasa panc'agi yistue.
man leopard-Stat. was-3-comp.
'When I approached it wasn't a cow, it was a leopard.' 
Here the important piece of information is that the animal which was encountered was a leopard. The information that it wasn't a cow is irrealis - a negation of the false assumption that held through the preceding sentences.

$\begin{array}{lll}\ldots \text { icayk'n hasi gostargu } & \text { sida } \\ \ldots \text { their } & \text { goods not-being-sold } & \text { remained }\end{array}$

'...their goods were unsold, they still had them.'

Here, the main verb presumably ends with $-a^{4}$ 'and', as described in 3.2.1. Closely dependent on the main verb is gostaru 'unsold', and, as Breeze comments, "This fact is the fact on which the rest of the story depends."

The same construction is found (but with the 3.p.f. + completive marker form of 'remain') at the close of the inciting incident of the lost cow story: ... yapstarga sidene 'unfound she remained'. Here, again, it is on this negative expression that the rest of the story depends-the continued search, the confrontation with the leopard, and the successful disentanglement from danger.

3.2.6. Cohesion. Overt explicit cohesion-as distinguished from script-determined implicit cohesion-is given via conjunctions and sequence signals such as ušam 'then' and esn 'so', temporal expressions such as mat 'woyn 'one day', and by subordinated clauses in backreference function. In the latter, the verbs are not gerunds, but have postpositional subordinators.

(32) ša'k'an hamagi ata.

forest-L going arrived.

ša' $k$ 'an yisi hamagi atnagušn

forest-L he-S going arrived-when

dawu bai surk'nsi yistn bek'a

antelope old having-lain being-SR he-saw.

'He arrived at the forest. When he arrived at the forest, he saw an old antelope lying (sleeping) there.'

The question regarding the distribution and function of such overt backreference needs to be raised. If they are not routinely used to join any event $A$ to another event B ("He A'd. Having A'd, he B'd"), then we must inquire as to the discourse constraints which govern the use of the construction. To think of them as "merely cohesive" will not do if such cohesion has some further implication. 8

${ }^{8}$ This is a general question to be touched on here and there throughout this volume. 
While I am not prepared at present to deal in any definitive way with this problem, I note that in (32) the backreference is very fulsome. It includes repetition of not only the verb 'arrive' but of the gerund hamagi 'going' and of the locative $\mathrm{s}^{\prime}$ ' $k$ 'an 'in the forest'. It is relevant to note in this connection that seeing the antelope is the inciting incident of the whole story.

Similarly, in the lost cow story, the clause which reports the sighting of the shining eye of something lying there in the forest is preceded by a summary backreference in which, instead of an imperfective gerund, we find a summary backreference with a subordinated verb.

(33) ša $^{\prime} \quad$ uškanndisa dyant wu koya ta yistagušn...
forest that-L-foc cow her searching I was-when...

'When I was in that forest searching for the cow...'

Here again the whole rest of the story turns on what occurs in the next clauses beyond the summary backreference.

Two further spots in the story (when the narrator was approaching the "cow" and when he found out that the "cow" was really a leopard) are also preceded by "when" clauses, so that this may be, in effect, a more consistent way of marking pivotal events than that suggested in 3.2.1.

3.2.7. Performative clauses. Still another category, and clearly the farthest from the storyline itself, is performative clauses. These have to do with the interplay between the narrator and his audience. This is seen in the use of discoursefinal mastue 'it was said'. This is a notification on the part of the narrator that he is passing on to his audience something that others have told him.

Breeze also mentions that "a rhetorical aside to the reader consisting of a second person conditional form of the verb mak 'say' may be interpolated as an introduction to an episode."

(34) icayk'n git" yisi harage?

their trade it what is

yinti makan mat'nasi...

you-Pl if-you-say one-of-them

'If you're asking, "What is their trade," one of them...'

3.3. Rank-shifting of gerunds. It is important to note that the scheme given in 3.2. can undergo a rank-shift in which the gerunds in the right hand column are shifted down, so that, for example, an unmarked gerund no longer depends on a storyline form but upon some other form in a lower band on the left hand side. A 
very simple rule applies here: The unmarked gerund is of the same storyline rank as the form on which it depends. If an unmarked gerund depends upon still another non-final form then ultimately we must tie the whole string together by reference to the final form. If an unmarked gerund is equivalent to something of less than storyline rank then further marked non-finals which are dependent upon the unmarked gerund are proportionally further down in rank. It's as if we were to cut the right column free from the left column so as to be able to slide the whole column down. The unmarked gerund would then be dependent on whatever appeared in the left hand side in the corresponding position.

yi mat'nasi haš mant ati eti šičank'u
his friend now ox arriving taking left-Pf-3

'Already his friend had taken the ox and gone.'

Here, since the main verb is pluperfect, ati and et $i$ which are dependent on the verb all have flashback rank. The unmarked gerund is rank-shifted from Band 1 to Band 2.

(36) kang aci ba kobam kobam hank'i

men all-S his direction direction going

dyanta enwu koyi koyi koyi koyi pešn

cow that searching searching spending-time-SR

yapstarga sidene

unfound remained

'Men all having gone each in his own direction and spending a lot of time searching, the cow remained unfound.'

Here the unmarked gerund hank ' $i$ 'going' is dependent on koyi...pešn 'spending a long time searching.' But the latter is an imperfective plus SR marker. Therefore hank ' $i$ 'going' is rank-shifted from Band 1 to Band 3B.

Example (32) affords an interesting contrast in the use of the unmarked gerund. In the first clause hamagi 'going' is a perfective gerund which ranks below ata 'arrived' the storyline final. Here a Band 3 gerund occurs in its unshifted position as lower than the storyline. But in the second clause hamagi precedes atnagušnn 'arrived-when' which is a subordinated verb in backreference. Here an element of Band 3 is rank-shifted to Band 6, as part of the backreference.

3.4. The storyline scheme and constituency structure. The storyline rank scheme given in 3.2. with provision for rank-shift among the gerunds as sketched in 3.3. gives the main criteria for constituency structure, i.e. grouping and layering 
both within the Gimira sentence (a unit terminating in a final verb) and within the paragraph, i.e. within a grouping of such sentence units. Rank scheme considerations can therefore serve as guidelines in the construction of tree structures within sentences and among sentences, i.e. within paragraph. They cannot, of course, of themselves provide labels for nodes or for branches in such trees. The labels which I use reflect sentence and paragraph analysis in a variety of languages around the world [Longacre 1983], inter alia.

3.4.1. Sentence structure. Various sentence types can be distinguished within Gimira narratives. In the list below I assume the main clause to have a storyline verb unless otherwise indicated (but the same relations hold if the main clause has a verb from Band 2). Furthermore, in the list below instead of saying in each instance "clause with unmarked gerund plus clause with main verb," I simply say "unmarked gerund plus main verb" as an abbreviated reference.

(1) unmarked gerund + main verb

(2) SR gerund + main verb

(3) imperfective gerund + main verb

(4) imperfective gerund + imperfective main verb

(5) unmarked gerund + main verb (where both clauses are descriptive/ambient)

(6) negative gerund + stative clause with focus marker on noun

(7) perfective gerund + main verb

(8) perfective gerund with yiam 'by it' and kay 'only' + main verb

(9) perfective gerund + 'be' + SR + main verb

All these sentence types (combinations of gerund and main clause) are found in the "Lost Cow" story.

Adopting the convention that we reserve the term "thesis" for that part of a sentence which carries the storyline and label every other constituent something else, we proceed to label as follows:

(1) Coordinate sentence

Sequential Thesis ${ }_{1}$ : unmarked gerund

Sequential Thesis $s_{n}$ : main clause

[with any number of Sequential Theses possible within the string]

(2) Sequence sentence

Antecedent: SR gerund (non-thematic subject)

Thesis: main clause (thematic subject) ${ }^{9}$

${ }^{9}$ There is an expansion of this for prolonged interaction, verbal or non-verbal, which is sufficiently distinct to suggest that it could be considered to be a distinct sentence type. 
(3) Simultaneous sentence 1

Simul $_{1}$ : imperfective gerund (SR in present examples)

Thesis: main verb

(4) Simultaneous sentence 2

Simul $_{1}$ : imperfective gerund

Simul $_{n}$ : imperfective main verb

[with any number of Simul $_{1}$ coming before Simul $n$ ]

(5) Paraphrase sentence

Paraphrase: unmarked gerund (descriptive)

(Thesis): main verb (ambient)

This is probably a fragment of a broader pattern in which the two clauses could pattern much as in (1) but which is semantically a paraphrase instead of truly sequential actions, while at the same time we have a radical rank shifting due to the non-active nature of the verbs involved. While within the sentence the clause whose verb is formally the most like a storyline verb dominates the sentence, the sentence as a whole cannot be storyline. For this reason I put Thesis in parentheses.

(6) Negated antonym paraphrase sentence

Paraphrase: negative gerund

Thesis: stative clause + focus marker on noun

[Considering $\mathrm{A}$ and $\mathrm{A}$ " as antonyms this sentence says, "It wasn't an A, it was an A".’]

Sentence types (7), (8), and (9) together span a spectrum of relations which express cause, means to an end, and reason. I call them all "Reason sentences".

(7) Reason sentence 1

Reason: perfective gerund

Thesis: main verb

(8) Reason sentence 2

Reason: perfective gerund with yiam 'by it' and kay 'only'

Thesis: main verb

(9) Reason sentence 3

Reason: perfective gerund + 'be' + SR

Thesis: main verb

I now proceed to exemplify each of the above. 
(37) Coordinate $S$

wu sumam c'ega ta šikue

her name-by calling (unmarked gerund) I approached-compl.

'Calling her name, I approached.'

(38) Sequence $S$

"Dodi t'ummi yiskue," ta makn

earth-S getting dark is I saying (SR gerund)

acndisind, "Haragi ni šerši yistageo," makue

men-they what you is-frightening is-it said-they-compl.

'I said, "It's getting dark," and the men said, "What are you afraid of?",

(39) $\underline{\text { Simultaneous }}_{1}$

dyanta enwu koyi koyi koyi koyi pešn

cow that-her searching searching spending-time (imperf. SR gerund)

yapstarga šidene

unfound remained-3f-compl.

'They having spent much time searching for that cow, she remained unfound.'

(40) $\underline{\text { Simultaneous }} \mathrm{S}_{2}$

gurt'a yista

trembling (being)

"Wo Yero ta keso," maka yista

Oh God me take-out saying (being)

opta hank'a ta yistue

walking going I was

'Trembling, saying continually, "Oh God, get me out of this," I was walking along.'

This example is of interest because of the pile-up of opta and hank'a before ta yistue. Customarily an imperfective gerund consists of but one unmarked gerund plus the verb 'be' (with the possibility of iconically repeating the gerund to indicate 
duration/repetition); but here we have two unmarked gerunds. This is itself an embedding-now an all but frozen one-of 'walking' and 'going' in the larger structure.

(41) Paraphrase S

dodnda tib tib maki t'ummi šikue

earth dark dark saying (=getting) to-get-dark approached-compl.

'It was beginning to get dark.'

(42) Negated antonym paraphrase $S$

bam dyant wus esaraga

itself cow she not-being

nasa panc'agi yistue

man leopard-foe was

'It wasn't a cow; it was a leopard.'

This could be considered to be a contrast sentence but I have treated the denial of the one as equivalent to the other.

(43) Reason $S_{1}$

tannd ušam esn tam šerk'nga

I-conn then so myself having-become-afraid

"Purk'n karti ni haman soyagizeo," ta makue

home returning we if-go it-is-good I said

'So then, beginning to fear for my own safety, I said, "It's better if we go home."'

(44) $\quad \underline{\text { Reason }}_{2}$

ta yiam yi apa sank'i yiskuš

I by-it its eye shining was-which only having-seen

gyar gyar yi dadn ta hank'ue

forward forward it to I went

'Guided only by the shining eye that I had seen, I worked my way towards it.' 
(45) $\underline{\text { Reason }}_{3}$

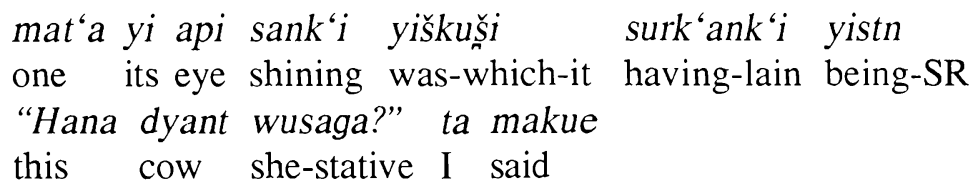

'Since there was something lying down out there with a shining eye, I said, "Is this the cow?"

In addition most of these sentence types could take subordinated adverbial clauses (verbs subordinated with 'when') and purpose clauses. Illustrations occur sporadically in previous examples.

By no means does the above list exhaust or exemplify all sentence types in Gimira. Rather, it summarizes sentence types of frequent use in narrative. Further discourse types, e.g. hortatory and expository discourse, call for other sentence types, e.g. various types of conditional, concessive, comparative, and contrastive sentences. For each discourse type a verb ranking scheme will need to be evolved, so that sentence types when posited can be correlated with such a scheme. In this way the analysis of verb morphology and of verb ranking can proceed conjointly with the analysis of sentence structure to the mutual elucidation of both.

To return now to sentence types in narrative, it is necessary to remember that sentence embedding can produce very long and complicated strings with several layers of embedding. By keeping firm hold on the relevance of verb ranking such structures can be analyzed successfully. In the interests of avoiding excessive and tedious length, I will not further exemplify here. Essentially, in such long sentence strings medial forms replace what would have been finals, i.e. a certain amount of rank-shifting takes place (cf. 3.3.).

3.4.2. Paragraph structure. On the paragraph level, i.e. among sequences of sentences that belong together 10 essentially, the same relations hold, but here we deal exclusively with mutual rankings of main verbs. Paragraphs tend to be somewhat simple because a large majority of the semantic and logical relations are disposed of on the sentence level as already illustrated.

The first paragraph of the "Lost Cow" story has five sentences each of which terminates as follows:
(1) aca kang...hank'ue
'all the men....went'
(2) ta hank'ue šidene
'I went'

${ }^{10}$ Essentially, the cohesion of a paragraph is (1) thematic and lexical and (2) grammatical, in the sense of sequence signals (conjunctions or particles) that signify paragraph beginning and/or end. 
(3) yapstarga šidene

(4) opta koya ta yistue

(5) t'ummi šikue 'she remained unfound'

'walking, searching I was'

'darkness approached'

To begin with, sentences (4) and (5) would seem to be off the storyline, (4) by virtue of having an imperfective gerund of Band 3 and (5) by virtue of having an ambient expression of Band 4. This works out well in the case of sentence (4); here we are simply told by the narrator that he was in the woods searching by himself. An initial particle ušram 'and then', which is found in sentence (4) can be taken to express result, and we can construe sentence (4), which ends in an imperfective, as the result of sentence (3) which says that after long search the cow was not found. But what of sentence (5)? Before we decide that it is simply a chronological/temporal observation ("Oh, by the way it was getting dark") we need to take account of a further fact: this is the only sentence in the paragraph that begins with a backreference via a when-clause (koya ta pešagušn̆n 'searching I spending-time-when'). Since elsewhere in the text when-clauses signal that an important event is to follow, we may need to consider here that the occurrence of koya ta pešagušn promotes the following meteorological clauses to Band 1 as especially significant or pivotal. To this we can also add the observation that the meteorological expression itself is paraphrastic, i.e. the narrator doesn't let this important piece of information go by too rapidly, but expresses it in two clauses (cf. 41). Taken this way, the paragraph, roughly indicated in Diagram II, is of coordinate or sequence structure (there is no difference in the two on the paragraph level but only on the sentence level, where the distinction turns on the presence of the unmarked gerund versus the unmarked gerund plus SR). See the accompanying diagram.

In commenting on this paragraph, I note the peculiar structure involving sentences (1) and (2). While they both have storyline verbs, it is not at all evident that the narrator's going out to search for the cow followed the going out of the other men to search. It is more reasonable to believe that the verb hank'ue 'they/I went' refers to the same event and that sentence (1) is generic, 'all the men went out to search,' and sentence (2) is specific 'I also went out to search.' This feature of on-the-storyline paraphrase as well as the promotion of a meteorological construction in sentence (5) to the storyline may reflect that this opening paragraph, rather than simply staging the story, is presenting the inciting incident: without the cow's getting lost and everyone searching for her, this story wouldn't have happened. The inciting incident of a story is likely to have certain peak-like characteristics. Of this four paragraph story, paragraph 1 (Inciting incident) and paragraph 4 (Peak: confrontation and denouement) are the most complex. The intervening paragraphs are one sentence each and are therefore termed simple paragraphs. 
(1) One day on its being reported that Mokan's cow was lost, all the men got up and went to find her

(2) I also got up and went to look for my friend's cow.
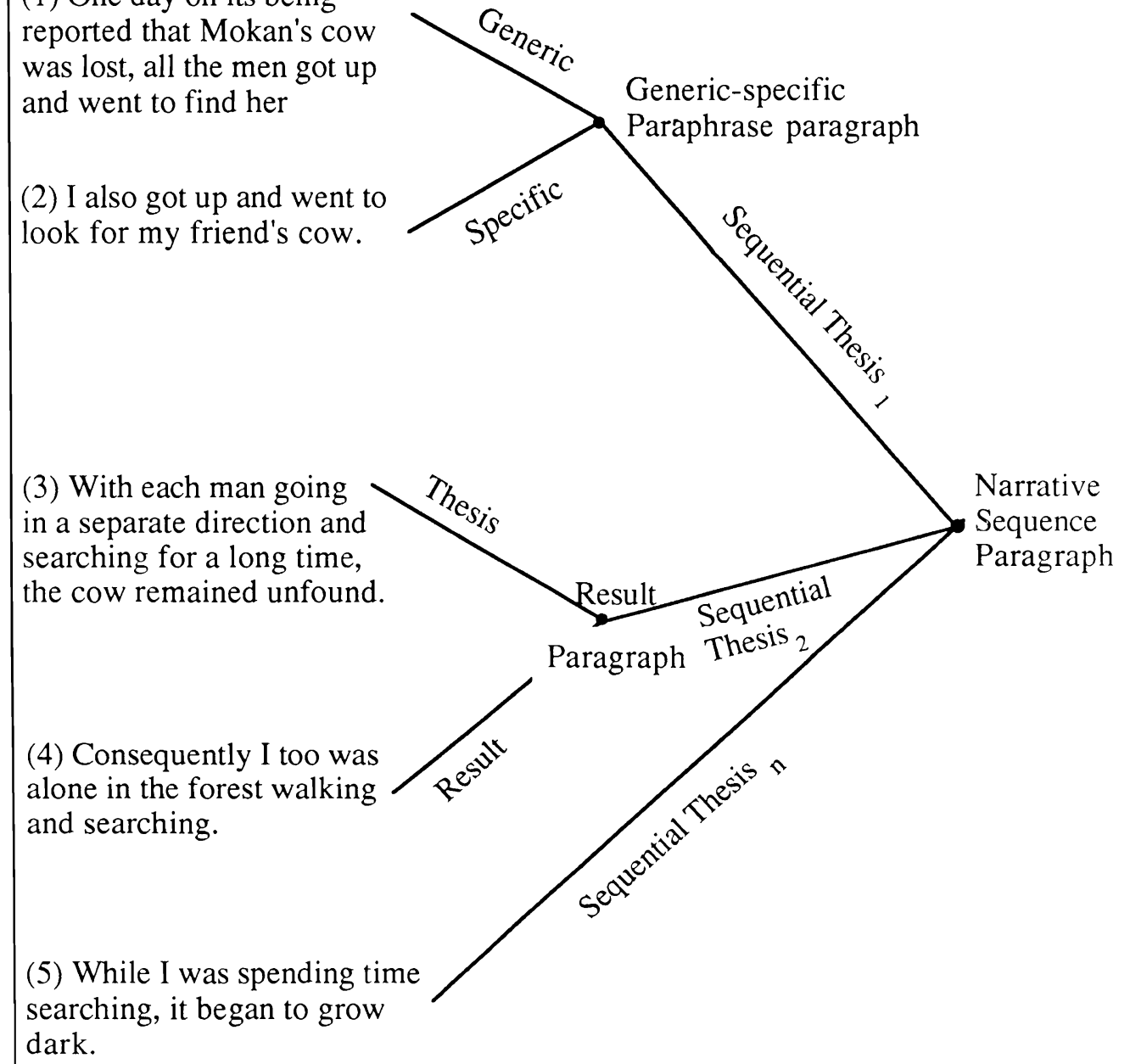

Diagram II. A Gimira paragraph analysis in accordance with verb/clause ranking 
3.5. Peak-marking features. Regarding peak-marking features in a Gimira story, Breeze mentions the following features:

1. At certain points there are extra long sentences. In routine narrative, there are usually no more than about four clauses in a sentence, but at peak there may be as many as ten or more.

2. There is great grammatical complexity within the peak sentences.

3. There is frequent switch reference between subjects, often only marked by the verb suffixes.

4. Details are often added to slow the story down.

5. Generally there is a lack of sequence markers [conjunctions] but some exceptions to this have been found.

6. There is fronting of elements which are not usually fronted.

Of the above, (1) - (4) form a related bundle of features: length, complexity, frequent $S R$, and added detail.

The use of the suffix $-a m^{4}$ to mark the resolution of the action, i.e. the denouement, is also mentioned here by Breeze as relevant to peak marking. See (14) with accompanying discussion.

If my hypothesis regarding the use of adverbial backreference when-clauses to underscore pivotal events (which follow the when-clause) is correct, we should expect to see a frequency of such clauses approaching and at the peak of a story. Breeze's examples seem to bear this out. She also notes that the suffix $-a m^{4}$ can occur on such a 'when' subordinated verb at peak: yard-am-agušn-is 'when he enters in' (a snake into a hole).

One striking peak feature in the "Lost Cow" story is the lack of a cognitive verb at peak in the sentence "It wasn't a cow; it was a leopard," rather than "Then, I perceived that it wasn't a cow, but rather it was a leopard." In peak, a certain immediacy of reporting events is to be expected. Such immediacy is attained here by omitting the storyline cognitive verb. When omitted however, the construction from which it is omitted must be considered to be promoted to the storyline regardless of its inherent rank, which is here Band 4.11

\section{Kambaata (Cushitic)}

Kambaata (data from Mirja Saksa) affords an interesting comparison with Gimira. While I shall point out these contrasting features, I shall not attempt to give

${ }^{11}$ This device certainly holds for other languages besides Gimira. Consider the Drama in Real Life story, "Tiger! Tiger!" by David Taylor (Reader's Digest, March 1981, pp. 122-126). Here at the Peak where the man realizes that he is confronted by a tiger, the cognitive verb does not occur. Rather, we are told, "There, wreathed in smoky haze, was the tiger, one paw pressed hard against the wire and each scimitar-shaped claw extended." 
as much detail and exemplification for Kambaata and the other languages mentioned below as I have for Gimira.

4.1. Kambaata compared with other languages. Whenever two languages, in this case Gimira and Kambaata, are analyzed from the same overall perspective with somewhat differing resultant analyses, the question must be raised as to whether the languages themselves are structurally different in respect to the posited distinctions or whether these distinctions are an artifact of the analyses themselves. Obviously, if the latter has happened the "overall perspective" has failed to provide adequate control and guidelines in the analytical work. Or, as clearly happens in some instances, the selection of texts on which an analysis is based does not include one or more features that are, as a matter of fact, found in other texts within those languages. While I believe that interference from the first factor is not so probable (since the analyses reported on in this chapter were elaborated simultaneously and under the same overall direction) interference of the second sort is more difficult to control. This sort of interference must be watched for and allowed for at certain stages of the comparison of two or more languages in respect to their discourse structures.

In the three-way comparison of Koorete, Afar, and Gimira above, semantic and structural differences were observed in regard to the relative status of medial (unmarked) verb forms versus final (main) verb forms. This also correlated somewhat with the relative amount of grammaticalization of final verbs. In Afar, where grammaticalization of finals has been rather extensive, a privileged type of medial (Bliese's perfect participle) is often storyline rather than the final. In Koorete and Gimira, where there is not so much grammaticalization of finals, the simple past tense (or completive aspect) final verb is storyline with the role of the unmarked gerund differing somewhat in the two languages: (1) a secondary storyline in Koorete; and (2) main storyline status in Gimira (provided it depends on a simple past tense final). In this three way comparison, the structural/grammatical distinctiveness of Afar sets it apart while the comparison of Koorete and Gimira involves what is largely a semantic decision.

Kambaata is more similar to Gimira than to Koorete, i.e. it places both simple past tense finals and the preceding unmarked gerund on the storyline.

(46) hikkannic zakkiin maaliic matu k'at'a icci duubbi that after of-meat one portion eating getting-full $c^{\prime} o^{\prime} u$ jammarri illisi t'okk'a'i

to-skin starting eyes lifting

wošicu t'uü̈i a agurri "wošaanwoše" yee“i

the-dog seeing leaving "doggie" he-said.

"After that, he ate part of the meat, got full, started to skin it, and saw the dog, and said, "Doggie." 
Here the unmarked medial gerunds are icci 'eating', duubbi 'getting full', jammarri 'starting' $t^{\prime} \mathrm{okk}^{\prime} \mathrm{a}$ ' $i$ 'lifting', $t$ 'uujji 'seeing', and agurri 'leaving', while yee ' $i$ 'he-said' is the final verb.

In spite, however, of this similarity of Kambaata and Gimira in respect to the status of the unmarked gerund vis-à-vis the final verb, there are fundamental grammatical differences which determine differences in storyline schemes between the two languages. Keeping in mind that we are concerned here with the grammar of narrative discourse rather than with an abstract overall grammatical scheme for all possible discourses in the language, 12 I note the following: (1) Gimira narration has more tense distinctions in main verbs (simple past, perfective, pluperfect, and imperfective) than does Kambaata (simple past versus imperfect). (2) Gimira has a system of gerunds which distribute out vertically through five ranks of the storyline scheme; all are plus or minus the SR marker except for the negative gerund (Band 5: irrealis). Kambaata has fewer gerund forms, and they cluster rather neatly together into the following system: 13

$\begin{array}{lll} & \text { Same Subject } & \text { Different Subject (SR) } \\ \text { Succession } & \text { unmarked } & \text {-aan } \\ \text { Simultaneity } & \text {-ani } & \text {-aniyaan }\end{array}$

(3) Gimira makes limited use of subordinated verbs (adverbial clauses) in narration: purpose clauses and when-clauses are used on occasion, with the latter perhaps marking important developments which are reported in the following clause. Kambaata, on the contrary, makes very frequent use of adverbial clauses in narrative discourse with a considerable and varied inventory of such clauses. In Kambaata, a variety of postpositions subordinate modified finals; in Gimira postpositions are added directly to the stem, making them, however, not so different in principle from gerunds.

4.2. The storyline scheme (more comparisons). Against the background of these differences, Saksa constructs the accompanying storyline scheme, which does not, like Gimira have two parallel sides for finals and medials.

12I have become rather impatient of the latter sort of grammars. It seems to me that most grammars have been constructed prematurely without proper attention to the grammar of distinct discourse types. The overall grammar should be a generalization from the particular grammars of different discourse types.

${ }^{13}$ This identical scheme is basic in Highland Papua New Guinea chaining languages as seen in Longacre [1972:1-25]. 


\begin{tabular}{|l|l|}
\hline Bands & Verb and clause types \\
\hline $\begin{array}{c}\text { Secondary } \\
\text { Primary }\end{array}$ & Final verb (simple past) + preceding un-marked gerunds \\
Gerunds with SR marker and/or simultaneous suffix
\end{tabular}

Diagram III. Kambaata verb/clause ranking

Let us immediately dispose of certain differences between the Gimira and Kambaata schemes on the grounds that they may be more apparent than real. (a) The category of backgrounded events is narrower in Kambaata than the "non-storyline actions" band in Gimira but the two bands are broader similar. Saksa in particular does not report backreference in main verbs, but only in relative clauses. (b) Saksa posits a category, "evaluation", which is lower than cohesion in her scheme, in that she feels that the latter is closer to the storyline. As for presence of evaluative elements-intrusive author comments in Gimira-none have been 
recognized and catalogued in the texts that Breeze has analyzed to date, but this may well be a fortuitous gap in the data. Topicalization in Kambaata is a kind of nominalization and cleft structure, which may also have a counterpart of sorts in Gimira.

For a more substantive difference between storyline schemes in Gimira and Kambaata, I suggest that the differing placement of gerunds is of considerable interest. Breeze considers the unmarked gerund + SR to be a secondary storyline and places it in Band 1. Furthermore, Gimira does not have a system of closely related gerund forms; the perfective gerunds have distinctive endings and the imperfective gerunds are periphrastic, aside from one non-periphrastic form that seems not to take the SR marker. Kambaata on the contrary has the symmetrical system of gerunds in two parameters that is presented above. Taking out the unmarked gerund (intersection of same subject with succession) Saksa puts all the other gerund forms into a secondary storyline which thereby combines backgrounded events (with SR), with certain background activities whose duration is not explicitly stressed by resort to the construction which is found in Band 3. This apparently strains somewhat our etic scheme in Diagram II of the Introduction since it puts some simultaneous activities on the secondary storyline--in effect, combining elements from Bands 2 and 3 with some elements that resemble items from Band 6 (but which are not in backreferential function.)

In regard to the above problem, it is helpful to note (a) that the central difficulty is the placement of the dependent clauses, i.e. clauses whose verb is a modified final subordinated by means of a postposition. In general, experience gained elsewhere, plus the fact that such clauses are grammatically demoted and seem less central than the gerunds (which attend final verbs), seems to indicate the desirability of ranking gerunds above dependent verbs, as here in Kambaata. This is only slightly compromised in Gimira by putting dependent clauses (not in backreference) along with certain gerunds in Band 2. (b) Examples come to mind of languages such as French and Totonac (Mexico) which have an imperfect tense used to background certain events and activities, at least some of which are simultaneous with the sequential and punctiliar action of the main storyline verb, while the imperfect, in turn, contrasts with periphrastic past tense forms which more specifically express duration. Again, the Kambaata ranking is not dissimilar in principle.

There is rank shifting of gerunds in Kambaata as in Gimira. Saksa mentions this tersely: "Gerund forms or suffixed gerund forms can be used before other than final verbs." There follows an illustration in which unmarked gerund $(-1)$ depends on (a) a dependent verb subordinated with -hanniic zakiin 'after' and (b) on a SR gerund (-aniyaan). 


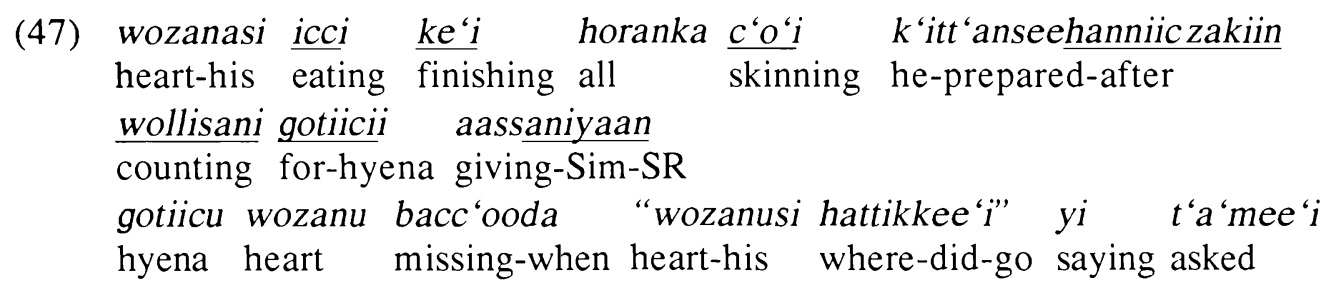

'After it had eaten, skinned, and prepared everything, while counting and giving them to the hyena, since the heart was missing the hyena asked, "Where did the heart go?"'

4.3. Peak-marking features. Saksa's analysis is based on six narrative texts, one of which is not a folktale but a piece of history (hostile relations between the Kambaata and the Haddiyah). In regard to marking peak in these stories, Saksa mentions (as did Breeze for Gimira) extra long sentences at peak, great complexity of sentence structure, and the crowded stage - the latter presumably resulting in the very frequent use of suffixed gerunds with switch reference.

Saksa stresses the predominance at peak of active verbs and gerundive active verbs (again, note the relevance of the primary and secondary storylines with the whole system of gerunds clustered in the latter). She tells us that "other elements are reduced to a minimum," i.e. the dependent verbs (as opposed to gerunds) are not so prominent here. Saksa gives graphs for several stories concerning the percentage of active verbs over other verbs in differing parts of the story. Here the augmentation of the storyline (see Introduction) is clearly illustrated.

In these respects I doubt if Kambaata is radically different from Gimira. But there are respects in which Kambaata (cf. Gimira suffix $-a m^{4}$ ) makes use of factors specific to that language to partially indicate peak: (1) "In some narratives there are suddenly one or two imperfect subordinated verbs not giving the idea of durative or habitual action (as usual), but rather one single pivotal action that precedes something that is important for the rest of the story." (2) She further notices that "the use of ke?- 'rise, stand up' that often occurs with other verbs (giving them the meaning of finishing of one action relative to the next) does not seem to occur here [at peak]." I interpret this to mean that the precipitous flow of the action line at peak does not encourage such indications of deliberacy as, "He finished doing A. Then he did B."

Saksa further mentions that all six stories exhibit a peak structure of spike and rapid decay. While "the build-up of tension is long and well-constructed," there is "rapid change from a highly active episode to an actionless episode in which dialogue often figures." Possibly what all this means is that the peak is typically the climax (the nouement or maximum tension), the tension is quickly resolved (denouement), and the first post-peak episode is comparatively placid and nonturbulent. 
As to the difference in style between the folktales and the history, Saksa does not have too much to say. She mentions, however, "In some stories where there is a lot of repetition in the earlier episodes there is none in the action peak, but straightforward movement instead. Kambaata history is generally full of action and has hardly any repetition except at the two peaks of the story" [italics mine].

\section{Haddiyah (Cushitic)}

Haddiyah (data from Elsa Korhonen) makes more restricted use of its gerunds than either Gimira or Kambaata with consequent more frequent use of modified finals with postpositions than is found even in Kambaata. Korhonen has constructed a parallel column scheme for finals and medials which I reproduce here with adaptations. ${ }^{14}$

5.1. The storyline scheme (upper bands). In Haddiyah the storyline is carried by simple past forms $(-u)$. The use of a storyline perfect rather than a past is rare, and Korhonen speculates that the latter may be a marker of paragraph final in at least one style (cf. Gimira, 3.2. above). It is not exemplified here. Dependent storyline forms are either (same subject) unmarked gerunds or are modified finals (simple past or more rarely imperfect) with the switch reference marker -aare. As Korhonen states, "There is no switch reference marker (SRM) that is added to a gerund; SRM always goes with the modified simple past or modified imperfect." Here we see that dependent verbs (modified finals) have apparently encroached on the domain of the gerund. In the example below, final storyline forms occur as sentence-final. Storyline gerunds are underlined.

(48) ee hurbaata itaa garukko.

that food he-eating spent-the-night

farasonne koora issaa, minenne daba'laa marukko.

horse-on saddle he-putting-on at-home returning he-went.

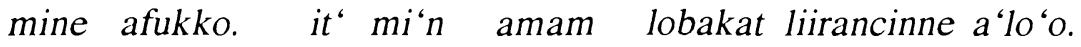

house he-reached his house- mother- very happiness- she-received

gen. and by

'He ate that food and slept. Having saddled his horse he returned home. He arrived there. His wife welcomed (him) very happily.'

${ }^{14} \mathrm{My}$ main adaptation is the separation of Background Events and Background Activities into separate bands. Korhonen had simply one background band. I also interpret her "past gerund" as a "perfect gerund". The simple past is marked with - $u$ and the perfect with $-a$. The gerund in question has the second marker rather than the first. 


\begin{tabular}{|c|c|c|}
\hline Bands & Main Verb & Gerund \& Dependent \\
\hline 1. Storyline & $\begin{array}{l}\text { Simple past } \\
\text { Perfect (Paragraph } \\
\text { final in some stories) }\end{array}$ & $\begin{array}{l}\text { Unmarked gerund } \\
\text { Mod. simple past }+ \text { SR } \\
\text { Perfect gerund }\end{array}$ \\
\hline $\begin{array}{l}\text { 2. Background } \\
\text { Event }\end{array}$ & $\begin{array}{l}\text { Pluperfect tense } \\
\text { [gerund }+t+\text { 'be'] }\end{array}$ & $\left.\begin{array}{l}\text { Unmarked ger. } \\
\text { Rel. Cl. + Abl. }\end{array}\right\}+\begin{array}{c}\text { lasonne/lasage } \\
\text { 'after' }\end{array}$ \\
\hline $\begin{array}{l}\text { 3. Background } \\
\text { Activity }\end{array}$ & $\begin{array}{l}\text { Past continuous } \\
\text { [gerund }+-m+\text { 'be'] }\end{array}$ & Mod. s.p. + -uyy(a) 'while doing X' \\
\hline 4. Explanation & $\begin{array}{l}\text { Stative } \\
\text { Copula } \\
\text { Nominal Clause }\end{array}$ & $\begin{array}{l}\text { Mod.s.p./pres. + bikkin 'because' } \\
\text { Rel. Cl. + loc. 'when' } \\
\text { Inf. + -anne 'by' }\end{array}$ \\
\hline 5. Irrealis & $\begin{array}{l}\text { [negatives of main } \\
\text { clause?] }\end{array}$ & $\left.\begin{array}{l}\text { Jussive I } \\
\text { Jussive II } \\
\text { Inf. +/- -ina (inst.) } \\
\text { isa 'as' } \\
\text {-eebe 'until' }\end{array}\right\}$ Purpose \\
\hline $\begin{array}{l}\text { 6. Performative/ } \\
\text { Evaluation }\end{array}$ & $\begin{array}{r}\text { Perf. form of kur 'tell' } \\
\text { Impf in cleft } \\
\text { All involve t }\end{array}$ & $\begin{array}{l}\text { Rel. Cl. in cleft structure } \\
\text { tructure } \\
\text { Dicalization }\end{array}$ \\
\hline 7. Cohesive & & $\begin{array}{l}\text { Unmarked gerund +/- ki 'aa 'finish' } \\
\text { Unmarked gerund I + lasonne, lasage } \\
\text { Rel. Clause + Abl.J 'after' } \\
\text { Rel. Cl. + loc. 'when'/-k "nominalizer", } \\
\text { Mod. s.p.+-luyya/-ammanennc 'when' }\end{array}$ \\
\hline
\end{tabular}

Diagram IV. Rank scheme for Haddiyah (adapted from Korhonen) 
yito" ammarenne, maramaa afukkaare;

said-she time going reaching-he-SR

barc'umma uwwita'a beyyo matta'a mo'lamaare, beyyidu gataako. chair giving-she place going-she seeing-she-SR place was-left

'When she said that, he went and reached to place; on her giving him a chair and going to the place and looking, [she saw that] the place was empty.'

In the above examples, notice the distinctive masculine (-aa) and feminine ( $a$ 'a) forms of the "unmarked" gerund. The storyline in (48) involves eating, spending the night, saddling his horse, returning, going, and being received happily by his wife. To be sure, 'saddling the horse' and 'returning' could be considered simply preliminary to the main verb (cf. Koorete above) in sentence 2, but itaa 'eating' in sentence 1 is not in this category. In fact the story turns on the protagonist's having eaten there. In (49), we have unmarked gerunds forming strings the ends of which are indicated by modified finals (with SR). This could be considered to be a rudimentary form of rank-shifting, but Kohonen does not rank SR dependent verbs below same subject unmarked gerunds. On the contrary, the gerund is ranked below the modified final $+\mathrm{SR}$.

In Band 2, Background Events, the forms on the main verb side seem clearly to code flashback while the examples on the dependent side signal events of less prominence (etic Bands 2 and 3 of my etic scheme). Again, it seems logical to me to treat all these elements, including flashback, as in the same broad category.

As for flashback, Korhonen cites one example of a pluperfect formation in a final verb. It is a periphrastic formation which she describes as gerund $+-t$ plus a form of the verb 'be'.

(50) gaas ka uullan t'aaliyan oor k'assaa lasage aaggaat he'ukko.
earlier this country-in Italian war winning after he-had-entered

'Some time ago an Italian had entered this country [after (his country) had won the war].'

Here this event is backset from the main storyline.

The same example also illustrates in oor $k$ 'assaa lasage 'after winning the war', a backgrounded event which is indicated in an unmarked gerund followed by lasage 'after'. Here a postposition occurs with a gerund (which is clearly rank-shifted). The largely synonymous postposition lasonne 'after' can occur with the gerund in similar function. Korhonen reports that a relative clause in the ablative case (aannii) followed by either postposition can also indicate backgrounded events. 
For backgrounded activities, Korhonen cites periphrastic final verbs consisting of an unmarked gerund $+-m$ followed by a form of "be'. This she calls the "past continuous".

(51) [Korhonen entitles this whole paragraph "a background paragraph".]

hund amman baddam he'ukko.

all time fearing was-he.

beet baddoo maška'oomim annii amaa la'amam he'ukkoyyo.

boy fearing reason-and father-and mother knowing were-they-not.

beetoom land woron matic he' $u$ bikkin

boy girls among one was because

araka' iittamam he'ukko.

very loving were-they

ee hannii ki isamukkok sooddoohaare

that from what-happened ( $\mathrm{Rel} \mathrm{Cl}$ ) when-morning-came (SR)

darindarindiricii $\quad k i{ }^{\prime}$ isamaa timhirt

morning by morning from-sleep waking-up

min marookkisa issamam he'ukko.

school to-go putting were-they.

'He was afraid all the time. But the father and mother didn't know the reason that the boy was afraid. Because the boy was the only one among the daughters, they loved him very much. Consequently what happened was every morning they woke him and up and sent him [habitually] to school.'

On the gerund/dependent verb side we have a modified simple past + -uyya( $m$ to indicate background activities. Kohonen has an example in which badditu'uyyam 'being afraid' occurs before the final form kutto 'o 'she told'.

5.2. Possible diachronic storyline developments. Looking at the top three bands, Storyline, Backgrounded Events, and Backgrounded Activities, several things can be observed in respect to gerunds, gerund-like forms, periphrastic formations, and the use of modified finals with postpositions: (1) While the unmarked same-subject gerund indicates storyline before a storyline final, we find the modified simple past + SR in the same function. (2) Although there is a perfect gerund as well as the unmarked gerund, the former is of infrequent use and its role in narrative is poorly understood while the final verb in the perfect has now come to pattern as a marker of paragraph end. (3) The final verb in backgrounded events (flashback) has a peculiar gerund formation ending in $-t+$ 'be', while the final verb in backgrounded activities has a peculiar gerund formation ending in $-m+$ 'be'. 
The unmarked gerund + lasage or lasonne 'after' is now used in much the same function as a case-marked relative clause with the one of these two postpositions.

I believe that the above observations may indicate a three-stage diachronic development. (a) At an earlier stage there was a larger system of gerunds than at present. This system included the present unmarked gerund, the perfect gerund in broader and more distinctive function than at present, and gerunds ending with $-t$ and $-m$. (b) Increasingly, modified final verbs with postpositions, as well as relative clauses + case endings + postpositions, and infinitives marked in various ways, have crowded in on the former distribution domains of some of the gerunds. (c) The old gerund forms in $-t$ and $-m$, whatever they once meant, are now found only in periphrastic verb formations with 'be' (cf. Afar compound verbs). In brief, Haddiyah probably had in the past a rather extensive system of gerunds such as we find in Gimira, but there has been progressive diachronic attrition of their structural domains and functions so that other items involving postpositions fill slots once filled by gerunds.

5.3. The storyline scheme (lower bands). I will proceed more summarily in respect to the remaining structures which are indicated in the Haddiyah rank scheme. In the Explanatory (Setting) band Korhonen reports existential clauses with he 'ukko 'there was...' equative clauses with the copula -tte, which is a bound form (as also in Kambaata), and nominal clauses which do not have any verb at all. On the dependent side, she reports various temporal and causal clauses which consist of modified finals, locative case-marked relative clauses, and infinitive clauses marked in much the same way. Presumably these clauses encode new information unlike some similar constructions in the Cohesive band, which are backreferential in function.

There is a bit of functional overlap and smear between the last two bands in Haddiyah. The Performative band, typically a slot for author comment, employs relative clauses in cleft structure: This which I've written/talked about is X" or "X is therefore necessary/desirable", etc. Since, however, such topicalization structures are presumably also used to mark closure of a discourse or of a section of a discourse, the secondary function of articulating the structure of discourse is similar to the cohesive function (cf. the grouping of topicalization and cohesion in the same band for Kambaata above).

I pass over saying anything further about the Irrealis band in Haddiyah. Korhonen says nothing here about negatives/modals in final verbs in the narrative framework (as opposed to reported speech) in narrative discourse. On the dependent side she lists a considerable variety of constructions for expressing purpose, 'as if', and 'until'.

5.4. Peak-marking features. In regard to the marking of peak, Korhonen stresses "features that slow down the flow of action". Presumably this has to do 
with the building up of tension to a climax (nouement) instead of denouement. In regard to the latter she comments, "The final solution is told very fast, maybe in one short clause. The tension rises and rises, but after the solution, there is not much left to tell." All this is apparently parallel to what Saksa reports regarding Kambaata.

In regard to the difference between routine narration and narration at peak, Korhonen remarks in her verb-ranking write-up "... in one sentence there is usually one unmarked gerund that carries the story on or none." But at the peak area of a discourse, the frequency of unmarked gerunds as backbone verbs increases (there are examples of ten or more backbone gerunds in one sentence). In her write-up of peak features, Korhonen makes it clear, however, that at least some of these backbone verbs are pseudo-actions/events as I mentioned in the Introduction $\$ 4$. She gives an example uraa maraa guullaa 'leaving, going, finishing' for simply 'leaving'. 15

Korhonen also mentions that backreference (via cohesive elements as indicated) including the unmarked gerund, flashback to earlier actions in the middle of a subsequent flow of actions, and apparently otherwise unmotivated explanation, all can occur to slow down the action flow in a build-up towards climax. She also mentions a switch from non-verbal to verbal actions resulting in onset of dialogue which sometimes changes to drama, i.e. reported speech without the use of formulas of quotation.

Some more specifically Haddiyah peak-marking features are as follows: (1) A subject noun phrase can be shifted to occur after the final verb. ${ }^{16}$ (2) Reference to an important participant can take a suffix -ooma 'that very one' at what Korhonen calls "the very tense or decisive moment". (3) The particle - $m$ 'and' appears at the peak area more commonly than otherwise in the story. (4) "Perfect tense is used in two stories. Also, an imperfect -oo- ["present or future"] can suddenly appear in the middle of simple past forms" (cf. Kambaata above).

She also mentions paraphrase and repetition and use in one story of onomatopoeia. These are certainly not specific to marking of peak in Haddiyah, but can be attested in many parts of the world [Longacre 1983].

\footnotetext{
${ }^{15}$ Obviously here a fruitful turn for future discourse analysis in Haddiyah might be the precise discourse roles and functions of such verbs that pad the context with pseudo-actions/events at certain places in Haddiyah.

${ }^{16}$ This is (a) impossible in some SOV languages; (b) it occurs, but is corrected and shifted to nonfinal position in some languages with indications that such "afterthoughts" are marginally grammatical at best; or (c) it is systematically exploited for discourse purposes, e.g. in Cayapa of Ecuador (cf. Wiebe 1977). At any rate, (d) I would hazard the guess that any such post-verbal occurrence of nouns in consistently SOV languages is set off by a well-defined phonological pause (cf. Maxacali of South America, Popovich [1985]).
} 


\section{Amharic (Ethio-Semitic)}

Amharic (Bliese [1984], summarizing research by him along with Dr. Mikre Sellassie, Gebre Ammanuel, and Peter Unseth) is, as we have observed, a Semitic language whose structure was not historically SOV but which has become so by the influence of surrounding Cushitic and Omotic languages of the sort summarized and illustrated in previous sections of this chapter. This language has formally but one sort of gerund and bears no evidence, as does Haddiyah, of an extensive system of gerunds in the past. Furthermore, storyline finals can be coordinated, a feature which is not typical of SOV chaining languages. ${ }^{17}$ But, although Amharic has formally but one sort of gerund, two functions of this construction are phonologically distinguishable: the consecutive gerund, which has final high stress and figures in Bands 1-4 of Bliese's scheme and the coextensive (stative) gerund which does not have the final high stress and figures in the lower bands. Consecutive gerunds primarily occur as storyline forms before storyline finals, but they may rank shift downward to precede any final or dependent clause in the next three lower bands, i.e. before any form that encodes an action/event or activity. Coextensive gerunds primarily have their place in cohesive backreference clauses but may be found preceding elements of the next three bands up (Bands 5, 6, and 7). In a word, consecutive gerunds are dynamic and coextensive gerunds are static.

6.1. The storyline scheme (upper bands). Bliese gives a coherent and clear rank scheme in his paper, which I reproduce here substantially as he gives it. My only major departure from his scheme consists in changing his ranking Storyline, Flashback, Routine, and Background Activity to Storyline, Routine, Background Activity, and Flashback. Flashback seems to be well defined in Amharic as a morphological category and is evidently not infrequent. Futhermore, it can apply to actions/events or activities, and the two are distinguished morphologically. Therefore, unlike the previously described languages where flashback is not as distinctive or frequent (and may therefore be grouped with one or more other categories) it clearly emerges in Amharic as a separate band. As such, it seems to me to belong at the bottom of the dynamic half of the storyline scheme. More specifically, (a) while Routine script predictable events flesh out the main

${ }^{17}$ Notice here that the claim is that surface structure coordination of final verbs is not typical of an SOV language. I am not considering the fact that a medial plus a final, with great frequency, structure in what could be called semantic coordination [James 1970]. Such "semantic coordination" is implicitly assumed by putting a medial and its final both on the storyline or off the storyline. 


\begin{tabular}{|c|c|c|}
\hline Bands & Main \& Dependent & Gerunds \\
\hline 1. Storyline & $\begin{array}{l}\text { Pivotal actions (direct speech) } \\
\text { \{Main: Perfect Aspect of Action } \\
\text { \{Coordinate Main }\end{array}$ & $\begin{array}{l}\text { Consecutive Gerund } \\
\text { (final high tone) }\end{array}$ \\
\hline $\begin{array}{l}\text { 2. Routine Script } \\
\text { Predictable }\end{array}$ & $\begin{array}{l}\text { Perfect Aspect in Dependent } \\
\text { Clauses }\end{array}$ & Rank Shift \\
\hline $\begin{array}{l}\text { 3. Backgrounded } \\
\text { Activities }\end{array}$ & $\begin{array}{l}\text { Imperfect in Main Clauses } \\
\text { Imperfect in Dependent Clauses }\end{array}$ & \\
\hline 4. Flashback & $\begin{array}{l}\text { Actions/events: Gerunds }+ \\
\text { näbbar/noro 'was' } \\
\begin{array}{r}\text { Activities: Imperfect }+ \\
\text { näbbar/noro 'was' }\end{array}\end{array}$ & $\downarrow$ \\
\hline 5. Setting & $\begin{array}{l}\text { Main Cl's with }\left\{\begin{array}{l}\text { 'be' } \\
\text { Inanimate Subj. } \\
\text { Motion vbs. }\end{array}\right. \\
\text { Dependent } \mathrm{Cl} \text { with Temp/Loc } \\
\text { Conjunction }\end{array}$ & $\uparrow$ \\
\hline 6. Irrealis & $\begin{array}{l}\text { Neg/modal in Main Clause } \\
\text { Neg/modal in Dependent Clause } \\
\text { (Purpose Clauses) }\end{array}$ & \\
\hline 7. Evaluation & $\begin{array}{l}\text { "It is said" at end of DISC } \\
\text { Reason Cl's at end of INTRO } \\
\text { Final exhortation via Imperative } \\
\text { or "should" }\end{array}$ & Rank shift \\
\hline 8. Cohesion & $\begin{array}{l}\text { Coexistent Gerund + Rel Clause } \\
\text { Temporal Cl. + Relative Cl. } \\
\text { "as" Clause }\end{array}$ & $\begin{array}{l}\text { Coexistent Gerund } \\
\text { (without the final } \\
\text { high tone) }\end{array}$ \\
\hline
\end{tabular}

Diagram V. Storyline scheme for Amharic 
Storyline, and (b) Background Activities overlap with either of the above, (c) Flashback is out of sequence and even further removed from the main storyline.

A category of pivotal events (cf. Gimira above and several languages cited in Longacre [1989b]) is posited by Bliese: "The highest level of salience in a narrative is found where there are pivotal events." These are clauses with heightened vividness; they often report the unexpected. In the stories which he and the others analyzed, the most common grammatical feature at such points was the use of direct speech. For example, in the story "The Rich Farmer" the farmer passes his guests unnoticed while dressed in work clothes, but when he dresses in respectable clothes and returns, they stand up and greet him. His response is, "I'm the previous one, say welcome to my clothes." The unexpected response is given heightened vividness by the cryptic direct speech quotation. Bliese goes on to point out that the final verb of such a quotation sentence is the verb 'say' in the perfect aspect, which regularly marks storyline actions/events. Here a speech act qua speech act has special storyline status.

Main actions/events (which Bliese carefully points out "are punctiliar and sequential, carrying the storyline forward") are indicated by perfect aspect verbs as well as by consecutive gerunds which depend on such verbs. Bliese goes on to note that "often two perfect verbs were also coordinated by the conjunction -nna 'and'." The latter is of interest in that it shows that not all the sentence structures of Amharic are chaining structures but that at least one co-ranking structure exists in which clauses with perfect verbs are coordinated. This is not true of any Cushitic or Omotic language included in the scope of this research. 18 Bliese further points out "In the Amharic tense system the perfect verb is the only independent verb form which does not have an auxiliary," or, in my terms, is non-periphrastic in structure. 19

Regarding the band which I have made second (but which occurs as third in Bliese's original scheme), i.e. Routine, Script-Predictable actions/events, Bliese writes, "These are events which, if left out of the story, would not leave a gap in the main line since the hearers share a common script and would fill in the information automatically." Here, while perfect verbs are used, as in Band 1, the clauses are subordinated by elements preposed 20 and postposed to the verb. Some subordinators are simply preposed to the verb, e.g. ayya 'while', onda 'while', and others bracket the verb, e.g. : bä...gize 'when', kä...bähwala 'after'.

${ }^{18}$ Two questions arise: (1) In any part of the world, wherever there are chaining structures which exist side by side with co-ranking structures, is this a possible indication that the language in question was once not SOV in basic word order? (b) What are the discourse constraints in Amharic on perfect + perfect vs. gerund + perfect?

${ }^{19}$ Bliese [personal communication] reports that he has also heard narratives in Amharic told with imperfect verbs without auxiliaries and connected by -nna 'and' in a series ending with an imperfect plus the auxiliary.

${ }^{20} \mathrm{Cf}$. the discussion of this feature in the Introduction $\$ 2$, where the preposed elements are seen as witnessing to a former VSO state of Amharic or some ancestor language. 
Some typical script predictable events which Bliese refers to in his examples are going out to the entrance (after we've been told that a man purposed to go see about his cattle), getting up from sitting (on the arrival of a well-dressed person), taking a bundle of fresh grain (which a man has brought on request).

Band 3, Background Activity, is indicated by means of imperfect verbs which often occur subordinated, but can occur independently. Evidently the latter can be coordinated (cf. perfect verbs in Band 1). Common subordinating conjunctions here are si- and bi-, both of which are preposed to the verb and indicate 'when' or 'while'. All these are durative rather than punctiliar and overlap with one or more of the actions/events of Bands 1 and 2.

Band 4, Flashback, is of special interest because of its well defined structure and frequency of use. The structures are gerund + näbbär or noro 'was' for backset actions/events and the imperfect plus näbbär or noro 'was' for backset activity.

6.2. Rank-shifting of gerunds. The rank shifted consecutive gerund functions with Bands 2, 3, and 4 above. The rule here, as with Gimira, is very clear: the gerund is of the same rank as the form on which it immediately depends. Thus, a series of gerunds can occur before a clause of Band 2:

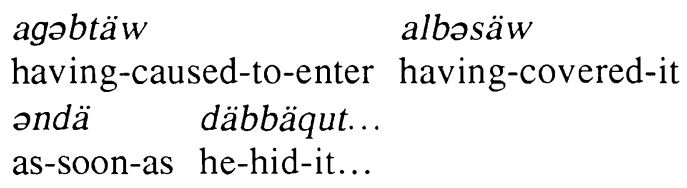

'As soon as he got [the leopard] into [the sack] covered it, and hid it...' [In the context this series of actions are routine and predictable.]

Here the rank-shifted gerunds form an embedded string along with the Band 2 element that occurs string-final (but not sentence final). The subordinator andä goes with the whole string but occurs only on the string-final verb.

Likewise, a consecutive gerund which occurs before an imperfect (Band 3) has the same function and meaning as the imperfect. Bliese cites an example which describes the habitual activity of a drunkard: 
yət'ätt'abbät-nna әyyä-säkkärä

he-drink-with-it-and while-drunk

si-mäsh hedo...tänyəto yadoral.

when evening going...lying spends-the-night

'He drinks with it and while drunk when evening comes, he goes, and lying down spends the night.'

Here, the first word is the imperfect of 'drink', which coordinates with the final imperfect and with structures which are dependent upon the final imperfect. The latter include the following features: (a) The construction with the ayyä 'while' conjunction, which is a rank-shifted Band 2 (while the construction with si-is ambient and remains Band 5). (b) The consecutive gerund hedo with final high stress is a rank-shifted Band 1 and is habitual in sense like the final imperfect that it precedes. On the contrary, the gerund tänyato 'lying down' has no such stress, is a coextensive gerund, and, according to Bliese, constitutes along with final verb a lexical unit 'spend the night'.

Nor is it difficult to find examples of rank-shifted gerunds which are dependent on a Flashback (Band 4). Gerunds thus occurring are part of the total flashback.

əswam betwan ant'əfa
she her-house having-decorated
täzägajjəta tət'äbbəqäw
self-having-prepared awaiting
səla näbbärä...
because was

'Because she had decorated her house, prepared herself, and had been waiting for him...'

Here the consecutive gerunds which refer to the woman are flashback no less than the explicitly flashback structure on which they depend. Notice, too, that the whole string is in turn subordinated by sala 'because' on the auxiliary of the string-final flashback verb.

6.3. The storyline scheme (lower bands). The lower four bands of Bliese's storyline scheme are static rather than dynamic. The Setting includes clauses with the verb 'be', clauses with inanimate subjects (ambient clauses) and "verbs of motion which change the place." A Setting clause with inanimate subject is illustrated in si-mäsh 'when evening' above in (53). Bliese considers that such a clause as 'when he arrived home' should also be considered Setting rather than Band 2 on the grounds that its function is to shift the locale of the story, just as much as a 
clause 'as he was in the kitchen', which shifts the story to the kitchen while the protagonist is talking to a rich man elsewhere in the house.

I will not comment on Band 6 which presents a typical picture such as we see in other rank schemes previously described for other languages, nor on Band 7. The note regarding the use of 'say' as a disclaimer could be added probably to every language here mentioned except for Afar, where it has been grammaticalized.

Perhaps the basic devices in Amharic for cohesion and backreference are the coextensive gerunds and the relative clause. Apparently each can be used alone in this function or they can be used together.

The rank scheme indicates that the coextensive gerund can be used not only in Band 8, but also can be used in the three ranks above it. Here it is not so much that the coextensive gerund depends for its rank on what follows it as the fact that it meets the specifications of a given band.

Thus,

wädajjoc honäw ayyä-täräddu

friends being while-helping-each-other

abəräw li-noru tässəmammu

live-together to-be they-agreed

'While the friends were helping each other, they agreed to live together.'

Here wädajjoc honäw 'being friends' is a gerund clause with a 'be' verb and clearly fits the Setting Band 5. But abəräw li-noru 'to live together' is an Irrealis (purpose) element from Band 6. Both forms honäw 'being' and abəräw 'live together' are coextensive gerunds without the final high stress that distinguishes the consecutive gerund.

The same lexical verb can have dynamic versus stative meanings when it is used as a consecutive gerund and when it is used as a coextensive gerund. In the Amharic text, "The Rich Farmer", Bliese notes that twice in the story läbaso "having dressed himself' occurs as a consecutive gerund in a string of punctiliar consecutive actions, but that toward the end of the story it is used statively and descriptively:

(56) läbəso käbəro b-ayyut gize...

dressed honorable when-saw they

'when they saw him dressed and honorable...'

Again, the phonological distinction between the two types of gerunds, the consecutive and the coexistent, correlates with the different semantic readings. 
6.4. Peak-marking features. Much of what Bliese says about the marking of peak in Amharic is general for many languages, e.g. the crowded stage at peak, dramatic shifts in sentence length, and intense activities (again, Longacre [1983a]). While shift to dialogue at peak occurs in narration in many languages, reported speech is associated with pivotal events in Amharic stories. We are not surprised to find this feature at peak as well as at other places, e.g. the inciting incident, but it is not specific to peak. For some specifically Amharic features at peak Bliese mentions (a) resort to compound verb forms with 'say' or 'do' and (b) use of the intensive verb form. Thus, at the peak of one story where a man who is hiding under the bed in a prostitute's house jumps out in terror and knocks the bed over onto the pottery utensils, we aren't simply told that they were crushed and smashed, but rather onkətkət saborbor bəlo, i.e. "saying "crush and smash" (they became potsherds)'. Here the reader is invited to hear the noise occasioned by the man's reaction. Also at the height of a story where the rich man knocks his head on the gourd and spills milk on his head we are not simply told dänäggät 'ä 'he was startled' but tädänaggät 'ä 'he was (intensively) startled'. Likewise at the peak of the story where the startled goat herder 'scatters' his basket this is reported not with the simple gerund bättono but with the intensive gerund bätattono 'scattered (intensively)'.

\section{Silti (Ethio-Semitic)}

Silti, (data from Ernst-August Gutt) like Amharic, has functionally only one type of gerund (suffixed with -a or -aane). Gutt does not report for this form a phonological distinction into consecutive and coextensive gerunds as does Bliese (based on Hetzron) for Amharic. A term such as "serial verbs" (Gutt's preference) or "medial verbs" is possibly better here than "gerund" since the forms in question are essentially modified (suffixed) finals.

The astute reader may have noticed in the preceding sections of this chapter that a semantic classification of verbs into action, motion, stative, equative (=copulative), and existential has entered into the discussion at various places. For example, the verb 'be' has been consistently assigned to setting in all the languages considered (except, of course, when auxiliary to action verbs and other dynamic categories). This assignment of 'be' verbs to setting has been made regardless of whether or not the 'be' verb happens to have the same tense/aspect form as verbs up in the dynamic parts of the rank scheme for the various languages. 21

${ }^{21}$ In the long paper [Longacre 1989b] in which the theory and approach which underlie this study are presented, I also have to make semantic distinctions having to do with the classification of verb types. For example, based on text analysis in English and other languages, I distinguish within the storyline in many languages a subranking in which action verbs outrank verbs that simply report contingencies or happenings. In brief, clauses with Subject as Agent $>$ clauses with Subject as Experiencer $>$ clauses with Subject as Patient. Cf. Introductiion $\$ 2$. 
The virtue of Gutt's paper is his airing of these semantic problems in the context of Ethiopian languages, since his brief paper certainly has relevance to more than Silti. Proceeding very methodically, Gutt lays out four parameters which he considers to be relevant to the ranking of verbs in Silti narrative:

(1) Tense: imperfect, simple past, present perfect, past progressive, and pluperfect.

(2) Verb status: final verb versus medial verbs which are either serial verbs or dependent (bearing certain affixes and postpositions that correlate with semantic relations "such as temporal succession, simultaneity, purpose, concession, etc., which this dependent verb has to its governing verb").

(3) Semantic verb types: action, motion, quotative [speech verbs], psychological, depictive, existential, equative, stative.

(4) Mood: affirmative, negative.

Having laid out these parameters, Gutt proceeds to chart verb forms in stories so as to correlate these parameters with five storyline scheme rankings: Mainline, Routine Activities, Setting, Collateral (Irrealis), and Cohesive.

For Mainline (storyline verbs) Gutt reports affirmative verbs in the simple past tense and serial verbs preceding simple past, provided that the verbs are semantically action, motion, quotative, or psychological. He comments, "Note that the mainline is not carried by dependent verb forms." He also mentions in passing that there are stories whose mainline is carried mainly by motion and quotative verbs rather than by action verbs.

Routine Activities ("which either establish a script or are script-predictable") are encoded in affirmative final verbs in the imperfect and present perfect tenses.

For Setting, Gutt's results are especially interesting. To begin with, tense is nondistinctive in that any tense can occur in Setting provided that the verb is affirmative. The significant crossplay is between semantic verb types and tenses. Gutt comments, "Thus, simple past verbs can manifest either the mainline of the story or setting--but, if they represent, e.g., setting, the verb type is either existential or stative, not action or motion. On the other hand, action verbs are found in setting too, but then their tense differs from the mainline verbs, being, e.g., past progressive rather than simple past."

For Collateral/Irrealis the criterion is simple in that it includes only negative verbs in the narrow corpus on which Gutt's study is based.

Cohesion is a backreferential use of a serial verb or of a dependent verb. Here presumably the backreferential function is the most definitive feature, although this is not one of Gutt's parameters.

Peak in Silti stories is marked by the increased complexity and length of sentence structure at that part of the story along with repetition of information from earlier parts of the story. This is apparently a quite regular feature easily documentable from the corpus of 14 stories on which Gutt based his statement. 


\section{CHAPTER II}

\section{SOME LANGUAGES OF SUDAN}

In this chapter I consider features of narrative structure in some Sudanic languages with special attention to Nilotic. Some of these languages are in normative word order VSO; others are SVO. One language Avokaya, is apparently basically SOV but only weakly so. It is a far cry structurally from the SOV chaining structures which are described in the previous chapter. These Sudanic languages, whether VSO, SVO, or (weakly) SOV are radically different from the languages which are described in Chapter 1: rather than having final verbs in final clauses preceded by medial verbs in medial clauses, many of these Sudanic languages have a special initial verb in the initial clause and consecutive verbs(relatively unmarked) in consecutive clauses, as is, indeed, a familiar feature in many languages which we find continuing to the west across Africa. Of special interest here are narrative structures which exploit alternative word orders for storyline ranking distinctions.

I consider below, in order, the following languages: (1) Toposa, a strict VSO language, which is Northeast Nilotic (data from Martin and Helga Schroeder); (2) Sabaot, a VSO structure with NV focus shifts, which is Southern Nilotic (data from Iver Larsen); (3) Murle, also VSO with NV focus shifts, which is Eastern Sudanic but not Nilotic (data from Cindy Miller and Jon Arensen); (4) Luwo (Jür-Luwo), basically VSO with other word order possibilities, which is Northern Nilotic (data from Randall Buth); (5) Anywak, SVO/SOV, which is also Northern Nilotic (data from Miles Reimer and Marie Lusted); (6) Avokaya, SOV/SVO, which is Central Sudanic (data from Lynne Callinan and Eileen Kilpatrick); and (7) Jur-Mödö, which is SVO and also Central Sudanic (data from Andrew and Janet Persson). All these languages are spoken in Southern Sudan, except for Sabaot (Kenya) and Anywak (Ethiopia).

Building on the research of my colleagues, research done with my stimulus and collaboration, I attempt in this chapter to confront word order variations and other morphological or syntactic features with the structure of narrative texts found in the various languages much as was done in regard to the SOV chaining languages of Ethiopia in the preceding chapter. In attempting to interpret and correlate research findings, I find it necessary on occasion to reinterpret some of the research results that were originally obtained. At any rate both in regard to the original research conclusions and my occasional reinterpretation of the data, further research will doubtless modify whatever conclusions have been reached on either horizon. A 
rapid survey has the advantages of a panoramic view of the linguistic landscape but some of the inevitable disadvantages of lack of focus on detail.

\section{Toposa (Eastern Nilotic)}

Toposa (data from Martin and Helga Schroeder) is the strictest VSO language I have ever encountered. I wrote with considerable confidence several years ago that VSO is the most unstable of all word orders because topicalization shifts in nonnarrative discourse and even in expository material embedded in narrative are at work in the direction of introducing competitive SVO and OVS orders into the language [Longacre 1982a:484]. Historically, this is seen in the development of certain former VSO languages into SVO as well as in the fact of the existence of weakly defined VSO languages. 1 Toposa, however, falsifies this former statement of mine: it is possible to scan not only pages of narrative text, but of hortatory as well, without finding a clear instance of a subject or object noun preceding the verb.

The storyline in Toposa is carried by a special narrative tense. While other tenses have agreement markers (prefixes) on the verb for person-number-tense, the narrative tenses have only the verb-class markers to- and ki-. Furthermore, the storyline narrative tense does not take tense suffixes such as are found in other tenses (including two varieties of narrative tense which are rare and do not figure much in the narratives that underlie the Schroeders' study).

In this respect Toposa's special narrative tense is illustrative of such tense forms in many languages from east to west across Africa. As we might expect, culling out from a text all clauses which have the narrative tense yields a good abstract of the story. At the same time, while the abstract captures well the movement of the story, it leaves much to be desired. Storyline clauses as such do not give clues to the identity of the participants involved nor the circumstances, connecting events, or flashbacks. Verb complements are missing. This is exactly what we might expect from the storyline and illustrates well on a Toposa base some of the contentions of this monograph.

To round out the story, Toposa employs a background band whose most characteristic tense form is the past. This past tense can occur in a clause which precedes a chain of narrative tenses. Here the verbs 'sit' and 'come' especially figure, similar to grammaticized initial forms. Thus, in a story regarding a cow who wouldn't let a starving old woman milk her, we find the Toposa equivalent of "sat (past) cow, sinned (narr) resisted (narr) woman, said (narr), 'are you too being milked?" Past tense forms are also used in adverbial clauses with certain subordinators (na 'when', and kotere 'because') and in relative clauses. One subordinator ani 'when/if' requires a present tense. All these dependent clauses round out the story by contributing further information.

${ }^{1}$ Hebrew is a good example of the former (VSO $\rightarrow \mathrm{SVO}$ ), while Koine Greek is an example of the latter (weakly VSO). 
The setting band further rounds out the story by resort to clauses with present or past verbs that are stative (existential and equational). These verbs do not occur in the special narrative tense form. These stative forms are especially used in introducing participants and circumstances: "There once was a cow of a woman called the mother of Locikeo..." [with the verb ayai 'was' clause-initial, and indeed text-initial]. This sentence is followed by, "There came (past) a year of hunger [note the use of a sentence-initial past here]; it was-like this..." In the following sentence some of the circumstances of the famine year are described as background past tenses. The uncooperative cow (who wouldn't be milked) is also brought in with 'came' in the past: abu nyaate 'came a cow...' Flashbacks apparently occur in three different time depths (cf. Sabaot below).

It is plain to see that there are the makings here of a "rank" scheme four of whose bands (Storyline, Background, Flashback, and Setting) are described by the Schroeders. Within the storyline band itself, they posit subranking according to voice distinctions (active $>$ reflexive $>$ passive) but caution that this may be in part conditioned by different types of narrative text. Thus while the uncooperative cow story and other folk tales have as their storylines active narrative tense forms, the Schroeders remark, "Another narrative, a cosmological myth about creation and the first men on the earth, by a different author-teller, employs almost exclusively passives on the event line [storyline]." The Schroeders also posit that action verbs outrank motion verbs. "A main distinction we have drawn is between action and motion. Most motion verbs take directional aspects, and they usually are intransitive verbs in the active voice or reflexive medial verbs..."

\section{Sabaot (Southern Nilotic)}

Sabaot is also a VSO language but permits left shifts of subject or object nouns. Iver Larsen (the source of these data) comments, "The basic word order is VSO. The subject may be preposed as a means of focusing, but it is not very common. The object may also be preposed for focus, which seems a bit more common." The storyline is carried by what Larsen quite properly calls "consecutive verbs", which, like the special narrative tense of Toposa, are unmarked for tense but are marked in Sabaot for person. Unlike the narrative tense of Toposa, however, these consecutive verbs can be rank-shifted after a non-storyline initial. Pronominal person markers are prefixal. ${ }^{2}$ The following example illustrates consecutive verbs in storyline clauses. It also contains an example of the left shift of an object noun:

${ }^{2}$ Here, the morphological structure of Sabaot and its syntactic structure are out of step, thus yielding a language of mixed typological characteristics. VSO languages "should" have pronominal suffixes with the latter presumably originating from former verb-noun sequences in which nouns are reduced to pronouns. A possible explanation is that pronouns were not originally used in obligatory routine fashion with verbs but were special "focus" forms in SV clause order. The use of the pronoun has been since generalized. If this be true, the pre-verb 
(1) 1. $\frac{k u-b a}{\text { They-went until }} \frac{k u \text {-choosyo. }}{\text { they-tired. }}$ 2. $\frac{k o ̄ o ̄-b u u r}{\text { They-sat }} \frac{n g \text { weny. }}{\text { down. }} \cdot \frac{k w \text {-oomiis. }}{\text { They-ate. }}$
4. ku-nam inee rwaanteet $\mathrm{n}$-ku-wiir-ta,
nto mōbōryēēnyii ku-konor. He-took HE stone and-he-threw away, but food-his he-kept.

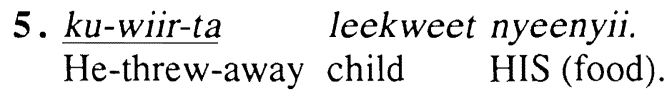

Notice that there are two good examples of full VSO clauses (first clause of 4 and sentence 5). The third clause of $\mathbf{4}$ has left shifted the object mōborryēennyii 'food his' into pre-verb where it contrasts with the 'stone' rwaanteet that he threw away in the previous clause. Possibly the left shift with resulting $\mathrm{V}_{1} \mathrm{~S}_{1} \mathrm{O}_{1} \ldots \mathrm{O}_{2} \mathrm{~V}_{2}\left[\mathrm{~S}_{1}\right]$ is a means of heightening contrast-here the contrast between taking and throwing away a stone and keeping his food-a strategem employed to cause the child to throw away his food (as in sentence 5).

2.1. The storyline scheme. Except for peak (see below), the storyline is top rank in Larsen's rank scheme which I reproduce here as Diagram I of this chapter. The parameters which are relevant to the construction of the scheme are the following: (1) tense/aspect (including consecutive verbs); (2) semantic verb/clause type (descriptive, non-descriptive, ${ }^{3}$ equative, staging); (3) grammatical status of clause, i.e. independent/coordinate, subordinated (including initial versus noninitial), relative. It is plain to see that these parameters correspond to three of those posited by Gutt for Silti (Chapter 1, §7). Gutt's fourth parameter, affirmation/negation, would also be relevant to Larsen' scheme for Sabaot were Larsen's to posit an irrealis band. The term "coordinated clause" on Larsen's scheme is equivalent to independent clause which may be coordinated with other such clauses in the framework of the sentence or the paragraph. The term "any clause type" includes coordinated clauses, subordinated clauses, and relative clauses. Larsen posits a peak band where other storyline schemes included in this volume have a pivotal band and treat peak as an extra-systemic set of imposed features. Cf. Jones and Jones [1979], where peak is treated as a separate band.

occurrence of pronouns in VSO languages need not be typologically inconsistent nor indicative of a former SVO stage.

${ }^{3}$ Here, somewhat more specific categories such as action, motion, cognitive event, etc. should eventually be posited, I feel. Larsen's "non-descriptive" groups such categories as I have just mentioned over against descriptive, which is presumably state. 


\begin{tabular}{|c|c|}
\hline Bands & Verb/clause forms \\
\hline 1. Peak & $\begin{array}{l}\text { Frequent use of indefinite verb forms (passives) } \\
\text { Imperfective aspect used on consecutive verb forms }\end{array}$ \\
\hline $\begin{array}{l}\text { 2a. Primary } \\
\text { Storyline } \\
\text { 2b. Secondary } \\
\text { Storyline }\end{array}$ & $\begin{array}{l}\text { Consecutive verbs in coordinated clauses } \\
\text { Past tense in Coordinated clauses } \\
\text { Initial subordinated clause ('when') with non-descriptive verb }\end{array}$ \\
\hline $\begin{array}{l}\text { 3. Background } \\
\text { activities/states }\end{array}$ & $\begin{array}{l}\text { Imperfect aspect in any clause type } \\
\text { Initial subordinated clause ('when') with descriptive verb } \\
\text { Non-initial subordinated clause ('as/because') in explanatory } \\
\text { function }\end{array}$ \\
\hline 4. Flashback & $\begin{array}{l}\text { Distant Pluperfect (often emphatic) } \\
\text { Middle Pluperfect (usually emphatic) } \\
\text { Recent Pluperfect (emphatic) }\end{array}$ \\
\hline 5a. Major setting & $\begin{array}{l}\text { Verbless clause (equative) } \\
\text { Past tense in coordinated/relative clause with "staging" verbs } \\
\text { such as 'be' (existential), 'have', 'be named', locational, or } \\
\text { temporal } \\
\text { Preposed locational or temporal expressions (word, phrase, } \\
\text { or clause) }\end{array}$ \\
\hline $\begin{array}{l}\text { 6. Author } \\
\text { comment }\end{array}$ & $\begin{array}{l}+/ \text { - exclamation }+/ \text { - evaluation word/phrase/clause }+ \\
\text { evaluation content (which may be a proverb in the present } \\
\text { tense) }\end{array}$ \\
\hline 7. Cohesion & Any clause type with back-reference and/or 'like that' \\
\hline
\end{tabular}

Diagram I. Sabaot (Larsen) 
2.1.1. The consecutive tense. I have already illustrated consecutive verbs in coordinated clauses and their function in carrying the primary storyline (1). It is interesting to note here, however, a functional parallelism to the unmarked gerund in various Ethiopian languages as described in the previous chapter. There it was noted that the unmarked gerund could be rank shifted downwards to lower bands whenever such an unmarked gerund was directly dependent on a final verb which was not storyline. Here, we note that a consecutive verb can be rank-shifted downwards to lower bands whenever the consecutive verb is directly dependent on (or ancillary to) an initial verb which is not storyline. There is here a certain parallelism between the final verb in chaining languages of Ethiopia (Cushitic, Omotic, and Semitic), and the initial verb in Sabaot and, indeed, in many languages across Africa. In comparing Ethiopian structures and Sabaot the parallelism is not complete: every chain requires a final verb in Ethiopian structures, while in Sabaot a chain of coordinated clauses (not necessarily in the same sentence) may or may not be preceded by a tense/aspect marked initial form. In comparing Ethiopian structures and certain other African languages (cf. Chapter 3), we find, however, a more perfect parallelism, i.e. in some languages a consecutive clause with unmarked verb requires the presence in sentence-initial of a previous clause whose verb is marked.

Larsen notes specifically that consecutive clauses can occur after the flashback or setting and thereby be rankshifted from Band 1 to Band 4 or 5 . Note the following example in which a consecutive clause follows a clause which is marked for flashback:

(2) kokoo-labat kibreng' wo ku-nyōōr kibreng'ōōk chuut. Had-run hare go he-found hares these.

As Larsen explains, "At this point in the story, the narrator backtracks one day to fill in what happened yesterday when the fleeing hare met some other hares." The verb form kokoo-labat 'had run' is specifically marked with a middle pluperfect ('yesterday' in the framework of the story) while the flashback continues by means of an unmarked consecutive verb ku-nyōōr 'he found'. The whole is a flashback. ${ }^{4}$

2.2. The secondary storyline. Larsen explains his secondary storyline as follows: "At times an event is demoted from the storyline to a secondary eventline. This happens especially if an event is somewhat script-predictable, or if it is not crucial to the main story." He explains that the formal mechanisms of the secondary

\footnotetext{
${ }^{4}$ In this respect, English narrative structures somewhat similarly: (1) a flashback may structure as a series of pluperfects, or (2) it may involve the use of one or more pluperfects early in the flashback followed by past tenses in the rest of the backset sequence, especially when the flashback is an extended one. Both structures can be illustrated in flashbacks found within Chapter 1 of Arthur Hailey's The Final Diagnosis.
} 
storyline are twofold: (1) by reporting the action/event in a clause whose verb is marked for past tense; (2) by reporting the action/event in an initial subordinated 'when' clause. The second operation can involve the first. The important thing to note here and in subsequent bands below is that any marked tense/aspect is outranked by the unmarked (except where rank-shift is involved). Mechanism (2), demoting an action/event by reporting it in an adverbial clause, is an all-butuniversal feature of narrative. Sabaot:

All this is complicated by the fact that there is not one but three past tenses in

Distant past: $k i$ - yesterday or earlier (DP)

Middle past: $k o$ - yesterday (MP)

Recent past: $k a$ - earlier today (RP)

Larsen further notes that "each past tense has a more emphatic form marked by a lengthened vowel", kii-, koo-, kaa-. In explaining the uses of these three past tense forms on the secondary storyline Larsen explains,

"The stories I have available all took place in the distant past, so it is the distant past tense (DP) which is used. Presumably, if the story had taken place yesterday, the middle past (MP) would have been used. Similarly, if it had taken place earlier in the same day, the recent past tense (RP) would presumably have been used."

(3) [The hare and the leopard have made a pact that each of them should go his own way to see who could bring back a sheep for them to eat.]

1. ki-noomēn chii kēèlto nyeenyi.

DP followed each-one way his-own

2. Bērē koo-soot kibreng "kule mē-ē-muuch-e kut ku-nam waarwa, when he-realized hare that not-he-manage at-all he-catch sheep ku-ng'oomēn-chi mèliilto.

he-became-clever-at leopard

3. ki-tay ku-wo kēēlto nyeenyi...an-ku-rub mèliilto lèt. DP-refused he-go way his-own and-he-followed leopard behind 4. ki-rub inee méliilto lèt ku-wuny-oot-ē. DP-followed he leopard behind while-he-hiding

'Each went his own way. When the hare realized that he really couldn't catch a sheep, he caught on to what the leopard was doing. He refused to continue on in his own way, followed behind the leopard. He secretly tailed the leopard.' 
This is an instructive example for various reasons. It illustrates the Distant Past in sentences $\mathbf{1}, \mathbf{3}$, and $\mathbf{4}$. The action reported in ki-noomèn 'DP-followed' is clearly script-predictable in terms of the previous argument. The action reported in $\mathbf{3} \mathrm{ki}$ tay 'he refused' likewise seems to follow on quite well from the rabbit's clever appraisal of the situation as reported at the end of $\mathbf{2}$. Sentence $\mathbf{4}$ is a paraphrase and amplification of $\mathbf{3}$. This example also illustrates the use of the imperfect aspect in a negated complement construction in sentence 2 mè-ē-muuch-e 'he was not able to' and in a non-initial adverbial clause ku-wuuny-oot-e 'while he was hiding'.' The example further illustrates the use of rank-shifted consecutive clauses. Thus the complement of 'he was not able to' is 'to catch sheep'. Here ku-nam 'he-catch' follows a negated imperfect and is presumably rank-shifted down to an irrealis band that is not symbolized on Larsen's chart. Likewise in $\mathbf{3}$ the complement of $\mathrm{ki}$ tay 'DP-he refused' is $k u$-wo 'he go'. Here the consecutive tense is rank shifted to secondary by virtue of following a secondary on which it is dependent. On the other hand, the verbs ku-ng 'oomen-chi 'he became clever at' and an-ku-rub 'he followed' are consecutive verbs in storyline clauses which dominate the paragraph.

A secondary storyline expressed in an initial subordinated 'when' clause seems to use the three past tenses somewhat differently. Here Larsen points out, for example, that a recent past is not relative to the speaker's time of storytelling but relative to the time of the clause on which it depends, i.e. story-internal time.

(4) Nto yu kaā-biyoong' ku-lēēnchi leekweet.

But when RP-satisfied he-said-to child. [Throw away your food.]

Here again the backgrounded event 'that they became satisfied' is somewhat scriptpredictable from $k w$-oomiis 'they ate' in the preceding sentence. But as a grammatically subordinated clause it does not take the distant past, which is in fact the time horizon of the whole story, but the recent past, with the result that the event in the subordinated clause is presented as recent (same day) in respect to the event of the main clause.

2.3. Background activities/states. Just as the secondary storyline is customarily marked by a past tense, so background is marked by the suffixation of imperfective aspect to the verb. Larsen also states that any non-initial explanatory subordinate clause is also background whether or not it has an imperfective marker and regardless of its tense, provided the verb in question is not an action/event verb. Larsen's reasoning regarding subordinated clauses seems to reflect three parameters: (1) the semantic type of verb; (2) preposing to main clause versus postposing to main clause; (3) presence or absence of back-reference. Postposed subordinate clauses are considered to be inherently exegetical (comparison or cause/reason) and are assigned to the background band. Preposed subordinate clauses, if backreferential, are assigned to the cohesive band. Otherwise, they split 
three ways: (a) if they contain action/motion/speech verbs, they are assigned to the secondary storyline; (b) if they contain descriptive expressions (not necessarily verbs), they are assigned to the background band, along with the postposed subordinate clauses; (c) if they are locational (Nto mii kēèlto 'But be-on road', i.e. 'But being on the road...') or meteorological (Nto yu ka-yeech 'But when RPdawn', i.e. 'But when it dawned...'), then they belong to the setting band.

In main clauses and in relative clauses and in many subordinate clauses, imperfective aspect indicates an element of the background band: $\bar{e}$ with most verbs, $-i i$ with the verbs 'come' and 'go', -tōōs with a plural subject of the verb. This marking is especially crucial in main clauses and relative clauses since background subordinate clauses are disposed of as outlined above with the result that the occurrence of the imperfective in them simply reinforces the identification of background elements. The imperfective aspect occurs with various tenses.

(5) ku-kas kurook kiyēē yēy-e mèliilto
he-saw first that-which do-ing leopard

'He first saw what the leopard was doing.'
(6) kee-yit
Wōli
$k a-b \bar{e} e \bar{t}-i i$
they-arrived-at this-place-which (they)RP-go-ing
'They arrived at the place to which they had been going.' 5

For a backgrounded main clause note the following example:

(7) ki-choom-tōōs mēliilto ākoo breng'uut miisin

DP-love-IMPF. leopard and hare much

'The leopard and the hare greatly loved each other.'

2.4. Flashback. Flashback is expressed by means of three pluperfect tenses whose markers are derived by reduplication of the corresponding past tense markers:

${ }^{5}$ The 'they' in 'they-arrived at' is different from the normal 'they'. It is an "indefinite third person". Semantically it corresponds to a passive with the function of "subject-role suppression". In Sabaot orthography this is marked by a grammatical tone marker, 'kee-yit. 
$\begin{array}{ll}\text { Distant pluperfect: } & \text { kiki- } \\ \text { Middle pluperfect: } & \text { koko- } \\ \text { Recent pluperfect: } & \text { kaka- }\end{array}$

The first two pluperfect markers also have emphatic forms (kikii-, kokoo-) which, according to Larsen, "are normally the ones used to signal flashback". For an example of Middle pluperfect in a flashback in a main clause see (2) above. Here, the flashback reference is to events of the previous day in reference to the time horizon of the story at that point in its development.

The following example contains a Distant pluperfect in a relative clause. The tenses found in the surrounding clauses are discussed below.

(8) 1. Ākoo ki-maalta keey wēēri sēkēērik

so DP-put-on himself this-boy cowrie-shells

chee kikii-koo-neet kwaan.

which he-had-taught father

2. Ki-lēēn-chi kwaan, "Yoo kāruuyo

DP-said-to-him father if RP-fall-asleep

biiko, i-rāt-yi keey sēkēērichu koonyek."

people you-tie-on self these shells eyes

3. Ku-rat wēèri koonyekyii.

he-tied this-boy his-eyes

'So this boy put on himself the cowrie shells as (which) his father had instructed him. His father had said to him, "If people fall asleep, you tie these shells on your eyes." This boy tied (them) on his eyes.'

In sentence $\mathbf{1}$, which is on the secondary storyline, there is a flashback, introduced by chee 'which' and marked with a distant pluperfect kikii-koo-neet 'he had taught'. At this point in the story the boy performs an action as instructed several days in the past before the journey began, hence the choice of distant pluperfect. It is of some interest here that the explanation of the father's injunction is carried out in the following quotation sentence whose quotation formula has a verb in the distant past. Here an explanation/amplification of the relative clause with a distant pluperfect is via a sentence whose main verb is distant past. In brief, a flashback with distant pluperfect in a relative clause is continued via a sentence marked for distant past. This can be compared with (2), where a flashback in mid-past is continued via a complement in the consecutive tense. Presumably tense sequence differs for pluperfect plus verb complement versus pluperfect followed by sentential explanatory amplification. At any rate, in sentence $\mathbf{3}$ the primary storyline resumes with a consecutive verb. The paraphrase involved between $\mathbf{1}$ and $\mathbf{2}$ versus $\mathbf{3}$ is part and parcel of steering around a digression and resuming the storyline. 
For a flashback with a recent pluperfect, see the following:

(9) Nto mii taay, kēē-nyoor āynēèt ake.

but be in-front they-found river a

Kaa-kwaam kēmēwuut.

had-eaten-them hunger

'Further ahead they found a river. They had been hungry for some time.'

Here the temporal reference of the flashback is somewhere between when they started the journey that morning and their coming to the river, hence the choice of recent pluperfect.

2.5. Setting and author comment. Major setting, as Larsen exemplifies it, presents a rather predictable picture of verbless clauses (equative) and clauses with 'be' and 'have' verbs plus the verb 'to be named'. Minor setting is locational and temporal, whether phrasal or clausal, and thus includes some elements (noun phrases) not usually found on rank-scheme charts. Cohesion, Band 7, also is much of the sort found in other languages.

Band 6, the author comment band, is of somewhat greater interest. As to the placement of the comment, it can occur text-initial "Although hunger is bad, stealing is worse"), text-medial ("When you go visiting, you never know what will happen to you"), and text final ("Therefore stealing is bad"). Such comments use 'be' verbs or other verbs in present tense (no tense prefix and imperfective aspect). Exclamations can also occur as author comments, i.e. words or expressions such as "Well, too bad". Often a phrase is used to introduce the evaluation, "Listen...," or, "Therefore" (in text final "morals"). Larsen's summary of all this is, "In summary, if the evaluation is a proverb or a very well-known idiom it may be put in the text without introduction, but otherwise there should be an attention getter or evaluation introducer present."

2.6. Peak-marking features. Larsen's description of peak in a paper, "Elements of Sabaot discourse" (given to a seminar in Nairobi), follows:

"In Sabaot narratives several things are characteristic of a peak section. An almost language universal peak characteristic is 'crowding on stage', that is, a lot of participants take part in the actions at the peak. This is certainly true for 'Death is bad'. Another interesting characteristic of the peak in this story (71-82) is the extraordinary frequency of the 'subject indefinite' marker. (The 'indefinite subject' marker is kii-or kee-, depending on verb class, and it differs from the first person plural marker only by tone. These forms are marked in the text by the grammatical tone marker ' $/$ ' following standard Sabaot orthography. Semantically, they function as the English passive does.) Another peak feature is the use of imperfective aspect on a consecutive verb form. This is especially highlighted in the very last sentence of the peak (80-82), which is the "peak of the peak'." 


\section{Murle (East Sudanic)}

Murle, while not Nilotic like Sabaot, is a VSO language that employs left shift. While Cindy Miller is the immediate source of my information on Murle, she builds on the field work of Jon and Barbara Arensen, who have also criticized and revised her original statements.

3.1. The storyline scheme. Miller lists three parameters that are relevant to constructing a storyline scheme for Murle: (1) presence versus absence of a sequential conjunction; (2) imperfective versus perfective aspect; (3) word order, i.e. VSO versus SVO. These factors are closely interrelated. Thus, the sequential conjunction ma (dialect variant ba) plus the verb in imperfective aspect in a VSO clause, is normative of storyline forms in Murle. Conjunction selection is of great importance not only in defining the storyline but in distinguishing other bands as well (Diagram II). As for aspect, the imperfective characterizes most bands within the storyline scheme in Murle. The perfective has, as we shall see, a more restricted function of its own. A left-shift of the subject, i.e. $\mathrm{VS}(\mathrm{O}) \rightarrow \mathrm{SV}(\mathrm{O})$ presumably takes a clause off the primary storyline by focusing on a participant/prop rather than on the action/event.

The definition of storyline as ma 'and' plus the imperfective plus VSO order needs to be confronted with the fact that clauses sometimes occur without ma but in other respects seem to qualify for the storyline. Arensen suggests that this may simply be a feature of a great moment of a story (peak). An earlier suggestion of Miller's was that when $m a$ is omitted before an action verb in the imperfective in a VSO clause, then that clause amplifies a former ma clause but does not in itself propel the storyline forward (cf. (10), where some justification is seen for both these claims).

The left shift of the subject (VSO $\rightarrow$ SVO) in Band 3, serves to highlight a noun which is in contrast to another noun (often with use of clause-initial bar 'but' or aje 'as for') or to shift the thematic reference from one participant to another. Clearly, then, such left shifts of the subject have to do more with patterns of contrast and thematicity than with marking the storyline. They are considered here to mark a secondary storyline.

In narrative texts there is a fair sprinkling of clauses which take the perfective instead of the imperfective. Perfectives can be considered to mark pivotal events which, assembled together, constitute a high-level abstract of the story. At peak several perfectives can occur in successive clauses which sometimes involve a paraphrase relationship. The perfective commonly occurs without any conjunctions, but ma 'and' occasionally occurs as well as bakacin/makacin 'as a result'. These uses of the perfective are grouped together in Band 1. 
Subordinate clauses with mazi 'when' plus the imperfect occur in backreferential function in Band 7 in cohesive function. Further elements serve to articulate the text as a whole and are also mentioned in Band 7 as "thematic": elements of aperture and closure, e.g. odota 'finished', and an expository summary at the end.

Some further elements are mentioned on Diagram II, which I have compiled from two charts (one for true narrative and the other for folk tale). There have been some doubts as to the distinctiveness of the two storyline rank schemes. The seeming differences could in this case be due to limitations in the data.

\begin{tabular}{|c|c|}
\hline Bands & Verb/clause forms \\
\hline $\begin{array}{l}\text { 1. Pivotal- } \\
\text { Peak }\end{array}$ & $\begin{array}{l}\text { makacin/bakacin 'as a result' + Perfective } \\
\emptyset+\text { Perfective (rarely, ma 'and' + Perfective) } \\
\emptyset+\text { Imperfective (at peak) }\end{array}$ \\
\hline $\begin{array}{l}\text { 2. Primary } \\
\text { storyline }\end{array}$ & ma 'and' + Imperfective [or post-verbal bodo 'also'] \\
\hline $\begin{array}{l}\text { 3. Secondary } \\
\text { storyline }\end{array}$ & $\begin{array}{l}\text { Contrast: bar 'but'/aje 'as for' }+\mathrm{S}+\text { Imperfective } \\
\text { Thematicity shift: adoma 'then' + S + Imperfective }\end{array}$ \\
\hline 4. Background & $\begin{array}{l}\text { Iterative: } m a \text { 'and' + Imperfective }+z \varepsilon \varepsilon \text { 'on and on' } \\
\text { Amplification paraphrase, etc. } \varnothing+\text { Impf. (of action verbs) }\end{array}$ \\
\hline 5. Flashback & ma aje 'as for...' + Impf. $+/-e$ \\
\hline 6. Collateral & various kinds of negation \\
\hline $\begin{array}{l}\text { 7. Cohesive/ } \\
\text { Thematic }\end{array}$ & $\begin{array}{l}\text { 7.1. mazi 'when' + Imperfective Backreferential } \\
\text { 7.2. Special structures of Aperture and Closure, } \\
\text { odota 'finished' } \\
\text { 7.3. Postposed with actions/events in reverse order } \\
\text { (possible this is of expository structure) }\end{array}$ \\
\hline
\end{tabular}

Diagram II. Rank scheme for Murle 
3.2. An extended example. The following extended example illustrates several of the features discussed above. Imperfective Murle verbs are underlined.

(10) [from "Jon and the Buffalo"]

1. $\underline{a k g}$ jon ii baale konkona. goes Jon day before to Konkon

2. ako aroon kelek ci or. goes searches animals of shoot.

3. ma ako ajuwa kiziwant ram ci ogin liil otooga. and goes finds buffaloes two which sleep river edge

4. ma akat codoi oo $\varepsilon l \varepsilon$ and shoots one head itself

5. ma awoda and falls (perfective)

6. or bodo codoi

7. ma akat karatot and hits backbone

8. bar naan kelegiti nici arogi. but still animal this alive

9. mazi akunak kiziwan nici jon aroon kiya kaam when comes buffalo this to Jon wants to come to attack

10. agereny jon shouts Jon

11. awo $\operatorname{logoz} .$. calls to boy

12. anek ne jai goonya viirai... says thus bring bullets hurry

'1. A few days ago Jon went to the Konkon (river). 2. He went looking for animals to shoot. 3. He found two buffalos which were sleeping at the edge of the river. 4. He shot one right in the head 5. and it fell dead. 6. He shot the other one also 7. and hit it in the backbone 8. but this animal was still alive. 9. When this buffalo came at Jon wanting to gore him, 10. Jon shouted, 11. and called to the boy 12. saying, "Hurry up and bring the bullets."

While this one example cannot exemplify all the features mentioned above, note (1) Storyline ma 'and' plus imperfective in 3, 4, 7 above. (2) Note the use of the secondary storyline in $\mathbf{1}$ and $\mathbf{2}$, where the story is staged. A text will not start with 
ma 'and', but with a staging sentence such as sentence $\mathbf{1}$. Sentence $\mathbf{2}$ is an amplification paraphrase of $\mathbf{1}$ and is also secondary storyline. (3) The perfective in 5 marks the first important (pivotal) event-here the bringing down of one of the two buffaloes. (4) Sentence 6 has no initial $m a$ 'and', but has an equivalent postverbal element bodo 'also' (indicating here that we have an action/event which is script-parallel to a former action/event). (5) Sentence 8, which has bar 'but' $+\mathrm{S}+$ imperfective, signals that this second animal, in contrast to the first, is still alive (and dangerous, as are all alive and wounded buffaloes). (6) Sentence 9 illustrates a mazi 'when' clause. It is backreferential by virtue of the script-predictable fact that a wounded buffalo will turn and attack the hunter. The verb aroon 'wants'/"searches' [to come to attack] is the main clause. Here, the preposed adverbial 'when' clause takes the place of the customary storyline ma 'and'. (7) Finally, note carefully the verbs in 10, 11, and 12, 'shouts', 'calls', 'says'. None of these take the ma 'and'. All report presumably only one storyline event, viz. Jon's calling for more ammunition. Clearly an amplification paraphrase with a secondary storyline is involved here. On the other hand, this is also a high point of the story where Arensen suggests that the omission of $m a$ is, in effect, a peak marker.

3.3. Perfectives at peak. Finally, from another text ("Baboons") comes an illustration of perfectives at peak:

(11) [after the snare has gone off]

iita nyogeci ceez ona kadei noogo. iitak tatook. fell door of house which traps them fell door ivita naaga.

came we

'The door of the house fell (closed) trapping them (the baboons). The door shut tight. Then we came.'

Here all the underlined verbs are perfectives. The second sentence is a paraphrase of the first. The third is a subsequent action. All mark the target procedure of the script, viz. the actual capture of the baboons. Only two sentences follow, the second of which indicates regular narrative closure with odota 'finished' (perfective). A reversed sequence abstract of the story follows as a non-narrative expository tag.

I will not illustrate here any further elements of the Murle storyline scheme. 


\section{Luwo (Northern Nilotic)}

Luwo (data from Randall Buth) has a strict VSO order for storyline clauses. Other clauses with word orders SVO, OVS, and even SOV are considered to reflect degrees of deviation from the main storyline. The situation is complicated, however, by the presence of VSO consecutive clauses (with an $u$ - prefix) which have a two-fold function, (1) as main storyline of narrative discourse and (2) as a consecutive tense which continues a construction in any other tense, aspect, or mood (cf. Sabaot above). In the first function $u$-verbs are punctiliar or sequential. They begin sentences (and even paragraphs) and are not simply functioning as the continuation of some other verb form. In the second function they take the semantic value of the tense in the preceding clause, whether habitual, imperative, present, or future. In the first function they are somewhat autonomous while in the second they take their cue from what precedes.

4.1. $\boldsymbol{U}$ - verbs versus $\boldsymbol{a}$ - verbs. One of the basic oppositions in Buth's analysis is between $u$-verbs and a-verbs. Take, for example. the following sentences of a folktale, "Uriid and the Lions", which Buth has analyzed (the sentences are numbered in respect to their position in the text):

(12) 55. ruohw $\varepsilon$ puuh a dooa dom kardahd morrow and lion returned forest place-of hunt

56. $\varepsilon$ nyin moogo acahg bechn kechdo and boy another repeated come again

57. uyedhe wihy yaadh and-climbed-3s on tree

58. ucahge booge ke thoohr yi pany repeated-3s leaves to throw in mortar

"The next day the lion went off again to hunt in the forest and again, another boy came (to the house). He climbed up on a tree and again threw leaves into the mortar."

Two typical uses of a-verbs as opposed to $u$-verbs are seen here: (1) a-verbs typically occur early in a paragraph and indeed an initial spate of them is typical of the onset of a story. (2) They permit a noun (here subject) to come in front of the verb, while $u$ - verbs must stand clause-initial. From a study of many such instances-and from further data-Buth has generalized as follows: "While a-verbs are usually punctiliar and perfective they are backgrounded in reference to $u$ verbs. Clauses with a-verbs are preparatory or ancillary to clauses with $u$-verbs. This seems plausible in that rotation of nouns to the fore of an a-verb apparently 
throws a participant, e.g. the lion and the boy, into focus rather than their actions." Buth goes on to note that a-verbs, unlike $u$-verbs, can be used in relative and adverbial clauses.

4.2. $U$ - verbs versus maa verbs. Continuing with the text, a portion of which was given above, I now give the next sentences:

\section{(13) 59. maa cahg nyaahre po kec niids and repeated the girl $3 \mathrm{~s}(\mathrm{o})$ to see \\ 60. ucoone po piny and called-3s $3 \mathrm{~s}(\mathrm{o})$ ground}

"Once again the girl saw him and called him down."

In 59 a further and quite important verb form in Luwo narration is found, viz. verbs introduced with maa. Here a further opposition, $u$-verbs versus maa verbs, is illustrated. Notice that in the paragraph given, i.e. lines $\mathbf{5 5 f f}$., while $\mathbf{5 5}$ and $\mathbf{5 6}$ present preliminary events, and $\mathbf{5 7}$ and $\mathbf{5 8}$ initiate the main storyline of the paragraph, it is $\mathbf{5 9}$ and $\mathbf{6 0}$ that bring us to the main concern of the story at this point, i.e. (another) boy meets the girl. Here maa marks the onset of the more thematic material. The paragraph continues with $u$ - on a verb of saying and gives the girl's warning to the boy (the lion might eat him the way the boy was eaten the day before). Another maa verb introduces the boy's refusal to go away, while $u$ verbs continue the storyline: (the boy) went inside the house, and hid in the hole of the grindstone; the girl came and covered him with a sieve. Thus while the storyline of this paragraph is mostly carried by clauses which contain $u$-verbs, maa verbs mark the more significant actions: the girl discovered the boy and warned him, but he refused to listen (and embarked on the same course of action which had led to the death of the first boy the day before).

All this illustrates Buth's contention that both maa verbs and $u$-verbs (which are similar in their exclusive use of VSO order and rejection of noun fronting) are storyline, but that maa marks a sentence (or in a few instances the last clause of a sentence) as thematically prominent as opposed to $u$-verbs which mark the more routine parts of the storyline.

4.3. $A \boldsymbol{k} \varepsilon$ verbs. One further type occurs, i.e. verbs preceded by a particle ake. Clauses which contain a verb so marked are SV rather than VS and may not contain a definite direct object, but only an oblique direct object, i.e. an object introduced by a preposition. These features contrast ake verbs with both maa verbs and $u$ verbs, which are $\mathrm{VS}(\mathrm{O})$ and prefer the definite object but may also take the oblique object. On the other hand, ake verbs occur in clauses which indicate some portentous, although backgrounded event. Thus, in the staging of the story which is 
referred to above, a pair of clauses with a-verbs record that a woman gave birth to a girl who grew and matured, while a following clause has an ake verb 'and she became quite beautiful'. This bit of background is of considerable importance because her beauty provoked the lion to steal her and carry her off to his home. Likewise, after she hid the first boy in the house and tried to assure the lion that no one was there, "ake the rooster crowed" and told the lion where the boy was hidden. All such clauses marked with ake indicate pivotal points where a "change in fortune" occurs. Since however ake clauses resemble more the background clauses with a- verbs, Buth considers that ake indicates a thematic although backgrounded element.

4.4. The resultant storyline scheme. All this suggests the following arrangement for Luwo (taken from Buth):

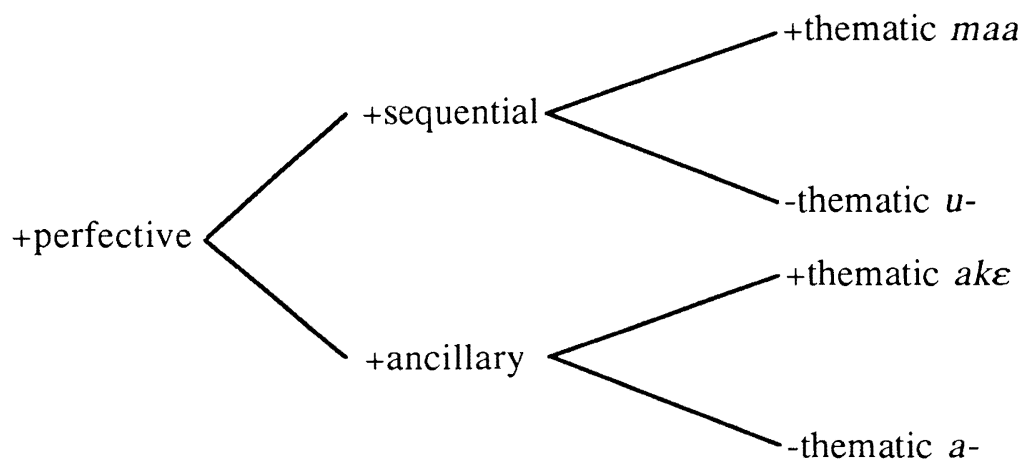

\section{Diagram III}

To complete Buth's storyline scheme, the imperfective is opposed to the perfective, while all the independent forms are opposed to dependent forms in clauses which are subordinated with naa 'when' (+a-verb) and $g \varepsilon$ 'whenever' (+imperfective). At the bottom of his scheme (which does not go into matters of collateral or author intrusion) are clauses with 'be' verbs. 6

${ }^{6} \mathrm{~A}$ further clause type is that which consists of reported speech marked simply with the verb $k \circ b$ 'say' without any tense/aspect marker whatsoever. Such simplified formulas of quotation exist along with fuller formulas in which verbs of speech are marked maa, u-, ake, and a- such as characterize other verbs in the rank scheme. But how should $k a b$ be ranked in quotation sentences without any of the usual marking? Ultimately the answer to this question must be given in the 
Interpreting Buth's scheme in terms of my generalized scheme, we can clearly see the storyline band (with a thematic versus non-thematic split), the backgrounded event band (also with a thematic versus non-thematic split), backgrounded activities (imperfectives), and setting (use of 'be' verbs in Luwo). Subordinated clauses are very rare in Luwo narrative because most of their function is taken up by ancillary a- verb clauses. It is important to remember that, unlike English, which distinguishes only main verbs from subordinated verbs, Luwo has a three-way distinction: main verb, ancillary verb, subordinated verb.

The above distinction, exemplified for Luwo, i.e. foregrounded and backgrounded actions/events issuing in primary and secondary storylines, is also seen in some other Sudanic languages, e.g. in Sabaot (Southern Nilotic), Jur-Mödö and Avokaya (both Central Sudanic) and in such non-Sudanic languages as Mündü (Niger-Congo). In spite of many mutual differences all these languages have, like Luwo, a consecutive tense (or at least a narrative tense) which is storyline while backgrounded events are specifically marked as perfectives. These primary and secondary storylines (if one prefers to call them that) are both opposed to imperfectives, which encode background activities. All these languages also have subordinated clauses which are distinct from all the above. In Mündü and Sabaot it is clear that the consecutive (or sequential) tense, while found on the storyline of narrative, can also be consecutive on verbs of other types which precede it and can take on the function of what precedes. This feature also proves important in many West African languages and is discussed in the following chapter.

4.5. $\boldsymbol{U}$ - verbs as a consecutive tense. On the storyline $u$-verbs occur without any dependence on a preceding initial form. Although a-verbs frequently precede them, especially in beginning a story, $u$-verbs do not depend on the preceding averbs. Rather, they dominate the latter which are ancillary to them. On lower bands in the storyline scheme (and presumably in other discourse types than narrative) $u$-verbs function as a consecutive tense whose meaning and function are dependent on what precedes them. I quote again from Buth:

"The tense aspect, and mood of an $u$-clause depends on the preceding material. If habitual then the $u$-clause is habitual (82). Following an imperative an $u$-clause is a sequential imperative $(30,33,185)$. An $u$-clause following a present or future is also a present or future, though there are no examples in this story" [referring to the story "Uwiid and the Lions", to which the numbered references above also refer].

context of a full consideration of the dynamics of reported dialogue in Luwo (as I have attempted to do so for Biblical Hebrew-cf. Longacre [1989a], Chapters 7 and 8). For the present, it is of interest that $k \supset b$ occurs marking (1) a counterproposal to that enunciated in a previous utterance or (2) an isolated bit of reported speech which expresses the heroine's despair but does not issue in dialogue. I would suspect that $k a b$ thus unmarked ranks probably in Band 2 ( $u$-verbs) but is responsive to certain special dialogue constraints which are beyond the scope of the research here reported. 
4.6. The storyline scheme and constituency structure. Since the data from Luwo are especially extensive and well analyzed (thanks to Buth) I use this language to illustrate (as was done with Gimira in the preceding chapter) how considerations of the ranking of verbs/clauses in storyline salience schemes intermeshes with constituent structure analysis. Here our thesis continues to be that clauses which are salient in the storyline scheme should be dominant in the constituency structure.

In Buth's analysis of Luwo there are many similarities between the sentence and the paragraph as structural levels. The sentence is a smaller unit. If it has more than one clause the clauses are united by thematicity considerations, distribution of conjunctions, and maa, a-, $u$-, and ake as described above. Paragraphs are similar combinations of sentence units. Thus, there are both sequence sentences and sequence paragraphs, coordinate sentences and coordinate paragraphs, antithetical sentences and antithetical paragraphs. On the other hand there are conditional and quotative sentences without counterparts on the paragraph level and there are dialogue and execution paragraphs without counterparts on the sentence level. Because of the extensive nature of the sentence structure as thus analyzed, there is less recursive structuring on the paragraph level than we find in many languages (cf. English and Gimira). Most recursion occurs on the sentence level and the sentences thus constituted are in turn constituents of the paragraph. ${ }^{7}$ Nevertheless some recursive structuring on the paragraph level occurs, as is illustrated in Diagram IV.

Because of the extensiveness of the sentence structure in Luwo and the limited amount of paragraph-level recursion I will not attempt, as I did for Gimira, to first list sentence types and relate them to storyline scheme rankings, and then proceed to illustrate the paragraph structure. Rather, I will simply present in one extended example below both sentence and paragraph structures, present Buth's constituency tree diagram of the same, and point out correlations with the storyline ranking scheme.

(14) [This comes from the same text "Uwiid and the Lions", lines 137-147, from which previous examples are taken. At this point in the story the hero and heroine are literally up a tree.]

137. Maa bechn juuhge

$(\operatorname{maa} \mathrm{V})$ and came lions

138. upahdh gene kiih yooh $k \varepsilon \quad$ jwej

$(u-\mathrm{V})$ fell $3 \mathrm{p}$ to-in path with running

${ }^{7}$ I personally do not think that all this is an artifact of Buth's analysis. I have been partner to paragraph analysis in a considerable number of languages around the world, and I believe that the particular sentence-paragraph structural balance in Luwo is such that sentences, in effect, fill slots occupied by embedded paragraphs in many languages. 
139. ubechn Uloope

$(u \mathrm{~V})$ came Mr. Hernia- $(\mathrm{S})$

140. udoohne caahn.

$(u$-V) became-3s back

141. Ee wahnh thar tuhwo gihn ni

$(a-\mathrm{V})$ and-3s-past reached under palm that this

142. $\varepsilon$ ake yuohmo.

$(a k \varepsilon \mathrm{V})$ and past-with rested

143. Abee ee maahnyo maalo

$(a-\mathrm{V})$ but and-3s-past looked up

144. Ee niid yaaw wihy tuhwo.

$(a-\mathrm{V})$ and-3s-past saw the-people on palm tree

145. Maa coohne puuhge can

(maa $\mathrm{V})$ and called-3s lions all

146. uriht gene

$(u-\mathrm{V}) \quad \operatorname{ran} 3 \mathrm{p}(\mathrm{S})$

147. unyoodhe yaa ni yihr gen.

$(u-\mathrm{V})$ showed-3s people this to them

'Meanwhile the lions took off running with Mr. Hernia lagging behind. He came to that particular palm tree and rested. Then he looked up and saw the people at the top of the tree. He called to the other lions who came running and pointed out the people to them.'

The above example is considered by Buth to consist of four sentences. Sentence (1), lines 137-140, consists of a maa verb in an initial clause followed by three clauses with $u$-verbs. The whole is a sequence sentence with four sequential theses (ST). Medial in this sentence there is a subject reference switch from "all the lions" 137-138 to one particular lion "Mr. Hernia" 139-140. Sentence (4), lines 145147, is a similar structure: it has three clauses with a maa verb in the first clause and $u$-verbs in the following clauses. Subject reference switch (from "Mr. Hernia" to the other lions, and back to "Mr. Hernia") is clearly indicated via singular versus plural distinctions in each successive clause and is implicitly indicated by the sequence of verbs 'call to', 'come', and 'show to' (presumably the one who calls the others to him has information to impart to them).

Both these sentences show a frequent use of maa verbs in the "initial" clauses followed by $u$-verbs, but as Buth has pointed out, maa verbs can sometimes occur other than sentence-initial, and an entire sentence can consist of $u$-verbs. Sentences (1) and (4) are marked as thematically important to the ongoing story by virtue of the initial maa verb in the initial clause of each sentence. 
Sentences (2) and (3) do not contain maa verbs or $u$-verbs. Since these sentences do not contain sequential verb forms they are considered to be coordinate sentences. Sentence (3), lines 143-44, consists of two a-.verbs (The a particle fuses with the $\varepsilon$ conjunction to form ee.) Sentence (2), in lines 141-42, consists of an a- verb clause followed by an ake verb clause. While this sentence is coordinated it is certainly end-weighted rather than equi-weighted, since an ake clause outranks an a- clause.

At this point note Diagram IV, which gives a tree diagram of the paragraph found in (14). This diagram is instructive both as to the insightfulness of tree diagrams and as to their limitations. Ultimately, it is the constituent groupings which are illustrated in such a tree. Thus, the groupings of clauses into sentences is represented in Diagram IV. The qualitative difference between a sequential sentence and a coordinate sentence cannot be shown by the branching structure of the diagram, but only by the labelling of and indication of the morphological structures which are involved. Thus, sequential sentences have sequential theses (Seq. T's) as their branches where indication is also made of maa or $u$-marking; the whole is labelled Seq. S (sequential sentence) at the node. On the other hand, coordinate sentences have theses (T's) on their branches where indication is also made of $a$ - and ake marking. The whole is marked Coor $S$ (coordinate sentence) at the node. Also the tree branching does not distinguish an equi-weighted coordinate sentence like sentence (3) from an end-weighted coordinate sentence like sentence (2). Here the marking eq-w (equi-weighted) and end-w (end-weighted) must suffice.

Shifting our attention to the right side of the diagram, we find a representation of how the sentences combine to form a paragraph. To begin with, however, we must reckon with the force of abee 'but' which begins clause 143. This conjunction serves to set off the first two sentences 137-142 from the last two 143-147, i.e. the portion having to do exclusively with the pursuing lions and the portion having to do with the discovery of the pursued.

In the analysis of this paragraph we note that sentences (2) and (3) have verbs of inferior rank status to those of (1) and (4). Since the paragraph divides at clause 143 it seems necessary to associate sentence (2) with (1) and sentence (3) with (4). The rank scheme tells us that (2) should be made ancillary to (1), and (3) should be made ancillary to (4). This is followed in making sentence (1) plus sentence (2) a fore-weighted (fore-w) sequence paragraph and sentence (3) plus sentence (4) an end-weighted (end-w) sequence paragraph. These two embedded paragraphs constitute an equi-weighted sequence paragraph, since both sub-paragraphs are dominated by verbs of the same rank, i.e. by maa verb $+u$-verb chains. 


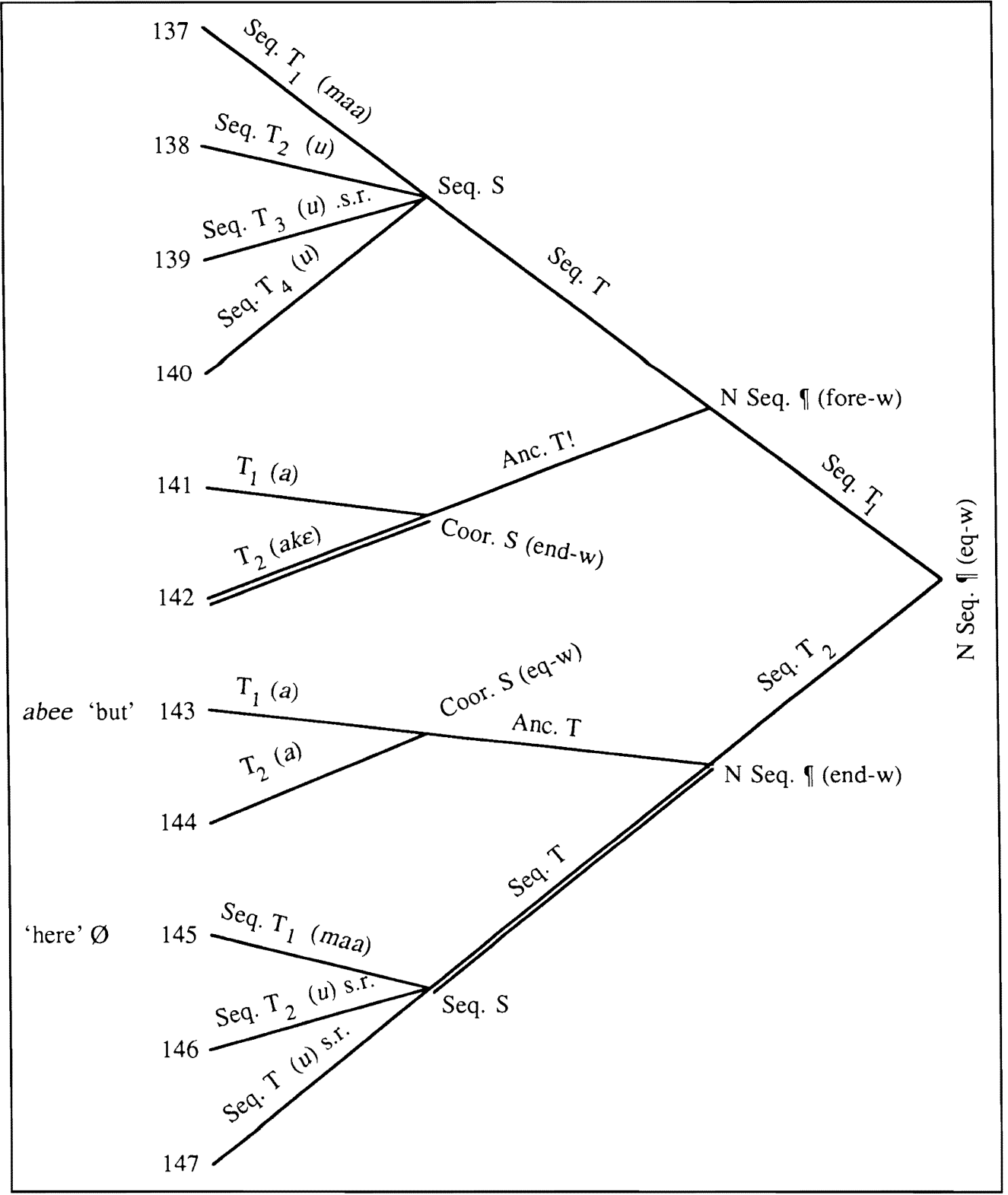

Diagram IV. Constituent tree structure of a Luwo paragraph 
Some of the failings of a tree diagram in recognizing relative weighting of branches on the sentence and paragraph levels can be overcome by using a double line to indicate a branch which is weighted relative to another branch from the same node. In this fashion I indicate clause 142 as weighing more than 141, sentence (1) as weighing more than sentence (2), and sentence (4) as weighing more than sentence (3). While ancillary theses are outweighed by sequential theses, an ancillary thesis with ake weighs more than one with simply a-verbs. Such a pivotal ancillary thesis can be symbolized AncT!

Note in the paragraph here under examination that ake marks a truly pivotal development in the story, i.e. the lion who lags behind stops to rest under the very tree that the boy and the girl have taken to for safety.

This exemplification of Luwo constituent structure analysis guided by rank scheme analysis illustrates two things: (1) The rank scheme is useful, along with other concerns, e.g. the distribution of conjunctions such as abee 'but' and participant-reference spans, in grouping clauses, sentences, and embedded paragraphs in a tree structure. For example, here it groups the maa-V, $u-\mathrm{V}$ chains together over against $\mathrm{a}-\mathrm{V}$ and ake clauses. (2) At the same time the rank scheme gives us a finertuned analysis (in terms of weighting) than can be represented per se in the branchings of a tree diagram. Our resort to the double-lined branch for representation of weighting is a recognition of the limitation of tree graphs in such finer matters of constituent analysis.

\section{Anywak (Northern Nilotic)}

Anywak (data from Miles Reimer and Marie Lusted) is SVO throughout except that storyline definite past verbs occur in SOV clauses, in which the object is apparently left shifted to precede the verb. Since the highest degree of transitivity in Luwo also has an approximate correlation with the highest ranking storyline forms (maa verbs and $u$-verbs) it seems valid here to consider that Anywak SOV clauses (with definite rather than oblique objects) are also of the highest rank in storyline salience. The shifting of the $\mathrm{O}$ to before the $\mathrm{V}$ in such clauses can be regarded as a further reinforcement of the object-oriented nature of the whole construction. These clauses occur, however, only initial in chains which continue with consecutive clauses which have definite verbs followed by the definite object.

5.1. Indefinite and definite verbs. Because of the importance of the cleavage between indefinite and definite verbs to certain storyline rank distinctions in Anywak, I reproduce here Reimer and Lusted's table involving teedo (indefinite) versus thaal (definite) 'to cook' as below-cf. Lusted [1976]. 
(15) Present Tense

SVO

a teedo ki kwon

I am-cooking Obl. porridge

SVO

a thaala kwon

I am-cooking the-porridge

Past Tense

SVO

aana teedo ki kwon

I-past cooked Obl. porridge

\section{SOV}

aani kwon athaala

I the-porridge past-cooked-I

Note in the above that when a verb form which is built on the indefinite stem takes an object it can be only an oblique object marked with ki (cf. Luwo $k \varepsilon$ in same function). As a matter of fact many indefinite forms are intransitive and take no object at all. Note also that the definite object is fronted to precede the verb only in the past tense, not in the present.

5.2. Consecutive clauses (compared with medial clauses in SOV languages). Consider now a further example, which involves consecutive clauses:

acok rec mo beyo-beyo ajiere

Achok(S) the-fish which good $(\mathrm{O})$ Past-chose-he

ni buul mook, ni cam geni

and roasted (he) some $(\mathrm{O})$, and ate (he) them $(\mathrm{O})$

ni kan moga.

and hid (he) the-rest $(\mathrm{O})$

'Achok chose the good fish and roasted them and ate some of them and hid the rest of them away.'

Here we have a chain of Anywak clauses. The chain begins with a special initial SOV past definite clause and continues with consecutive clauses introduced with $n i$ 'and' and with SVO structures. Sameness of the subject is assumed, and no further subject noun occurs. (There is a zero third person singular on the consecutive verbs above.) The consecutive clauses are not marked for tense since the tense is marked only once on the initial verb.

We have here a structure which is the mirror image of those described for the SOV languages of Ethiopia in Chapter 1. There we encountered chains which have a special final verb form (FV) with uninflected or only partially inflected medial verb forms $(\mathrm{MdV})$ in the preceding clauses. Here, we have a special initial verb form (IV) with uninflected consecutive verb (consV) forms in the following clauses. Note the following schematic representation: 
$\underset{\text { little/no inflection }}{\operatorname{MdV} \ldots \text { MdV...MdV }} \quad \underset{\text { FV. }}{\text { inflected. }}$

$\begin{array}{cc}\text { IV } & \text { consV } \\ \text { inflected } & \text { little/no inflection }\end{array}$

The mirror image is quite complete. SOV languages have a special structure to mark the end of the chain and SVO or VSO languages can have a special structure to mark the beginning of the chain. Either way, closure is marked within connected text.

Two additional observations need to be made here. (1) SOV languages consistently generate such structures which chain forward towards a final verb. This is so diagnostic of such languages around the world that any purportedly SOV structures which do not generate such chains may be regarded with suspicion as possible historical shifts from an earlier SVO structure, as in the case of the development within Anywak of the SOV pattern with special function. 8 Or, alternatively, an SOV language without such medial-final chaining may be the last stage in the historical attrition of an SOV structure (cf. Avokaya below?).

(2) SVO and VSO languages may or may not have a structure initial clause plus consecutive clauses as that just exemplified. Across Africa (not to speak of a larger world view), SVO languages may or may not have one or more consecutive verb forms. When a language has such a verb form it may or may not have a special initial storyline form in narrative. All this can better be exemplified in the next chapter. Of the three VSO Nilotic languages previously considered in this chapter, all three (Toposa, Sabaot, and Luwo) have a special narrative or consecutive tense without a distinctive storyline initial, while Murle, an Eastern Sudanic language, does not have a special consecutive tense.

The Anywak SOV clause illustrated above in (17) is primary storyline and is sentence initial in this situation. Are the consecutive definite verbs which follow of the same rank as the preceding initial or of lower rank? This is a question of the same order as that raised regarding the storyline status of unmarked gerunds versus finals in Ethiopian chaining languages. In regard to the latter it seems reasonable to believe that in most cases unmarked gerunds are of the same storyline status as

\footnotetext{
${ }^{8}$ This is a somewhat opposite thesis to that of Talmy Givón [1975] regarding Niger-Congo, where he explicitly theorizes that present day SVO structures are historically SOV. While much of Givón's evidence is impressive, I do not believe that he has taken account of such "classical" SOV structures as are found in Papua New Guinea, Korean-Japanese, South America, and Ethiopia. For a purportedly SOV language to have consecutive clauses rather than medial clauses which chain toward a final is, for me, a much more serious structural contradiction than the matters of noun phrase structure, postposition versus preposition, and distribution of tense/aspect particles, which preoccupy Givón. All these matters must be eventually explained in some more comprehensive framework than anyone has yet suggested.
} 
finals. Similarly, it seems reasonable to assign the consecutive definite verbs of Anywak the same storyline rank as that given to the initial SOV definite clause.

5.3. Storyline scheme elements. Without giving a storyline diagram as such I present here the crucial features of further levels of Anywak storyline scheme ranking as posited by Lusted and Reimer.

5.3.1. Secondary storyline. (1) Secondary storyline rank is given to past indefinite verbs and consecutive indefinites which follow them. Consecutive indefinites not only take $n i$ 'and' but a further coordinator $o$ and two constructions which turn on an auxiliary cän 'again' (which may be a grammaticalized earlier initial meaning 'repeat'). Thus, we have such initial past indefinites as below:

(17) [These examples of past indefinite verbs are culled out of various texts and are not contextually related.]

a. en arimpo doc...

he ran much

b. Acok ajito ki jwiili...

Achok Past-got Obl. wounds

c. gena roomo $\mathrm{ki}$ liec.

they-past met Obl. an-elephant

For consecutive past indefinites with various coordinators note the following:

(18) [Again, the following examples are not contextually related.]
a. ...ni piį̀ buut patogo.
and arrived (he) beside that-one
b. ...o but gok.
and slept (he) (in) Gok
c. ...o cäjge pääy...
and again-they arrived
d. ...keel-mana cägge duuo.
so again-they returned 
The variety of coordinators encountered with indefinite verbs suggests the possibility that they may not be strictly punctiliar/sequential as are the definites.

5.3.2. Promoted indefinite forms. (2) In between the definites and the indefinites, Lusted and Reimer indicate in their rank scheme indefinite forms which have been promoted-possibly to the primary storyline-by the occurrence of the auxiliary put 'immediately' with the verb (a) with an initial indefinite, as in likc aput oo thuws 'the elephant immediately came also' (where aput has the past tense marker) and (b) with a consecutive indefinite as in ni put ren paac 'and (he) immediately ran home' (where the consecutive verb put does not have the tense marker). The promotion of indefinites with put is especially crucial in stories that have a great deal of movement and conversation but little physical contact. Stories of this type presumably have a primary storyline with put, while stories featuring more action and physical contact have a primary storyline with definite verbs. Here again questions of narrative type complicate the picture.

5.3.3. Lower storyline scheme elements. (3) The lower ranks in the Anywak rank scheme can be summarized as follows: (A) Background activity is encoded in present tense verbs with less distinction between tense-marked initial forms and non-tense marked consecutive forms in that the present is the unmarked tense. No attempt here is made by Lusted and Reimer to subrank definites versus indefinites in this band. (B) Various sorts of further background are posited including verb complement structures (as opposed to consecutive verbs) and flashback via a specific pluperfect tense. (C) Setting is encoded in stative verbs. (D) Subordinate clauses occur in various functions. (E) An irrealis band includes subjunctives ("it should have stomped him", "he would have been caught by the elephant").9

\section{Avokaya (East Sudanic)}

Avokaya (data from Lynne Callinan and Eileen Kilpatrick) is an East Sudanic language in which, unlike Anywak, where SOV in one clause type can be explained as a motivated left shift from SVO, we must regard SOV as the basic word order.

6.1. Avokaya as a weak SOV structure. Although an SOV language, Avokaya has few of the characteristics of SOV languages such as were discussed in

\footnotetext{
${ }^{9}$ In closing this brief discussion of Anywak, which, along with Luwo, represents Northern Nilotic in this study, I mention a third Northern Nilotic language, Shilluk, for which we have some tantalizing but incomplete data from Leoma Gilley. She reports two types of narratives, folktales and histories, with different storyline structures. In the folktales, storyline structures are SVO and a tense distinction (present vs. past) marks the primary versus the secondary storyline. In historical narratives, both the primary and secondary storylines are past tense, but the former has VSO order and the latter has SVO. In both sorts of narrative, important participant-oriented background is given via OVS clauses.
} 
Chapter 1. For this reason, and others discussed below, Avokaya must be regarded as a weak SOV structure. 10

Avokaya has SOV structure in its narrative tense, in the imperfect, and in the otiri 'when' clause. It has SVO in its secondary storyline (the perfect), in irrealis constructions (both subjunctive and negative), and in the be...ri 'when' clause. There seems to be no motivated reason to explain the development of SOV clauses from SVO. On the other hand, as in many such situations, it may be somewhat easier to explain SVO as developing from SOV (cf. history of English).

That Avokaya is basically SOV agrees with the fact that the noun phrase adds postpositions rather than prepositions (as in SVO and VSO languages). On the other hand, Avokaya is clearly not a strongly SOV structure for the following reasons: (1) The alternative order SVO is also very prevalent and characterizes several constructions. (2) The verb is not clause-final as such. Rather, it occurs in an SOV clause as final in the nucleus, which is composed of subject, the object narrowly defined, and the verb. Beyond the verb there occur verb complements, indirect objects, and both temporal and locational phrases. (3) Structures chaining forward to a characteristic final verb are not found.

6.2. The storyline scheme and its parameters. In the accompanying diagrams, I give the conventional sort of rank scheme band arrangement which we have employed for most of the languages in this study (Diagram V). I also give a diagram with defining parameters as suggested by Buth for Luwo and implemented in his rank scheme analysis of that language (Diagram VI). The latter sort of diagram also seems insightful for Avokaya narrative. I have indicated in Diagram $\mathrm{V}$ the morphemes whose occurrence defines the various tense forms. In regard to Diagram VI, note the division between Content and Cohesion, as implied in many previous rank schemes where cohesive, backreferential devices take bottom rank. On the other hand, since cohesion and topicalization are both concerned with articulating the structural "chunks" of the discourse, in Avokaya the two concerns (see below) are considered to be related and are relegated to Band 6. Content, in turn, divides into irrealis versus realis structures, which sets Band 5 off from the above bands. Since the presence of an agent defines action, the absence of an agent sets Band 4 off from the above bands. Band 3, durative, is set off from Bands 1 and 2 which are punctiliar; while the primary and secondary storylines are set off by presence versus absence of sequential. Further comments are the folowing: (1) A primary storyline in any language is both sequential and punctiliar. Secondary storylines are punctiliar but not as strongly or necessarily sequential as are primary

${ }^{10} \mathrm{Cf}$., for example, weak VSO versus strong VSO languages as posited by Dik [1978:180-181]. It seems that apart from the horn of Africa where strong SOV chaining structures occur, SOV in the rest of Africa (cf. Supyire and other Senegalese languages) are best regarded typologically as weak SOV structures for such reasons as those argued above in relation to Avokaya. 
storylines. (2) At any rate, however, both primary and secondary storylines are set off from non-punctiliar elements such as are found here in Band 3.

\begin{tabular}{|l|l|}
\hline Bands & Verb/clause forms \\
\hline \hline $\begin{array}{l}\text { 1. Primary } \\
\text { Storyline }\end{array}$ & Narrative tense: S dri (O) V-zo \\
\hline $\begin{array}{l}\text { 2. Secondary } \\
\text { Storyline }\end{array}$ & Perfect tense: S V (O) tra \\
\hline $\begin{array}{l}\text { 3. Backgrounded } \\
\text { activities/happenings }\end{array}$ & $\begin{array}{l}\text { 3.1. Imperfect tense: S (O) V - 'a } \\
\text { 3.2. Reduplicative participle }\end{array}$ \\
\hline $\begin{array}{l}\text { 4. Setting } \\
\text { 4.1. Event: Perfect tense with inanimate subject } \\
\text { 4.2. State: non-verbal clauses }\end{array}$ \\
\hline $\begin{array}{l}\text { 5. } \text { Irrealis } \\
\text { topicalization }\end{array}$ & $\begin{array}{l}\text { 5.1. Subjunctive: S o-V O } \\
\text { 5.2. Negative: SVO ko }\end{array}$ \\
\hline
\end{tabular}

Diagram V. Storyline scheme for Avokaya 


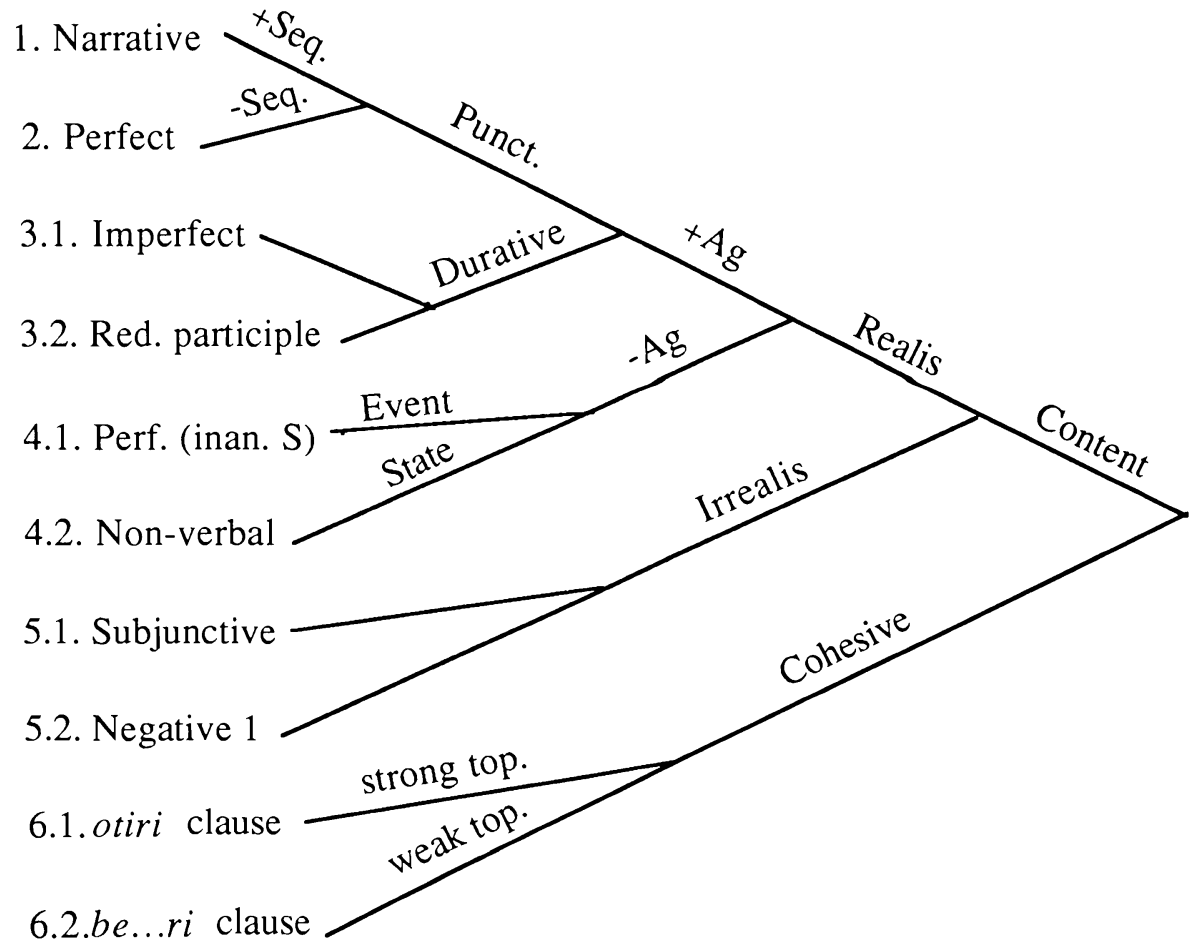

Diagram VI. Parameters that generate the Avokaya storyline scheme

6.3. The status of speech verbs. A further concern here has to do with the status of reported speech. In the Avokaya texts the verb ki 'say' is simply not marked for either the primary or secondary storyline. It may, however, on occasion occur in a clause which is preceded by another speech verb, which is so marked, as in the following example:

(19) ata ta tra oko la dri ki ni ri speak affair PRF. wife his to say LINK

'He spoke to his wife saying...'

In a similar example the verb 'ordered' occurs followed by a clause with the unmarked verb $k i$ : "After this Ruth ordered me; she said that, as for me, if I opened 
the door she would beat me." In both these examples the marked speech verb is perfect and is secondary storyline. In one case the verb 'call' introduces a quotation and the verb is in the narrative tense, i.e. it is on the primary storyline. Also a case occurs of the verb 'beg' in the narrative tense followed by the unmarked ki verb.

What then? In Avokaya narratives, as in narratives in other languages around the world, it seems necessary to accept speech acts along with other sorts of actions as elements which propel a story forward. But the marking of primary versus secondary actions is lacking for speech acts with $k i$ 'say'. I assume therefore that the contrast between primary and secondary storylines is neutralized for quotation sentences which employ only the unmarked verb. They are simply storyline. On the other hand, some speech acts, as seen above, are doubly introduced, i.e. with a clause whose verb is marked for tense/aspect and is more specific as to the nature of the speech act, followed by a clause with unmarked $k i$ 'say'. The marking of the first verb indicates the storyline status of the speech act in such situations.

6.4. Primary and secondary storylines. While in some Avokaya narrative texts the primary storyline statistically predominates and the secondary storyline is comparatively rare, there are other narrative texts where, if anything, the reverse is true. Nevertheless, whatever the relative frequency of the narrative tense versus the perfective, the summary of Callinan and Kilpatrick seems to be applicable: "The perfective is used for an eventline [=storyline] action for one of the following purposes: (1) to stage a sequence of actions; (2) to restage when entering a new sequence of actions; and (3) to show that particular actions are not scriptpredictable." It would seem that the secondary storyline as thus described typically involves staging at any point in the discourse, i.e. actions/events that are in some sense preliminary and preparatory to what follows. A new sequence of events, i.e. a new script, frequently calls for a new staging via clauses with the perfective. But this usage grades off into one of representing events that are not script-predictable but rather, of themselves, shift a sequence of actions/events in the direction of a new script.

In the story "Solomon and Ruth" (wherein a man Solomon tries to take a second wife but his wife Ruth successfully blocks his efforts), after the setting of the story (the identity of the narrator and his age when the events narrated took place) there is a stage which consists of nine sentences. Six of these sentences have perfective tenses. The first four such sentences do not advance the storyline much if at all:

...I came to stay with uncle- - his name was Solomon.

- I stayed with him.

- I stayed to serve him.

- I stayed with him about one year.

Here the perfective tense of the secondary storyline is seen to be more paraphrastic and amplificatory than the consecutive. After an intervening verbless sentence 
("His wife's name was Ruth") two more sentences whose main verbs are perfectives follow: "Solomon wanted to take another wife. He asked Ruth, his wife." The two following sentences are quotation sentences which involve the verb $k i$ 'said', which does not distinguish the primary and secondary storyline. So much for the initial staging of the story and the use of perfectives in the staging.

The primary storyline clearly sets in with sentence 13, "After this Solomon began courting a certain young girl." [Here the clause nucleus Solomo dri 'dezo 'Solomon began' has the narrative tense.] Another verbless clause intervenes and gives the girl's name. Then the primary storyline continues: "Solomon then began to arrange to buy her." The next clause is a perfective and records that, contrary to Ruth's former apparent acquiescence, "Then Ruth, when you saw that it was like that, you became very angry." 11 Here the use of the perfective shifts the story into a new script where Ruth is trying to prevent her husband's taking a second wife; the main verb 'you became angry' is now marked with tra. After an intervening quotation sentence with unmarked $k i$ 'said', the primary storyline continues with 'you followed Solomon'. The next sentence, with a perfective verb, pictures Ruth's breaking in on Solomon as he is quietly drinking beer-not exactly a scriptpredictable role for an African woman, even if she had gone so far as to follow her husband! This new script continues with primary storyline sentences, "Ruth, you became very angry. You separated them. You brought Solomon back home."

The text continues with a further visit of Solomon to the girl's house. There is restaging here: "Then, another day Solomon went to that girl's home again (perfective)." Following this there is a conversation between Ruth and the narrator in which a new script is laid by two perfectives: "Ruth ordered me (to bar the door against him)" and "we lay down to sleep." This new script continues with Solomon returning and begging to get in (two clauses with narrative tense) plus some clauses with reported speech (unmarked $k i$ 'say'). Then, two script-shifting actions occur as the context livens up further: "After this Ruth laughed (perfective). Solomon opened the door by force." This is followed by a primary storyline clause: "Solomon entered the house." The end of the text reports the reestablishment of equilibrium (like a final staging): Ruth's anger cooled off, and she was enabled to talk nicely to her husband. On the other hand she effectively chased the would-be second wife away. And the two of them lived happily every after. All this is reported in five sentences with perfective verbs and one irrealis clause: "Solomon did not return to that woman."

I have presented this text in a somewhat lengthy summary in an attempt to illustrate the switching back and forth between the narrative tense and the perfective as found in some texts. Other texts use the perfective less frequently. The role of the narrator in conceptualizing the situation is very much in evidence here. We can

${ }^{11}$ Note also the startling shift from narration about Ruth to addressing Ruth in second person. Discussion of this matter must be postponed until there is full consideration of participant reference in Avokaya and other languages which were included within this project. 
explain his choices between narrative and perfective ex post facto; we would hardly be so rash as to predict them a priori. Certainly pragmatic strategies are to the fore here rather than "rules" as usually envisioned.

6.5. The cohesive band. While I do not usually give much space to the discussion of cohesive elements in this study, the Avokaya cohesive band deserves special comment. There are two 'when' subordinators: otiri, which occurs with SOV word order, and be...ri, which occurs with SVO word order.

When an otiri clause occurs with $t a$ 'thing, affair', it is topicalizing and cataphoric:

(20) [Context: We slept on the path. In the morning we got up to leave. The petrol was finished. The lorry waited again.]

ma otiri ta ndre ri, arabiya aza
we when thing saw LINK car another
ri'a ani'a 3 saba lesi
PROG come-IMPF Juba from

'And then we saw something: a certain car was coming from Juba.'

Here the translation of the otiri clause into a subordinate 'when' clause in English is difficult because English does not use cataphoric clauses in preposed position. 12 Notice also, that the otiri clause is SOV and the otiri 'when' occurs after the subject.

An otiri clause with a motion verb and without the cataphoric particle ta contains some new information of a script predictable sort. The following example illustrates in its first otiri clause this further use of such a clause while the second otiri clause contains ta and is cataphoric.

(21) [Context: A car is approaching at great speed. The people on the road are scrambling to get out of the way. A certain boy is there, apparently in the path of the car. The car roars past, almost going out of control.]

$\begin{array}{lllll}\text { tapilindri otiri kpa wa ri, } & & & \\ \text { dust } & \text { when again settle LINK, } & & \\ \text { ma otiri ta ndre } r i & \text { go'da abiya 'di arabiya si tra gia } \\ \text { we when thing saw LINK then that boy car struck PERF far }\end{array}$

\footnotetext{
${ }^{12}$ Such a clause in postposed order is not unusual, however: "We had almost finished breakfast when we heard it: a low impetuous rumble like an approaching train. Immediately, the ground began to tremble..." An analytic alternative here would be to regard otiri not as a subordinator, but simply as a cataphoric topicalizaer. Against the later analysis is the fact that the verb which occurs with otiri does not fit the structure of any independent verb.
} 
'When the dust settled, then we saw it: that boy had been struck by the car and thrown some distance.'

Here the clause 'when the dust settled' is script-predictable from a speeding car passing on a dirt road [car passes, dust arises, dust settles]. It is, weakly anaphoric. But by contrast the second otiri clause is strongly cataphoric. Here the main point of the whole story is that a child was struck by a car and hurt badly. While several cataphoric otiri clauses occur in this text, there is but one (weakly) anaphoric otiri clause and it occurs here to underscore the importance of what follows. Callinan and Kilpatrick state that this is typical of otiri clauses with motion verbs: (1) they are weakly anaphoric, (2) they refer to an action/event that is script-predictable from the preceding context, and (3) they promote what follows to higher rank, so that perfectives and imperfectives in clauses which follow such an anaphoric otiri clause are of pivotal status much like ake verb clauses in Luwo, i.e. while encoding secondary or background activity they are presented as crucial and have a position of privilege within their bands. 13

'When' clauses with be...ri are more pedestrianly anaphoric and backreferential. They also seem to occur as promoters. Thus, in the Solomon and Ruth text referred to in summary above, there are two such be...ri 'when' clauses. One, in line $\mathbf{1 6}$ summarizes lines $13,14,15$ :

13. "After this Solomon began courting a certain young girl." (narrative tense)

14. "That young girl was called Nodongala." (verbless)

15. "Solomon then began to arrange to buy her." (narrative tense)

16. "Then Ruth when you saw that it was like that (be...ri), you became very angry." (perfective)

Here, not only does the perfective signal a change of script, but the be...ri 'when' clause promotes the following clause to a position of prominence within the secondary band: Ruth's anger is quite crucial to all that follows.

To return to the speeding car text, the clauses that occur after be...ri 'when' clauses are crucial to the latter part of the story:

(22) [Context: Sentence 9 reported that a further car was sighted coming towards them from Juba. Sentence $\mathbf{1 0}$ gives the background information that many people were on the road and many were still in the lorry.]

${ }^{13}$ If, indeed, they are not promoted higher. The difficulty with the latter in the few examples which we have is that the promoted clauses (a child had been struck by a car, a bush pig had fallen and died-in a hunting text) refer to events with patients instead of to actions with agents, so the former scarcely qualify as pivotal actions. Cf. the comments under Luwo re ake not being the highest level of transitivity. 


\section{1. ma ndre be arabiya 'di ani'a tola asi $\underline{r i}$, we saw when car that coming there from LINK go'da ri'a ani'a suko. then PROG coming-IMPF bad}

12. [Its speed was great.]

13. aca be anyi ri ngu la go'da ro reach when near LINK speed its then great

14. go'da ojila 'di 'bayi ndre be iti rí, then people those saw when like that LINK driliyi ngazo rale vole pavo asi nori they got up ran away path from that

'When we saw that car coming there, it was really coming fast. [Its speed was great.] When it got near us, its speed even then was great. Then, when those people saw it, they began getting up and running.'

Here the be...ri clause in $\mathbf{1 1}$ refers anaphorically to sentence 9. As a promoter, it underlines the importance of the main clause, 'It was coming very fast'. The be...ri clause in $\mathbf{1 3}$ refers back to $\mathbf{1 1}$ and through $\mathbf{1 1}$ to $\mathbf{9}$. Again, it is script predictable: a car coming rapidly towards you will "arrive near" (aca be anyi ri "when it got near'), but this underlines the importance of the verbless main clause in 13, "Its speed was then great". The be...ri in $\mathbf{1 4}$ is anaphoric and script-predictable (a car is coming fast and people see it coming). It underlines the depiction of the people scrambling to get out of the way, which is itself a perfective. Actually, the three promoted clauses (of various initial ranks) serve to reflect much of what is going on in the story: (the car) was coming fast...its speed even then was great...people began to run to get off the road. The last piece of crucial information is in a clause promoted by virtue of a preceding anaphoric otiri clause as shown in (22) above: a boy was struck and badly hurt. Thus, in this text the clauses promoted by anaphoric be...ri and otiri clauses yield an abstract of the main incidents of the story.

\section{Jur-Mödö (East Sudanic)}

Jur-Mödö (data from Andrew and Janet Persson) is of very regular SVO structure.

7.1. Problems in rank-scheme analysis. While Jur-Mödö does not use variation in word order to rank storyline elements, it has a considerable variety of structural devices which must be taken account of if we are to understand the dynamics of narration in that language. (1) To begin with, primary and secondary storyline are distinguished by the absence versus the presence of 'deni "perfective". 
As with Avokaya, the regular narrative storyline forms are primary while the perfective forms are secondary. (2) There is, however, a distinction within both the primary and secondary bands as to the absence or presence of a $k$-prefix "consecutive". (3) There is a narrative particle kina 'and then' which occurs freely clause initial on both the primary and secondary storylines. (4) The 'be' verb (ëdï) has all the above formal variations but functions in setting. (5) There is an auxiliary verb ari/a 'go' which, when preposed to a main verb, seems to promote the clause so marked. (6) There are ods 'when' clauses which are either backreferential or contain information that is script-predictable from the preceding sentence. Such clauses seem to promote the main clause to which they are preposed by marking the encoded activity as significant (ominous, pregnant) but still more preparatory than cumulative. To decide which of these elements should come in for consideration in ranking the various verbs/clauses of Jur-Mödö narrative and which should not is one question. To decide which elements belong to the rank scheme proper and which are promoters which operate on the rank scheme is still another question. And finally, to rank the relevant elements of the rank scheme is a third question.

After due consideration, the Perssons decided that kina 'and then' does not pertain to ranking considerations as such, but is relevant rather to the marking of sentence and paragraph boundaries within narratives. I have noted in one of the texts available to me that within action spans (major or minor peaks of the story) kina 'and then' is either deleted or is reduced to na 'and'. Furthermore, in the same text kina does not occur before $k \mathrm{~V}$ 'deni clauses (see below).

This brings us to our next question: which elements belong to the rank scheme proper and which are better described as promoters? Here, on due reflection, it seems best to classify as promoters the constructions mentioned in (5) and (6) above, i.e. the use of the auxiliary verb 'go', and the preposing of an odo 'when' clause.

This leaves the following elements to be ranked relative to each other: $\mathrm{V}, k \mathrm{~V}, \mathrm{~V}$ 'deni, $k \mathrm{~V}$ 'deni, forms of ëdi' 'be', $t \mathrm{~V}$ (nominalized), verbless clauses, and ods clauses themselves (aside from their value as promoters).

As with Avokaya and many other languages, formulas of quotation present a special problem. In Jur-Mödö narrative texts most verbs of quotation are unmarked, i.e. they are $\mathrm{V}$. There is, however, a smattering of $k \mathrm{~V}$ speech verbs and consequently the formal distinction $(\mathrm{V} / \mathrm{kV})$ must be accounted for even in speech verbs.

7.2. Ranking $\mathrm{V}$ versus $\boldsymbol{k V}$. In ranking $\mathrm{V}$ versus $k \mathrm{~V}$ as marking some sort of distinction within the primary storyline in Jur-Mödö, there is an initial problem of historical texts in two different registers: (A) In the text "Nowo's Feud with 'Bölömoza" (Text 30 of Persson's corpus), there is a well-defined plot with antagonist, protagonist, and helpers of both. The impression one gets is of a rather formal register of narration. (B) The text "Lali Mödö History" (Persson's Text 
28), by a different narrator, does not have a well-defined antagonist-protagonist plot structure (except for the background tension of the Dinka versus the Lali Mödö which pervades the text). It seems to be in a less formal register of narration. It seems possible to me that taking either text by itself one could arrive at a different ranking of $\mathrm{V}$ versus $k \mathrm{~V}$. In text (A) one would probably rank $k \mathrm{~V}$ above $\mathrm{V}$. The former would be the regular consecutive storyline form and the latter would be a special initial ("starter" clause) in a participant reference span (see below). In text (B) one would possibly rank $\mathrm{V}$ above $k \mathrm{~V}$. The former prevails everywhere and the latter occurs as consecutive on it only in limited context.

I believe that the crucial move here is to posit a participant reference span which is of relevance in both sorts of text. If the role of $\mathrm{V}$ is that of marking an initial clause in such a participant reference span, the above dilemma can be resolved and light shed on the behavior of speech verbs as well: (1) text (A) has well-defined participant spans; text (B) has a plethora of participants, especially where the birth of various ancestors and the formation of their clans are described. We find, therefore, shorter participant spans in (B) than in (A) with a consequent greater frequency of $\mathrm{V}$ in (B). (2) Dialogues in general are characterized by speaker alternation so that every new piece of reported speech is a new participant span, hence the predominance of $\mathrm{V}$ over $k \mathrm{~V}$ in Jur-Mödö dialogue. 14

A further difference between the two texts is that the distribution of secondary storyline forms (perfective) also differs drastically between the two texts. In Text (A) $\mathrm{V}$ 'deni and $k \mathrm{~V}$ 'deni forms are not uncommon; in Text (B) only one instance of $\mathrm{V}$ 'deni occurs, while $k \mathrm{~V}$ 'deni does not occur at all. Furthermore, while cohesive backreferences with odo 'when' occur in Text (A), nominalized verbs $(t \mathrm{~V})$ occur as cohesive backreference in Text (B).

Obviously only further research on a variety of historical and non-historical narratives can satisfactorily answer the apparent contradictions and tensions described above. We may, in effect, have here two different narrative genres. Or we may find that, given a sufficient body of texts, the differences are gradient rather than contrastive. If so, it may prove that $\mathrm{V}$ and $k \mathrm{~V}$ should not be ranked relative to each other but relative to other factors, i.e. the initiation or continuance in some span. We have here suggested the participant span as the relative unit. In the latter case $\mathrm{V}$ and $k \mathrm{~V}$ would be somewhat analogous - as initials and consecutives - to the final verb versus medial verb in SOV languages as reported in Chapter 1. There the final verb and the unmarked gerund were considered to be equally on the storyline for most languages of Ethiopia and the formal distinction between the two kinds of verbs is an artifact of the sentence structure. Here we might argue that $\mathrm{V}$ and $k \mathrm{~V}$ are equivalent and the formal distinction belongs to the architecture of participant spans or some such unit (presumably not to the paragraph as such where kina and backreference figure as boundary markers).

${ }^{14} \mathrm{Cf}$. the orthographic device in English of indentation with speaker change in dialog. 
7.3. The storyline scheme. As a rank scheme for Jur-Mödö I suggest what is presented in Diagram VII. This differs from the diagram as initially formulated together with Andrew Persson only in respect to my subsequent decision to not rank $\mathrm{V}$ versus $\mathrm{kV}$ as reflected in the discussion above. 15

\begin{tabular}{|c|c|}
\hline Bands & Verb/clause forms \\
\hline Primary storyline: & $\begin{array}{l}\text { 1. } \mathrm{V} \text { initial } \\
\text { 2. } k \mathrm{~V} \text { consecutive }\end{array}$ \\
\hline Secondary storylines: & $\begin{array}{l}\text { 3. } \mathrm{V} \text { 'deni initial } \\
\text { 4. } \mathrm{kV} \text { 'deni consecutive }\end{array}$ \\
\hline Setting: & $\begin{array}{l}\text { 5. ëdi 'be' initial } \\
\text { 6. këdi' 'be' consecutive } \\
\text { 7. Verbless clause }\end{array}$ \\
\hline Cohesive: & $\mid \begin{array}{ll}\text { 8. } & t \mathrm{~V} \text { (nominalized) } \\
\text { 9. } & \text { ods 'when' }+k \mathrm{~V}+\text { 'deni } \\
\text { 10. } & \text { ods 'when' + këdi' 'be' }\end{array}$ \\
\hline
\end{tabular}

Diagram VII. Rank scheme of Jür Mödö

I will exemplify a few of the above features, (hopefully) without being tedious. Example (23) below illustrates use of $\mathrm{V}$ forms versus $k \mathrm{~V}$ in Text $\mathrm{A}$ :

(23) kina Dokuru ari e'belano nìga. then Dokuru went his-uncles his Pl. kina e'belano ni ga kari ti ni Mbolo then his-uncles his Pl. went with him (place name)

'Then Dokuru went to his uncles and his uncles went with him to Mbolo.'

In the above note $a r i$ 'went' $(\mathrm{V})$ in the first sentence versus kari 'went' $(k \mathrm{~V})$ in the second sentence. These two sentences begin the story, and the $(\mathrm{V})$ form opens the 
initial participant span. A series of paragraphs follows in which Dokuru, repeatedly named, interacts with the 'Bölömaza people, with his uncles, and with the elders of his village. The name Dokuru is last mentioned in line 30 of the text as part of a quotation formula with the ensuing quote in the following lines. Presumably this initial part of the text belongs to a participant span in which Dokuru is central.

Continuing with the same text, another V clause occurs in lines 34-35.

lïjë isaki tënyi mi do kopiyari.

they began get-up (nominalized) in the evening

na lijë kilingere tara ro mi korondo

and they walked like-that in night

'They began to get up in the evening, and they walked like that by night.'

This starts a brief span which shifts from Dokuru (who is never mentioned again) to the warring party. The $\mathrm{V}$ form isaki 'began' occurs in the first sentence and the $k \mathrm{~V}$ form kilingere 'walked' in the second sentence. Another $k \mathrm{~V}$ sentence follows: "They arrived at an intermediate point".

Continuing with the same text, a V form occurs in the next sentence (given in the next example):

(25) i’di tölu lijë. na lïjë ka kömö

put black they and they went arrived

do lino 'ba bilaka moto amero bo pori lijë

head home of person other which as friend they

'They got lost. And they went and arrived at the home of someone who was their friend.'

This starts a span in which the warriors plus the friend, who became their guide, are central (the precise point at which the guide returns to his own home is not marked). Here again the initial clause is a V, $i$ ' $d i$ 'put', and the verb of the following sentence is $k \mathrm{~V}$, i.e. consecutive ka kömö 'went and arrived'.

I will not give further examples from this text. In each participant span (as I here conjecture) there is a $\mathrm{V}$ initial clause, followed by $k \mathrm{~V}$ clause (with an interspersing of sub-spans determined by lower-ranking participants as described below). Other spans occur with similar V clause introductions: (1) a span centering around ggoyi (chief protagonist among the 'Bölömaza); the initiation of this span is marked by two V clauses. (2) A span centering around the survivors of the raid ('Bölömaza people who had been out in the bush and therefore weren't killed) and their unsuccessful counterattack. 
Contrast all of the above with the more general use of $\mathrm{V}$ forms in text (B) and the sparing use of $k \mathrm{~V}$ forms. In the following example I will give only English translation with indication of certain Jur-Mödö features (especially $\mathrm{V}$ versus $k \mathrm{~V}$ ).

(26) [Opening of text]

Long ago in the beginning they lived (V) among the Dinkas. Kina Kanga lived (V) with the Dinkas a long time. His sons (verbless) three among the Dinkas there. Hunger went and fell $(\mathrm{V})$. Kina he went and left $(\mathrm{V})$. He came $(k \mathrm{~V})$ to the land of Mödö here. He went and got $(\mathrm{V})$ wild fruits. He took $(k \mathrm{~V})$ them to his sons. Kina he said $(k \mathrm{~V})$, "Look at the things of our Mödö country; they've borne fruit. See the Dinkas are troubling us a lot. We'll go to our own country."

The text opens with a $\mathrm{V}$ form. Kanga is mentioned in the next sentence, which also has a V form. The next sentence, which is verbless, is not germane here. It illustrates, however, Band 7 in the rank scheme. 'Hunger' is the subject of the next clause which has a $\mathrm{V}$ form. Kanga is again the subject of the next clause, which also has a V. Notice how the subject reference has shifted from 'they' (ancestors in general) to Kanga, to the sons, to hunger, and back to Kanga. This may well correlate with the choice of $\mathrm{V}$ forms over $\mathrm{kV}$ forms in these sentences. The next sentence has a $k \mathrm{~V}$ consecutive form with Kanga as the continuing subject. In the next sentence, however, although Kanga continues to be the subject referent (unnamed), we find again a V form. But here we apparently start a brief span in which the wild fruits are thematic. Consequently, the next few sentences have $k \mathrm{~V}$ consecutive forms. Even in the quoted speech he is talking about the wild fruits of Mödö land as a testimony to the goodness of the land.

The preceding stretch is typical of the whole text. The impression that the high incidence of $\mathrm{V}$ forms correlates with the comparative brevity of participant spans is further strengthened by looking at a genealogical part of the text:

(27) "That girl became pregnant (V). She bore (V) a still-born child. After that she bore (V) Ajani. After that she bore (V) Jërë. Then, from after that, she bore (V) E'be-Nyaka...."

Here the birth of each successive child determines a new one-sentence span in which the $\mathrm{V}$ form initiatory of such a span is used. Further, as Andrew Persson argues, the forms are not consequential: the birth of one child does not depend on the birth of the preceding child.

In Text (A), a secondary storyline marked with 'deni perfective is used frequently. The use of perfectives in this text in fact can be fruitfully compared with the use of the perfective as a secondary storyline in Avokaya. While $k \mathrm{~V}$ 'deni 
clauses occur in odo 'when' clauses in backreferential function (as do occasionally $k \mathrm{~V}$ clauses), I want to notice here the use of Jur-Mödö $k \mathrm{~V}$ 'deni clauses in staging via independent clauses. The staging function of $k \mathrm{~V}$ 'deni clauses can be seen in the following composite example:

(28) [from Text A]

1. kina 'Bölömaza kisaki kako 'deni do Mbolo. then B. began came PERF. to Mbolo

[This brings the B. people on stage to interact with Dokuru within his span.]

2. kinime Dokuru koloma 'deni yömu abo ko'bo then D. stayed PERF. day his enough

'Dokuru had stayed long enough.'

[This sets the stage for D's precipitous flight back to his own village.]

3. lïjë na kömö 'deni li'jëa ko'ja 'deni... they it-is arrived PERF. they went found PERF ...

'They arrived there. They found that (ngoyi was at home with just the women and children).'

[This stages the section in which the attackers file into the stockade, take up positions, and wait to attack at dawn.]

The occurrence of $\mathrm{V}$ 'deni rather than $k \mathrm{~V}$ 'deni in this text seems to be associated with introducing a minor participant span, often embedded within a major participant span. Again, our next example is composite. All these examples of $\mathrm{V}$ 'deni clauses occur without an initial kina 'and then', which may argue that these forms are not paragraph initial.

(29) [from Text A]

1. [This follows on 2 of (28).]

e'belano bo ga i'di 'deni toto go bo.

uncle his Pl. put PERF. accompany back him

'His uncles accompanied him back.' 
[This is initial in a very brief participant span centering on the uncles--whose disappearance from the scene is recorded in the $\mathrm{ods}$ 'when' clause of the next sentence.]

2. 'ja moto $\frac{\text { odo }}{\text { woman other }} \stackrel{\text { 'deni kari bi yadi, }}{\text { came-out }}$ ko'do tiyadi do bo moto di kpa dötu'du nearly to-urinate on person other from mouth rubbish-heap

'A woman came out to urinate, and nearly urinated on a person (concealed there) by the rubbish heap.'

[The woman referred to here is mentioned only as (suspenseful) detail; she plays no real part in the story and disappears from the scene in the odo 'when' clause of the next sentence.]

3. Nöwö a'da lïjë 'deni. inda'ba 'deni tupö...

N. defeat then PERF. take PERF. killed...

'Nöwö (village name) defeated them; they took and killed (more this time than in the original killing of ngoyi and those with him).'

[This is curious in that the proper name Nöwö (clan) occurs here for the first time in the text, although the previous war party came from that faction as well as the narrator himself. In the text an odo 'when' clause closes this scene and attention focuses on someone else who closes the story by making peace. Apparently here the very use of the name Nöwö occasions the marking of a new participant span which is treated as minor because of its brevity.]

4. u'du ndëli' 'deni kari go Nöwö. throw hammer ERF. go for $\mathrm{N}$.

'He threw the smithy hammer at Nöwö.' (symbolic of suing for peace)

[In this example the elder who sued for peace by throwing the hammer is first mentioned two sentences back via $k \mathrm{~V}$ clause and a $\mathrm{V}$ speech verb. This sentence closes the span centered on the elder and the smithy hammer.]

In the above examples I've tried to show the role of $\mathrm{V}$ 'deni clauses in minor and brief participant spans. Unlike the $k \mathrm{~V}$ 'deni clauses, these $\mathrm{V}$ 'deni clauses cannot clearly be shown to stage within their spans. The spans are somewhat too brief for this to be evident. In sentence 4 of (29), very obviously the action referred to by 
the 'deni clause is crucial rather than merely staging. Nevertheless it is followed by the sentence, "Then all the killing stopped," so that even here the action of throwing the anvil is preparatory in some sense to what follows.

In brief, in Text $\mathrm{A}, k \mathrm{~V}, \mathrm{~V}, k \mathrm{~V}$ 'deni, and $\mathrm{V}$ 'deni are seen to all have distinct roles in which matters of propelling the storyline forward are interlaced with considerations of participant ranking and tracking.

Text (B), as we have said, has but one use of 'deni perfective in the whole text. Primary and secondary storylines are neutralized with a marking only of the primary by means of $\mathrm{V}$ and $k \mathrm{~V}$, which in turn keep track of the rapid shifting of participant focus which characterizes the text. The latter feature of the text also precludes a meaningful separation into major and minor participants. Thus, the use of both $k \mathrm{~V}$ 'deni clauses (for staging) and $\mathrm{V}$ 'deni clauses (for minor participant spans) is precluded in Text $B$.

7.4. Promoters. To return to 'go and do $X^{\prime}\left(a^{\prime}\right.$ 'go' $\left.+V\right)$ as a promoter, note some uses of this in Text (A). The focus of this text is on the actions of the war party in killing 'Bölömaza people in revenge for having had many of their own women and children killed. Everything else in the text is preparatory or resultant (except for the making peace at the end). The crucial actions of the war party are marked with 'went and did X' clauses as follows:

(30) (only in translation)

1. They went and arrived in the middle of the forest (where they got lost) [line 36]

2. and they went and arrived at a friend's house (who became a guide). [line 37]

3. They went and found that ggoyi was at home with just the women and children, [lines 43-45]

4. and they went and killed him [ngoyi] out in the fields, [line 58]

5. and they went and killed the people of his house. [lines 59-60]

6. They went and saved only the chickens. [line 60]

7....(an elder) went and got a smithing-hammer. [line 72]

Text (B) also seems to mark crucial actions by went and did $X$ promotion. While Text (A) in most instances has 'went and did $\mathrm{X}$ ' $(\mathrm{V}$ ' $\mathrm{go}$ ' $+k \mathrm{~V})$, Text (B) has many instances of $k \mathrm{~V}$ ' $\mathrm{go}^{\prime}+k \mathrm{~V}$. This distinction should be studied someday for its possible significance in discourse structure.

An odo 'when' clause promotes the clause which follows it. It seems clear from the study of Text (A) that while the clauses so promoted by virtue of preceding ods clauses are crucial, they are more pregnant than cumulative. For example, in Dokuru's return from his encounter with the 'Bölömaza: "When his uncles were turning back, he threw away his fish [which encumbered him] and ran and arrived 
home exhausted." Here the throwing away of the fish, probably the original reason for making the trip, symbolizes Dokuru's desperation in striking out rapidly for home. Again, "When he arrived home, the elders who were at home questioned him." While the careful questioning of the elders is not in itself an important part of the story it presages the involvement of the whole village. Again, "When that woman (who had gone off to urinate) was returning to the hut, they got up." The main clause here is ominous; the killing will follow. Finally, "When they left, someone who was one of the elders went and got a smithy hammer." Here the getting of the hammer presages an attempt to sue for peace. At this particular point in the Jur-Mödö text (1) the main clause is promoted to crucial importance by the odo 'when' clause, (2) its importance is also marked by went and did (otherwise applicable to actions of the war party), and (3) its use of $\mathrm{V}$ instead of $k \mathrm{~V}$ indicates a new major participant span, relating to brief but important action of making peace. The odo clause promotion is part of a conspiracy of means to underscore the importance of the main clause.

With further features of the Jür Mödö rank scheme I will not concern myself here. They are, as a whole, somewhat routine compared to the features which have been discussed here. I trust that the discussion given here will be provocative and motivate further research into the subtle variations in the primary and secondary storylines, the promoters which operate on them, and the crucial role of participant spans in this language.

\section{Summary}

It is instructive here to pause and draw a few "lessons from the Sudan" to guide the balance of this study.

8.1. Storyline typology crisscrossing other classifications. The various languages which are described in this chapter can be classified as to storyline marking as follows:

A. Two languages, Toposa and Avokaya, have a special narrative tense on the primary storyline with a past or perfective on the secondary storyline.

B. Two languages, Sabaot and Luwo, have (1) a consecutive tense on the primary storyline, which (2) is rank-shifted to occur after non-storyline initials. Past tense or perfective is of lower rank.

C. Two languages, Anywak and Jur-Mödö, have consecutive tenses which follow initial forms on primary and secondary storylines. Initials are relevant to different size-level spans: the sentence in Anywak, a higher-level span (presumably de- 
termined by participant reference) in Jur-Mödö. In Jur-Mödö the perfective marks the secondary storyline.

D. One language, Murle, has neither a special narrative tense nor a consecutive tense, Rather it uses the imperfect in VSO clauses plus the conjunctive ma 'and' to mark its storyline and reserves the perfect for special functions.

One is immediately impressed with the fact that this storyline-typology classification crosses genetic lines. Toposa is northeast Nilotic, and Avokaya is a different branch of eastern Sudanic. Sabaot is southern Nilotic and Luwo (Jür-Luwo) is northern Nilotic. Anywak is also northern Nilotic (same sub-group as Luwo), and Jur-Mödö is central Sudanic. In this case an eastern Sudanic language and a central Sudanic language are grouped together. Evidently languages arrive at different or similar narrative strategies without overmuch regard to genetic origins. 16

One is further impressed with the fact that word order typologies only roughly correlate with the above groupings. Toposa is strict VSO but groups with Avokaya is which weakly SOV (alternating to SVO in certain storyline bands). Murle is also VSO like Toposa but has a distinct narrative strategy. Sabaot and Luwo are both VSO but shift to SVO under somewhat different conditions: in Sabaot for participant focus, in Luwo not only for such participant focus but also to mark bands which are lower than the primary storyline. Anywak is SVO with SOV only on initial forms of the primary storyline. Its narrative strategy is somewhat similar to that of Jur-Mödö, which is more regularly SVO. But all these differ in narrative strategies from the strongly SOV languages (Cushitic, Omotic, Semitic) described above in Chapter 1.

8.2. Narrative tense versus consecutive tense. Before concluding this chapter, I also want to make explicit the difference between a narrative tense and a consecutive tense. A narrative tense, whether relatively marked or unmarked, is a special form which carries the primary event line of a story and is neither dependent on a special initial form in some span nor is rank-shifted in sequence with non-storyline initials. By contrast, a consecutive tense, which also carries the primary storyline, is either dependent on a special initial form in some span and/or is rankshifted in sequence with non-storyline initials. ${ }^{17}$ I have gone to some lengths in this chapter to emphasize the close, mirror-image structural parallelism of constructions in which consecutive tense forms necessarily follow an obligatory

\footnotetext{
16Even granting that the present genetic classifications may well be faulty and remain so for the foreseeable future, pending the if-and-when careful application of the classical comparative method family by family and stock by stock.

${ }^{17}$ In some instances, a form which is used as a verb complement but which never is on the primary storyline has been termed a consecutive tense by some Africanists. I regard this as a confused and somewhat obfuscating use of a good term.
} 
initial form to constructions such as are described in Chapter 1, where medial forms precede an obligatory final form.

Finally, as seen in the case of Murle, a language need not be characterized by either of the above strategies; it may depend more on the role of conjunctions and other signals to differentiate storyline ranks. An overall observation about the languages cited in this chapter is that for most of them, the past or perfective is not primary storyline but is secondary or specialized in function.

These various narrative strategies will be the basis of our grouping of languages in Chapters 3 and 4 below. In Chapter 3, I consider further languages which have a consecutive tense, in Chapter 4, further languages that have no such tense but have either a special narrative tense or mark the primary storyline in some other way. 


\section{CHAPTER III}

\section{OTHER LANGUAGES WHICH HAVE A CONSECUTIVE TENSE}

It is the purpose of this chapter to consider features of narrative structure in some further languages which have a consecutive tense as defined at the end of the previous chapter. I first consider Mündü, an eastern Niger-Congo language where the role of the consecutive tense is prominent, then go on to consider further languages where the role of the consecutive tense is less prominent and is confined to serialization structures. All languages here considered are of SVO structure.

\section{Mündü (Eastern Niger-Congo)}

Mündü (data from Dorothea Jeffrey) has a consecutive tense (called "sequential" by Jeffrey) which marks the primary storyline. Often, but not necessarily, the time of the story is set by the use of the past tense (secondary storyline or setting) in the initial sentence(s) of the text, but this tense as an obligatory initial verb form is not found in all stories. In most cases (precise control conditions not known) the consecutive tense occurs along with clause-initial particle fü 'and then'. The consecutive form plus or minus the preceding fü is freely rank-shifted following other non-primary-storyline forms. In fact, in other discourse types, given proper initial form, the mainline of the discourse can also be continued via the consecutive forms. ${ }^{1}$

${ }^{1}$ Jeffrey gives us a summary description of Mündui tense/aspect as follows (her "sequential" equals consecutive). The tense/aspect of a Mündii verb is shown in three different ways:

(a) tone on verb root: high-low, mid-low, or low-low

(b) prefix on verb root: a-, é, or $\varnothing$

(c) various particles and auxiliaries

(a), (b), and (c) can combine together in various ways. For the purposes of this paper I will deal only with a few of the possibilities.

$\varnothing$-CV̀CV past or irrealis

é-CV́CV incompletive, continuous, or habitual

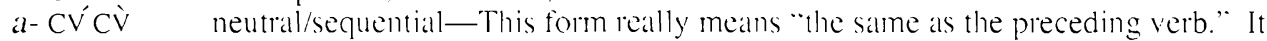
is used for the backbone of narrative, and therefore I used to call it the "narrative" tense, but it is also used for the hackbone of other discourse types (perhaps all other discourse types?) so "sequential" is a better name.

fü (sentence initial) secpuential particle-oceurs only and almost alwalys with sequential tense. 
1.1. Storyline scheme elements. The following three examples, taken from Jeffrey's write-ups, illustrate the beginnings of three stories (all factual and anecdotal) and onset of the primary storyline (marked with fü 'and then' plus the consecutive tense:

\section{(1) wü komoko ta ladü de ìrî wü}

(pl) man (past) exist with name their

Ngondima ake Kümba...

Ngondima and Kümba...

gbü gara ra fü Kümba amálà fü

in other day (seq) Kümba speak to

Ngondima ga...

Ngondima saying...

'Once there were two men called Ngondima and Kümba... One day Kümba said to Ngondima...'

(2) ma emálà ngú dene me-ra teka awuama ka-ra

I speak word this myself about cousin my

ta de ìrì ye Dawìdî. Aba

(past) with name his David Daddy

tìmàta awuama ka-ra, ga, ah nü ah bï

sent (past) cousin my saying he go he carry

ngbaga ka-ni. dela o a di kpa gbï Kongo.

bed his that while we were at in Congo

fü awuama ka-ra ne ayía anü...

(seq) cousin my this get-up go

'I'm going to tell you about my cousin. My father sent him to fetch his bed. That was while we were in the Congo. Then my cousin arose and went...'

(3) ngü engu te ma emálà ne, ngü

word him which I speak this word

ta fairly remote past tense particle (at least a year ago)

eyi (at the end of the clause nucleus,i.e.immediately following the object, if any) completive particle-often used with the past tense. 
$\begin{array}{llll}\text { ka gba. } & \text { fü } & \text { ra ayíà ake Bü'da... } \\ \text { of buffalo } & \text { (seq) } & \text { I } & \text { get-up with Bü'da... }\end{array}$

'The story which I am about to tell is a story about a buffalo. Bü'da and I arose...'

Notice that in (3), the time is not really set in the aperture of the story. Jeffrey comments, "However, the fact that a story is coming is clearly indicated, and the hearers will therefore take the past time for granted." Here a verbless clause opens the story and the primary storyline with fü 'and then', and the consecutive tense immediately follows.

Some other features of Mündü storyline structures are also exemplified in the three examples above. Thus, in (1) the main verb of the aperture sentence is a 'be' verb and as such falls into the category of setting. The first sentence of (2) contains as its main verb the incompletive of 'speak' and is performative (interactional) in thrust: "I'm speaking this word concerning...". This also belongs to the category of setting. The same sentence illustrates the use of the past tense marker ta with a noun phrase instead of with a verb phrase. The second sentence in (2) illustrates a past tense verb (tìmà ta 'sent') on the secondary storyline. It represents an action and is thus much nearer to the primary storyline than are the setting elements. But while this sentence represents an action, it is preparatory to the action on the main storyline as represented in sentence 4, 'Then my cousin got up and went...'. Example (3) illustrates an initial verbless clause of the setting category.

Rankshifting of consecutive tenses to the storyline scheme rank of whatever elements that they follow is well illustrated in the examples of paragraph analysis at the end of this section. I will not further exemplify here. It is important to note, however, that although the storyline consecutive tense outranks, for example, the past tense, when the consecutive tense is rank-shifted downwards and comes to be dependent on a past, it typically ranks lower than the past on which it depends.

Finally, before giving the rank scheme worked out by Jeffrey, I mention and illustrate a very important feature of that scheme: the use of a past tense with eyi completive particle, to mark a pivotal event of the story. The past tense verb thus marked is promoted to a higher place on the rank scheme than the consecutive tense itself. Thus, in the text from which the illustrative paragraph analysis is taken, there are only three sentences which are marked with the past tense + eyi completive, but these three sentences can be considered to mark highlights of the entire story (which concerns a hunter who was ambushed and killed by the buffalo which he was hunting): 
(4) [Numbers represented numbered sentences of the text.]

31. te ewü nü akoro, wüh maka nga gba eyi. when they go come they find footprints buffalo completive

'When they reached a certain place ['go' + 'come' = change of scene of action, according to Jeffrey] they found buffalo tracks.'

41. gba koro nza eyi. buffalo came finish completive

'Then the buffalo came.'

46. yiyi wü ka ye nda eyi

shout sound of it completive

'Shouting sounded forth.'

These three sentences mark (1) the refinding of the buffalo tracks which had been sighted before, (2) the charging of the buffalo out of where he lay in ambush, and (3) the screaming of the man who had been fatally gored. The actual goring of the man is not reported in this fashion but is given in a long sentence initialed with the rare connective kalasi 'and then' and containing six consecutive verbs which give the gory details of the man's death. This sentence is climactic in its paragraph which reports the peak (climax) of the story. Sentences marked with past + completive are pivotal rather than peak, but as pivotal can occur within a peak.

1.2. The storyline scheme. I now present in Diagram I a rank scheme for Mündü (from Jeffrey with adaptation). Mention is made here and there in the rank scheme of certain auxiliary verbs which affect the ranking, and which have other discourse functions which are not related to storyline ranking; these verbs will be discussed later.

Some matters relative to the cohesion band are of interest. Regarding cohesive backreference in general, Jeffrey remarks, "This may be an exact repeat of the event referred to, or a paraphrase, or a script predictable result. Back reference is used in taking up the event line [storyline] after a longish break, and also to slow things up in the environment of peak. Some authors start every paragraph with a back reference." As to the distinction between back reference via a past verb and via an incompletive (with the puzzling accompanying difference in the ordering of te 'when'), this seems to be a matter of temporal overlapping and immediacy. With the past tense the back referenced event is simply antecedent in 


\begin{tabular}{|c|c|}
\hline Bands & Verb and clause types \\
\hline 1. Storyline & $\begin{array}{ll}\text { Pivotal: } & \text { Past tense + eyi 'completive' } \\
\text { Primary: } & \text { fü (usually) + consecutive tense } \\
\text { Secondary: } & \text { (1) Past tense } \\
& \text { (2) Past tense of }\{\text { adu }\}+\text { 'return' verb } \\
& \text { in the incompletive (pre/post peak) }\end{array}$ \\
\hline 2. Background activities & $\begin{array}{l}\text { Independent clauses } \\
\text { 2.1 Incompletive tense } \\
\text { 2.2 Cons. tense of angbü 'sit' + incompl. verb } \\
\text { 2.3 Cons. tense of adi 'be' + incompl. verb } \\
\text { Dependent clause, i.e. da 'while' + incompl. verb }\end{array}$ \\
\hline $\begin{array}{l}\text { 3. Setting } \\
\text { (elements are not sub- } \\
\text { ranked) }\end{array}$ & $\begin{array}{l}\text { Verbs with inanimate subject } \\
\text { Past/Incompletive of stative verbs } \\
\text { Incompl. of angbü 'sit' + adj./stative vb./abstract noun } \\
\text { Verbless clauses } \\
\text { Relative clauses }\end{array}$ \\
\hline 4. Irrealis & $\begin{array}{l}\text { Negative of past tense (consecutive tense cannot be } \\
\text { negated) }\end{array}$ \\
\hline $\begin{array}{l}\text { 5. Cohesion } \\
\text { (Adverbial clauses in } \\
\text { backreference) }\end{array}$ & $\begin{array}{l}5.1 \text { te 'when' }+S+\text { verb (past) } \\
5.2 \mathrm{~S}+\text { te 'when' + verb (incompletive) }\end{array}$ \\
\hline
\end{tabular}

Diagram I. Mündü storyline rank scheme (from Jeffrey)

regard to that reported in the main clause. Regarding back reference via the incompletive Jeffrey comments, "This indicates that the next event [that referred to in the main clause] occurred either before the event referred to in back reference was completed or immediately after. It gives the impression of fast-moving events and contributes to tension. As you might expect, it occurs in the environment of peak."

1.3. Auxiliary verbs and storyline scheme ranking. It is evident that the choice of the auxiliary is important to storyline ranking; but there is a curious cross 
play between the tense of the auxiliary and auxiliary selection in the secondary storyline versus the background activities. Thus, the auxiliaries adu 'return', ayia 'get up', and possibly some others, when in the past tense and followed by an incompletive verb, are the secondary storyline. But the static auxiliaries angbü 'sit' and adi 'be' in the consecutive tense and followed by an incompletive verb encode background activities. Finally, the incompletive of angbü 'sit' followed by a stative verb, adjective, or abstract noun is setting.

But there is much more which needs to be said regarding auxiliary verbs and their functions in narrative. Most of the auxiliary verbs have been already referred to, but I list here the auxiliaries as given by Jeffrey:

$\begin{array}{llll}\text { akoro } & \text { 'come' } & \text { anü } & \text { 'go' } \\ \text { ayia } & \text { 'get up' } & \text { adu } & \text { 'return' } \\ \text { angbü } & \text { 'sit' } & \text { adi } & \text { 'be' }\end{array}$

The auxiliaries akoro 'come' and anü 'go' when used before other verbs have to do with the positioning of participants on the stage. Thus, Jeffrey comments that "akoro 'come' brings a participant on stage." She gives the following example where akoro 'come' signals the advent of the husband.

(5) fü würüse ne aga, "ye nga la anga."

(seq) woman this say you be-quiet that are-quiet

fü ewü adu anga.

(seq) they returned are-quiet

fü komokone akoro gere emögïti ka-ye

(seq) man this come at once at-door his

aî wara ye...

call wife his

"Then the woman said, "Be quiet!" So they kept quiet. Then the man (her husband) came and stood in the doorway and called to his wife..."

Jeffrey goes on to comment that "anü 'go' is not used to take participants off stage", but rather (to continue the metaphor of the theatre) to backstage or off to the side. Jeffrey continues, "A nü takes a participant a little way into the background, still in sight, but a little bit out of focus. Usually he goes to fetch someone or something and then returns." For the occurrence together of anï 'go' and akoro 'come', Jeffrey shifts the stage metaphor to that of the cinema: "When 'go' and 'come' are used together they shift the scene of action... Imagine the participant moving gradually into the distance with 'go'. Then with 'come' the camera man uses his zoom lens and brings us up close to the participant again." 
In the following long example first the buffalo moves away (sentence 1); then the narrator and his party move away and hide behind a rock (sentence 2 ); then, after the intrusion of another animal (sentences 3 and 4), the hunting party moves up again to the side of the presumably dead buffalo and take up their new locale at that place (sentence 5).

(6) 1. fü gba adû ayíà dela fí bala,

(seq) buffalo return get-up that still thus

anü anü arâ eküte ta bala,

go go lie at-body anthill thus

angbü kpala da ekû gba bane-ene-la.

sit there crying cry very-much

2. fü a ayíà ayia 'buru anü awô te-a,

(seq) we get-up get-up all go hide ourselves

angbü ekere da.

sit behind rock

3. a te ecékà kpala, gara mba nü akpe akórò kpala... we (incept) looking there, other animal run come there

4. te nü ne wì a... fü ayíà

when animal this saw us (seq) get-up

alügü nga ye akpe atáfà.

return tracks his run go off

5. fü a adu ayíà dela afáraaa

(seq) we return get-up that go-stealthy

anü akórò ade gba ne.

go come beside buffalo this

'Then the buffalo went and lay down on the anthill and was crying very much. Then we got up and went and hid behind a rock. As we watched...another animal came running... When it saw us it ran away again. Then we got up stealthily and went over to the buffalo.'

The auxiliaries ayia 'get up' and adu 'return' have script-related functions. This is especially clear in the usage of the former. I can do no better here than quote Jeffrey at length:

"People vary a bit in their use of ayia 'get up'. Some texts have 'get up' tacked onto almost every event line. However it is generally used for the start of a new script. In "Buffalo Story A", the man first gets up and goes into the bush, where he finds the tracks of a wounded buffalo. He returns home and tells his wife about it, then gets up and goes back to the bush, and tracks the buffalo. When they find the buffalo-much livelier than they had expected-the brother-in-law gets up and climbs a tree. The buffalo gores the first man and mortally wounds 
him. Then it gets up and runs off into the bush. The man's wife and brother-in-law then get up and make a stretcher and carry him home."

For adu 'return' the picture is not so clear, since this auxiliary has several functions. Jeffrey mentions its being used much like 'come' to bring a participant on stage and/or shift the scene of the action. She also mentions that it can simply signify close connection ("usually result or outcome") with the previous context (more like English "in turn..." than "return"?). Nevertheless, adu also has a script-related function, i.e. that of 'returning' us to an interrupted script. The examples below illustrate both the use of adu to signify result/outcome and to signal return to an interrupted script.

(7) wara ka-na ayíà de gara enga-eyì tane, wife his get-up with other brother her

ayíà ka-wü anê-sü ka-wü kpah kpa

get-up theirs go-away theirs also at

gbü Rïngasii. fü ra adú angbü ekötï sela kpikpi-ra.

to Ringasï (seq) I return sit at-home there alone

'His wife got up with her brother, and they also went off to Ringasï. And as a result, I remained alone at home.'

(8) [From the same text: The child, left alone, has a very hard month of it. As Jeffrey puts it, "Then comes the peak of the story-a long description of how the child lived on his own-what he ate (not much), where he slept, and how much he cried."]

fü ewü adu ace kpa wü te Olìva.

(seq) they return leave hand their to Olivar

fü ah $\underline{a d u}$ akoro amaka ra...

(seq) he return come find me

[return to interrupted script] 'Then they released Oliver. [And as a result] he came and found me.'

The two auxiliaries angbu 'sit' and adi 'be' have been discussed above in relation to ranking in the storyline scheme. As to the distinction between the two, the former is possibly associated with continuous or repetitive activity while the latter is less dynamic and more habitual. For example, in the background material cited in square brackets in (8), the description of the child's getting on all by himself (eating, sleeping, crying) uses the adi 'be' auxiliary. 
This excursion into the meaning and use of certain auxiliary verbs in Mündü should alert us to the fact that some apparently storyline-ranking distinctions may actually be relevant to other matters such as positioning of participants, scriptspans, and logical relations. Cf. also Jur-Mödö at the end of the last chapter, in regard to presence or absence of $k$ - on storyline forms. Such matters as the marking of participant spans and script spans (often not correlating with otherwise marked paragraph units) can greatly complicate the ranking of verbs/clauses in storyline schemes.

1.4. The secondary storyline and flashback. In Mündü the secondary storyline and the structure of flashbacks are not distinguished. Both are marked by past tense forms. ${ }^{2}$ In the following example there is a two-fold flashback: (1) from the narrative time to the activities of the brother-in-law before coming onto the scene and (2) from the time of the brother-in-law's discovery of the meat to an earlier time when the lion made his kill.

(9) fü yoko ye-na akórò, te kòrò
(seq) brother-in-law his come who came
kpa gbü gü da endórò. angü komoko
at in bush wandering for man
la nü màkà so, enga gba te kami
that went found meat child buffalo which lion
zòrò, gbèkè nü di ò kpa esa bìrì.
caught pulled went with it put at under stream

'Then his brother-in-law came from the bush where he had been hunting. For he had found meat - a young buffalo that a lion had caught and dragged down to the river.'

1.5. Storyline scheme ranking and constituency structure. I turn now to illustration via Mündü of how storyline ranking can be used to guide constituent analysis. To illustrate this I use two Mündü paragraphs from the same story (called "Buffalo Story A" in Jeffrey's corpus). The first paragraph analyzed (Diagram II) is the initial one of the narrative and has little primary storyline movement. It has several rank shifted uses of the consecutive tense. The second paragraph analyzed (Diagram III) is at the climax of the story and has considerable primary storyline movement. The analyses are given as tree diagrams accompanied by an English translation of the Mündü text with identification of Mündü tense forms and clause types.

${ }^{2} \mathrm{Cf}$. classical Hebrew where the perfect tense is also a secondary storyline and is used as well for flashbacks [Longacre1989a]. 


\section{Aperture of discourse:}

1. I want to tell you a word which happened during the war of the Arabs and the Anyanya.

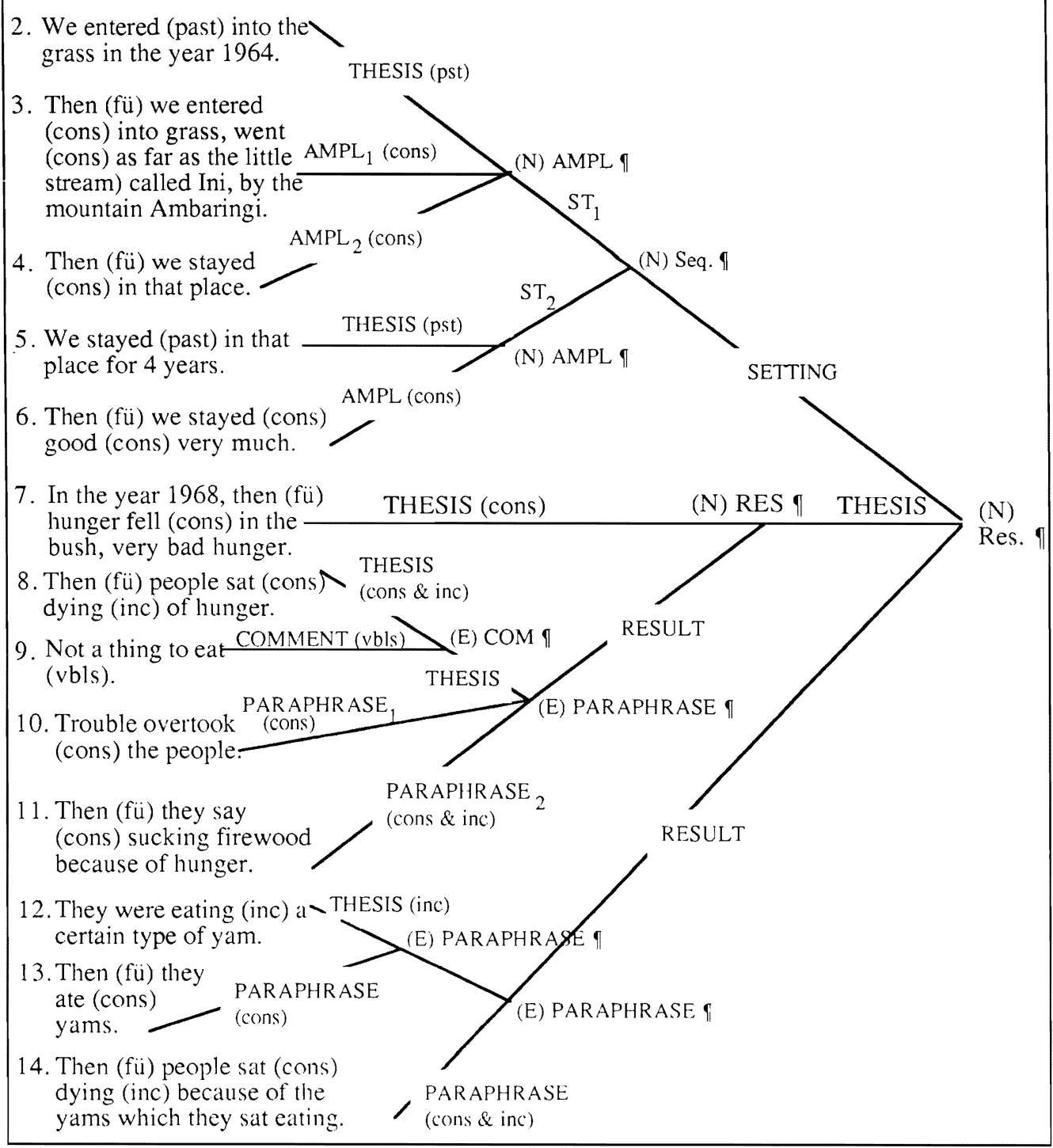

\section{Diagram II}


In Diagram II, sentences 2-4 constitute an embedded narrative amplification paragraph within which Sentence 2 with a past tense verb dominates over Sentences 3 and 4 which have rank-shifted consecutive tenses which depend on the preceding past tense of Sentence 2. Essentially Sentences 3 and 4 seem to expand upon Sentence 2. Sentences 5 and 6 seem to form another such embedded amplification paragraph in which Sentence 5 dominates by virtue of its past tense over Sentence 6 , which is ancillary and has a rank-shifted consecutive tense. The latter sentence functions as an amplification (maybe even simply a comment). Sentences 1-6 have past tense verbs in their theses, i.e. in the dominating sentences. They constitute an embedded narrative sequence paragraph in which 1-4 are sequential thesis ${ }_{1}$ and 5-6 are sequential thesis 2 . Since Sentence 7 seems to mark a fresh beginning (note the temporal phrase 'in the year 1968'), we assume that its consecutive tense verb is not dependent on anything else and is on the primary storyline of the narrative. Consequently, Sentences 2-6, whose highest ranking verbs are past, must be considered as ancillary to Sentence 7 (and whatever proves to group with it). We here consider Sentences 2-6 to be Setting of the paragraph and label Setting on the first main limb of the tree accordingly.

Actually, the only sentence in this paragraph which occurs on the primary storyline is Sentence 7, "In the year 1968, then (fii) hunger fell (consecutive) in the bush, very bad hunger." As we have seen, Sentences 2-6 are assigned to setting, and as we shall propose, Sentences 8-14 record effects of the onset of famine. This leads to interpreting the entire paragraph as a narrative result paragraph, i.e. a paragraph in which we do not find a series of primary storyline happenings but rather one such happening with recountal of the results.

The results in this paragraph do not seem to form a simple list but group into two embedded paragraphs, the first composed of Sentences 8-11 and the second composed of Sentences 12-14. Sentence 8 dominates within its unit. Its verbs are 'sat' in the consecutive tense auxiliary to 'dying' in the incompletive. This marks Sentence 8 as neither primary nor secondary storyline, but as belonging to band two (Background Activities). Clearly then Sentence 8 is off the storyline and must be interpreted as ancillary to Sentence 7 . We show the ancillary nature of Sentence 8 by making it a result of what is reported in Sentence 7. Sentence 9 is verbless, "Not a thing to eat," and belongs to an even lower band (band three). We group it with Sentence 8 as an embedded comment paragraph. Sentence 9 is so far removed from the storyline that we suggest that we have here essentially an expository instead of a narrative structure, hence the label "expository comment paragraph". Sentences 10 and 11 apparently paraphrase Sentences 8 plus 9 by emphasizing the severity of the famine. ${ }^{3}$ Although we have drawn Sentences 10 and 11 as coordinate paraphrases of Sentences 8 and 9. note that there is a difference of verb forms between the two, i.e. While Sentence 10 has a rank-shifted

3Sentence 11 does not literally mean "sucking firewnod" but is an idiom to the effect "so hungry" that they could suck firewood". 
consecutive tense-here dominated by the consecutive and incompletive in Sentence 8 (band 2)-we find Sentence 11 to have the latter tense sequence (Band 2) as well. Probably, therefore, Sentence 11 should be ancillary to Sentence 10, and then both as a unit ancillary to Sentences 8 and 9 . According to this alternative, we would obtain the subtree as given Diagram IIa.

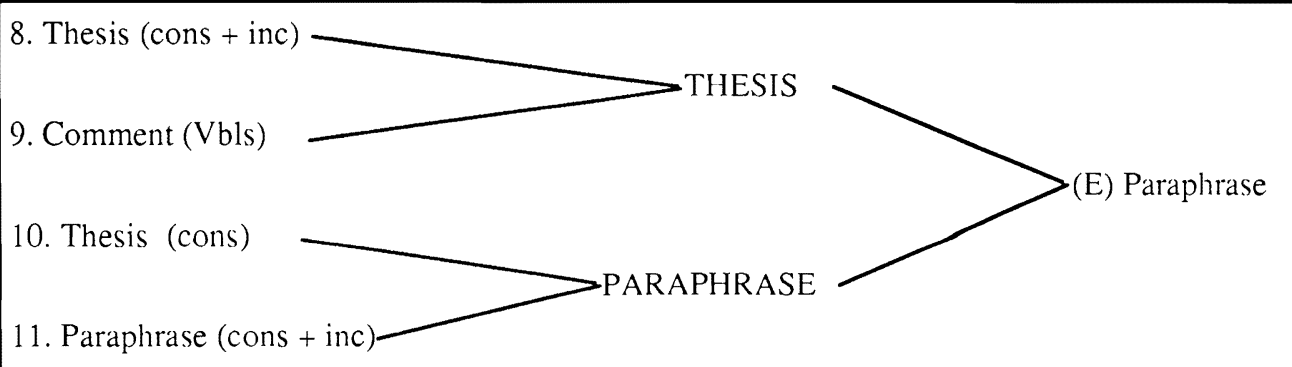

\section{Diagram IIa}

The remaining sentences of this paragraph, Sentences 12,13 , and 14, constitute a second result. Its dominating sentence, Sentence 12, is, however, of lesser rank than Sentence 8 which dominates Sentences 8-11. To show this difference in ranking, we have joined 8-11 first of all to Sentence 7 in a narrative result paragraph, then made the whole unit, Sentences $7-11$, a thesis in respect to $12-14$, i.e. we have grouped units with higher ranking verb structures over against a unit with a lower ranking structure: Sentence 12 has an incompletive verb and belongs to band 3 while Sentence 8 has a consecutive and incompletive and belongs to band 2 . Sentence 13 has a consecutive tense that is rank-shifted down in respect to Sentence 12 to which it is ancillary. Sentence 14 again is of lower rank, i.e. consecutive plus incompletive and is made ancillary to Sentences 12 and 13 in an expository paraphrase paragraph.

I believe that paragraph analysis carried out in accordance with the ranking scheme gives a plausible semantic exegesis of the paragraph which I will paraphrase as follows in English:

"We fled into the bush in the year 1964; we went as far as the little stream called Ini by the mountain Ambaring; we stayed there. We stayed there for four years, and things went very well for us. Then, in 1968, a very severe famine set in. Consequently people sat around dying of hunger-there was not a thing to eat, we were in terrible trouble; we were practically reduced to gnawing on firewood. A further result of all this was that people began eating a certain kind of yam, yes, they ate those yams-and then people sat around dying of the yams that they ate."

Against this example, with heavy embedding of paragraph structures and with rank-shifted sequences of consecutive tense, consider the next example, Diagram 
III, which has less embedding of paragraph structures and does not use rank-shifted consecutives. What consecutives occur are on the primary storyline in this paragraph.

Sentences 39, 40, 41, 42, and 44 dominate the paragraph. All of them except Sentence 41 have the consecutive tense. Sentence 41 has the past plus eyi completive and is not merely primary storyline but pivotal. It pictures the ominous event of the wounded buffalo charging the hunters from ambush.

Now, in detail, Sentences 37 and 38 are verbless clauses of band 3. We combine them into an antithetical paragraph which is expository rather than narrative, whose two sentences are equally weighted and which together constitute the setting of the paragraph. Sentence 39 is the first sequential thesis of the paragraph, "They went on their way (tracking the buffalo)." The next sequential thesis is expounded by a narrative coordinate paragraph composed of Sentences 40 and 41 . The main verb in Sentence 40 is consecutive (but without the fü 'and then' particle), and the main verb of 41 is slightly higher in rank (pivotal, i.e. past + eyi). While we coordinate the two they compose an end-weighted narrative coordinate paragraph in which the latter sentence outranks the former. Sentences 42 and 43 constitute a narrative antithetical paragraph which is fore-weighted. Sentence 42 with consecutive verbs outranks Sentence 43 which has the past of adu 'return' plus the incompletive and thus ranks as the secondary storyline. 4

It seems plain, however, that the two participants, the brother-in-law who was tall (Sentence 37) and the original tracker who was short (Sentence 38), are meant to be contrasted here even as they are contrasted in the setting 5 (Sentences 37-38). Finally, Sentence 44 gives the last sequential thesis of the paragraph; it is marked as climactic by means of the unusual connective kalasi 'and then' in sentence initial and by the long chain of consecutive tenses within a sentence. 6

\footnotetext{
${ }^{4}$ Alternatively, Sentence 43 could rank even lower if it were considered to be irrealis, i.e. "the man tried in vain to climb a tree". However, even as irrealis, this seems to be a momentous failure on which hinges the outcomes of the story. Consequently, we probably do not want to rank Sentence 43 as low as band 4 .

5 Furthermore, were there any doubt that the two trackers are meant to be contrasted in Sentences 42 and 43, a fine detail of Mündii structure seems decisive here, viz. the fact that in Sentence 42 there is a shift to the second person in the Miindii text: "Man, brother-in-law, you managed to climb a tree." Jeffrey [1983] specifically cites the use of a second person to refer to a third person as a device to contrast participants.

${ }^{6}$ The parallel to SOV chaining languages of Ethiopia is very close to this point. An unusually long sequence of medials maly precede a final at peak in those languages. Here, in a Niger-Congo language of SVO structure, an unusually long sequence of consecutive clauses can mark peak. The effect is the same: that of a quick moving action sequence.
} 


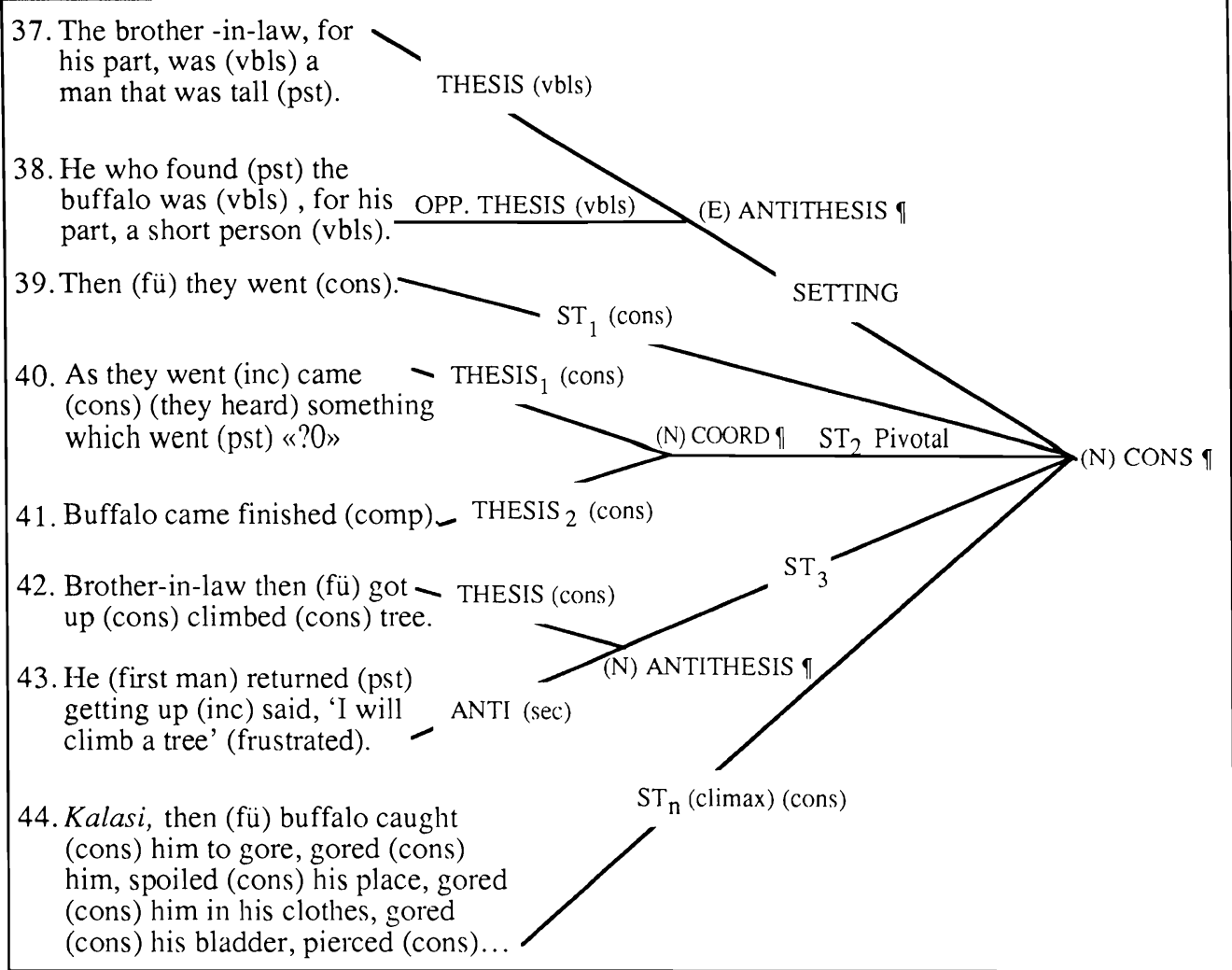

\section{Diagram III}

This paragraph, which has a straightforward sequence of actions/events, (1) preposes an antithetical paragraph in its setting. Here, the heights of the two hunters are contrasted. (2) It has four sequential theses of which $\mathrm{ST}_{1}$ is a simple one-clause sentence while $\mathrm{ST}_{\mathrm{n}}$ is a climactic multi-clausal sentence. (3) It coordinates in $\mathrm{ST}_{2}$ the sound of something snorting and the buffalo's unexpected charge, but marks the latter as the more substantive and pivotal. (4) It contrasts in $\mathrm{ST}_{3}$ the brother-in-law's success in climbing the tree to safety with the other man's ineffectual attempts to find such shelter.

I have tried in presenting these two Mündü paragraph analyses to emphasize again that verb ranking is not an end in itself but serves as a set of constraints for paragraph analysis. I have furthermore attempted to show that paragraph analysis is likewise not an end in itself but ties into the exegesis of texts. Verb ranking becomes therefore a tool of hermeneutics. 


\section{Nzema (Kwa Niger-Congo)}

Nzema (data from H.M. Rowson) has a consecutive tense whose occurrence is dependent on the prior occurrence either of a past tense or of an historical present, i.e. the Nzema consecutive tense requires an initial form on which it is dependent. ${ }^{7}$ In this respect Nzema is unlike both Luwo (Nilotic) and Mündü (Eastern NigerCongo) where the consecutive form in and of itself bears the primary storyline but can be rank shifted following various non-storyline initial forms (see previous chapter and Section 1 above of this chapter).

2.1. Storyline scheme elements. The storyline preterite-consecutive sequence is illustrated below.

(10) ohopele baka odole kome zo;

he-went/cut-past a-stick he-put-past his neck on

yeava nyema bie yeale o sa nu.

he-then-took rope some he-then-held his hand in

${ }^{7}$ Rowson summarizes the relevant Nzema tense forms as follows:

I. Verbs have two stems, e.g. fa (first stem), va (second stem).

II. Verbs can have either a thematic person prefix, e.g. o- 'he, she, it', or a sequential person prefix, e.g. ye- 'he, she, it'.

III. The preterite:
e.g. o-
them.per. +2 nd stem
+ past suffix
va-
le
'he took'

IV. The consecutive tense:
e.g. ye-
seq. per. $+\underset{a^{-}}{\text {seq. marker }}+\underset{v a}{2 n d \text { stem }}$
'he then took'

V. The historic present:
them. per. + first stem
e.g. o-
fa
'he takes'

VI. The progressive:
e.g. 2 -
them. per.
$+p r$
first stem
ko
'he is going'

VII. Iterative/progressive:
e.g. o-
them. per. + reduplicated first stem totooto
'he keeps turning'

VIII. The perfect:

seq. per.
e.g. ye-
va
va

'he has/had taken' 
'He went and cut a stick and put it on his neck; then he took some rope and held it in his hand.'

Here the first two verbs, ohopele and odole, are preterite and are on the primary storyline. They group together here in a closely-knit unit. The sentence continues with two consecutive verbs which continue the primary storyline: yeava and yeale.

The historic present, progressive, and iterative forms figure prominently in Nzema narrative (at least in the folktale) where they function not so much to advance the storyline as to slow it down and create suspense-what Rowson describes in reference to one text as "an eyewitness account of what is essentially temporally unordered activity within a single storyline event span." She notices the absence within such a span "of conjunctions na, akee, and yec which signal movement along the storyline." Thus, she gives the following example:

(11) [The hero is approaching the place where many pythons live.]

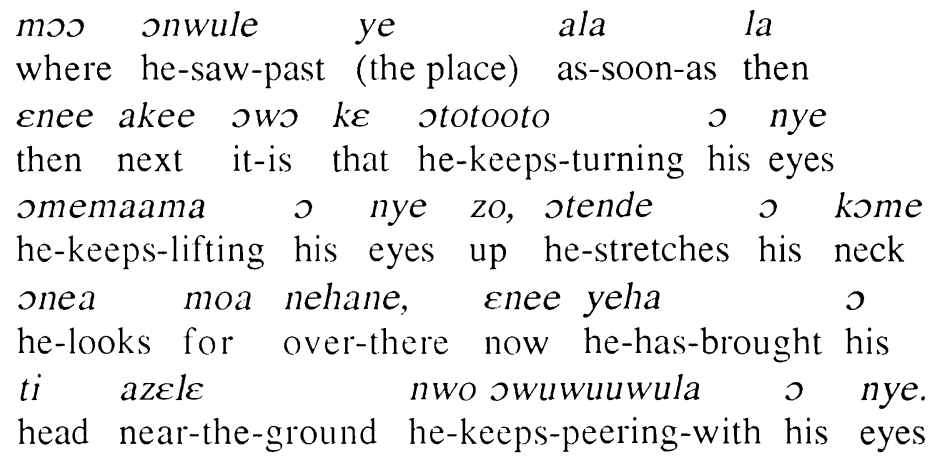

'As soon as he saw the place he kept turning his eyes, lifting his eyes up, stretching out his neck-as he looked over there. Then he lowered his head to the ground and kept looking with his eyes.'

The past time orientation is given in the initial adverbial clause by the form onwule 'he saw'. The conjunction enee 'now' plus the strongly cataphoric akee 'next' plus the topicalizer $\supset$ wo $k \varepsilon$... 'it-is-that...' introduces the string of iteratives and historic presents that follow. Rawson argues here that both the adverbial clause, which presents a cognitive event 'he saw', and the cataphoric topicalizing construction have "triggering" and promoting effect on what follows. If this be true, then it can be argued that the iterative and progressive forms are promoted to storyline status where they constitute a "pseudo storyline", i.e. while the storyline is not advancing the effect of a crowded storyline is conveyed. The iterative forms here are glossed with 'keep', while the historic presents are simply glossed as present tenses. There is a perfect form ycha 'he has brought' in the next to the last 
clause. It is presumably backgrounded in respect to the iterative form owuwuuwula 'he keeps-peering-with' in the last clause.

For (unpromoted) background activity, Rowson cites progressive forms with the prefix $l \varepsilon$-. In the presence of the conjunction $\varepsilon$ nee, progressive verbs indicate simultaneous activities, as in (12).

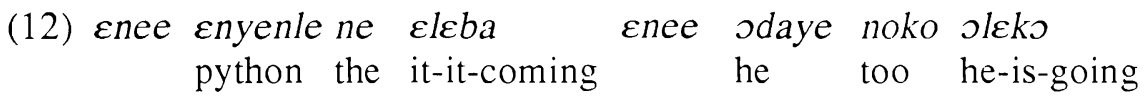

'The python was advancing as the hero was going [to meet him].'

The perfect is typically used for a backgrounded event and flashback. Rowson observes, "A string of perfect aspectual clauses intervening between a past tense (preterite) setting adverbial clause and a storyline verb seems to background certain events by moving them into past time relative to the temporal setting of the main storyline events." Thus, at the beginning of a story certain backgrounded and prior events are mentioned as considerably earlier than the time of the storyline but relevant to the story. Flashback within the story itself is marked more elaborately, i.e. by $\varepsilon$ nee 'now' plus a perfect aspect verb plus the adverb debadeba 'earlier'.

Setting is given in 'be' clauses and stative clauses for the most part. Rowson posits that a whole initial section of storyline can, in effect, be demoted to setting by following it with $\varepsilon$ nee 'now' + the strongly cataphoric akee 'next' + the topicalized owo ke... 'it-is-that...'

2.2. The storyline scheme. Without describing or illustrating any more narrative features of Nzema, I give in Diagram IV a storyline ranking scheme along the general lines suggested by Rowson.

I have a few comments on this rank scheme: (1) Rowson indicates that the consecutive tense can also occur after a progressive in band 4 , but apparently cannot follow a perfect in band 3; (2) one form of the purpose clause is the coordinator na (which usually joins like verbs) before the consecutive tense. Notice that both these comments suggest expanded roles of the consecutive tense (a) as rank-shifted down (thus in many languages) and as having modal properties in clause contexts. (cf. certain other West African languages.)

Especially lacking in my summary of Rowson's work in Nzema is her careful accounting for various types of conjunctions and their role in Nzema narrative. 


\begin{tabular}{|l|l|}
\hline Bands & Verb/Clause forms \\
\hline \hline $\begin{array}{l}\text { 1. Primary storyline } \\
\begin{array}{l}\text { (dynamic, and with pro- } \\
\text { per initiators can be pro- } \\
\text { moted to storyline) }\end{array}\end{array}$ & Preterite \pm consecutive tenses \\
\hline $\begin{array}{l}\text { 3. Backgrounded events/ } \\
\text { flashback }\end{array}$ & Perfect (near beginning of story) \\
\hline $\begin{array}{l}\text { 4. Backgrounded/simulta- } \\
\text { neous activities }\end{array}$ & $\begin{array}{l}\text { Progressives (in independent or in adverbial } \\
\text { clauses) and iteratives }\end{array}$ \\
\hline 5. Setting & $\begin{array}{l}\text { 'be'verbs or statives } \\
\text { demoted piece of storyline (before } \varepsilon n e e+ \\
\text { akee }+ \text { ows ke 'now then it was that...' })\end{array}$ \\
\hline 6. Irrealis & $\begin{array}{l}\text { Negatives } \\
\text { Purpose clauses }\end{array}$ \\
\hline 7. Author intrusions & Imperatives/exhortations \\
\hline 8. Cohesion & Back-reference \\
\hline
\end{tabular}

Diagram IV. Nzema storyline ranking scheme 


\section{Obolo (Lower Cross Group Niger-Congo)}

Obolo (data from Uche Aaron) has several ways of connecting clauses and complexes of clauses into more inclusive sequences: (1) serial verb constructions occur, in which there is no interior connective such as mè 'and'; (2) clause chains (which like serial constructions have the same subject and tense/aspect/mood) occur with the connective mè 'and' which joins successive clauses; (3) a sentence, the fundamental building block of Obolo paragraphs, can consist of a single clause, a serial verb construction, a clause chain, or a clause chain which contains one or more serial verb constructions. A sentence can, furthermore, contain parenthetical elements that interrupt its flow but do not terminate it.

3.1. Initial and consecutive structures. The distinctive verb of a sentence determines the storyline status of the whole, although embedded and parenthetical units may be of different status. Thus, for example, there is a background activities band characterized by a variety of verb formations all of which have a $k i$ continuative morpheme in the initial verb. Storyline verbs, which do not have this element, mark a three-way functional distinction having to do with the segmentation of the narrative. Again, it is the form of the initial verb which marks this distinction. (a) Pivotal sentences are important turning points of the story. (b) Initiatory sentences (not to be confused with initial verbs or initial clauses) occur after a break in the narrative (change of script); when reinforced by a paragraph marker such a sentence also marks the beginning of a new paragraph. (c) Sequential sentences, which are neither pivotal nor initiating, mark neither a turning point of the story nor a further segment of it, but simply track on after one of the other storyline forms.

As to the formal distinctions among the three, note Diagram $V$ which summarizes features of clause chaining and the distinctive markings on initial verbs in the three sorts of storyline sentences.

Thus, the initial clause of a pivotal sentence reduplicates the verb stem within the verb phrase, while the initial clause of a sequential sentence may (but need not) reduplicate the auxiliary within the verb. Initial clauses of initiatory sentences reduplicate neither the verb stem nor the auxiliary, but have different pronominal markers on the verb, i.e. instead of the subject pronoun, or $i$ - as in pivotal and sequential, they have $\hat{\imath}$ in the singular and $m \hat{\imath}$ in the plural. All succeeding clauses in such chains have mè 'and' but only the final clauses in such chains may have an auxiliary on the verb. (See Diagram $V$.)

It is clear here that the overall design which is evident in these Obolo structures is the structural cleavage between an obligatory initial verb in initial clauses and consecutive verbs in consecutive clauses. This is the characteristic feature of narration in Obolo. This overall structure is elaborated (1) to include serial verb 


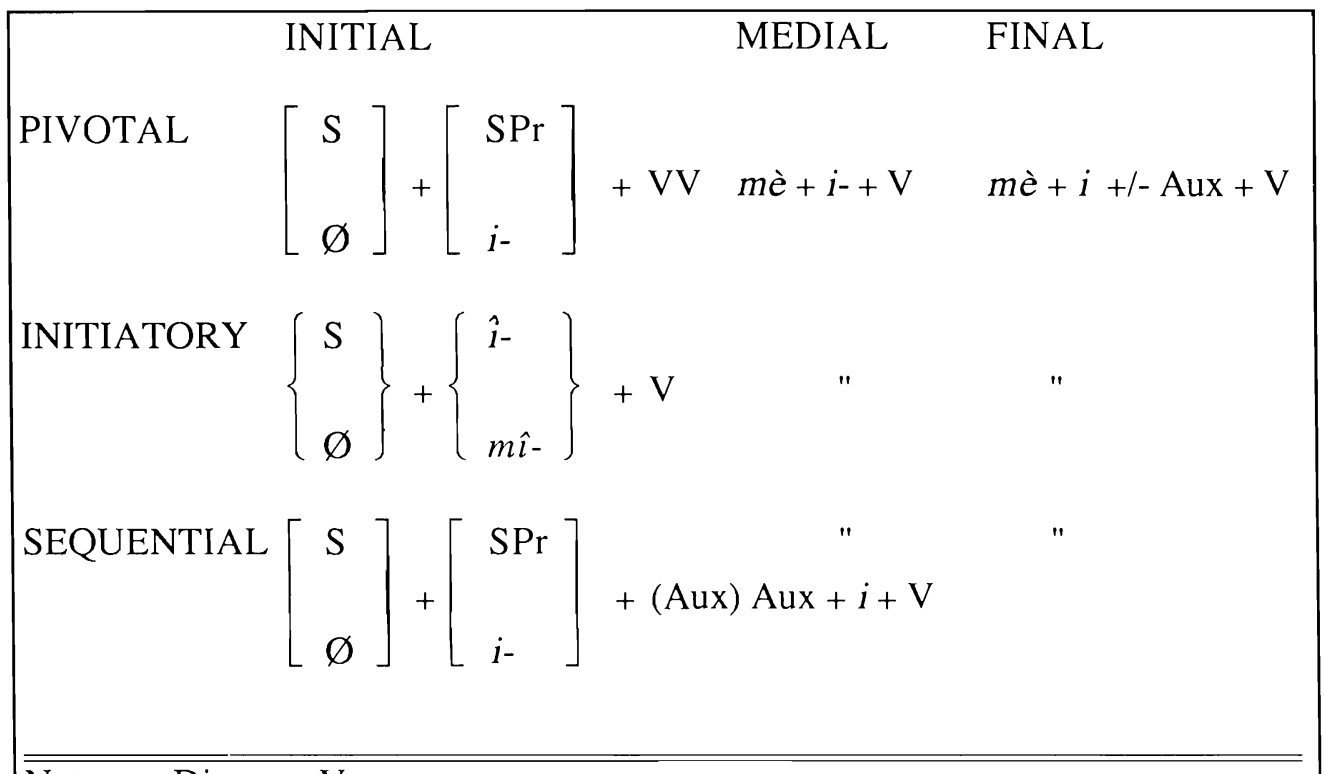

Notes on Diagram V:

1. On the left hand side, $S=$ overt subject noun, $\varnothing=$ lack of such a noun.

2. $\mathrm{SPr}=$ subject pronoun (co-occurs with subject noun): $i$ - prefix which occurs when there is no $\mathrm{S}+\mathrm{SPr}$

3. $\hat{\imath}-, m \hat{\imath}$ are singular and plural subject markers respectively; they occur whether or not there is $\mathrm{S}$

4. $m e ̀$ = 'and'

5. $\mathrm{VV}=$ reduplicated verb stem, (Aux) Aux = optional reduplication of the auxiliary

Diagram V. Clause chain structure in Obolo storyline sentences

constructions as a more cohesive unit than the clause chain and (2) to distinguish initial clauses, which classify storyline sentences in various functional ways having to do with highlighting and segmentation. A further detail, unattested in any other language with a consecutive verb, is the weak marking in Obolo of the final clause in the chain as well, since the auxiliary can occur only in the final clause not in the preceding consecutive clauses. 
(13) Ikwut onộno mè inifo.

Tortoise he-heard and come-go-home

'The tortoise heard and went home.'

In this example the verb stem with onộno 'he heard' is reduplicated and mè introduces the final clause in the chain with the auxiliary 'go' fused with the verb stem 'come'. The event represented here is pivotal: the tortoise has managed to obtain a crucial piece of intelligence that will shape his strategems for the remainder of the story.

(14) ichêchî̀k

he-agreed

This is also a pivotal event as seen by the reduplication of the verb stem. This sentence is a one-verb, one-clause chain that tersely represents an action that led to the breaking out of warfare between the Obolo and the Bonny peoples. An Obolo man agreed to sell the Bonny a fish that he had just caught, but they were to take it and refuse to pay for it and get somewhat violent about their refusal.

3.2. Exemplification. An extended example follows:

(15) 1. îmọ̀nọ mkpo ya itàp me uji he-took thing that put in canal

2. mè itàp ukook kàñ, and put hooks his

3. mè itàp òtĩn ibat me uji and put pot mud in canal

4. mè ikọbo ibat... itap ijot òtĩn yà... and scooped mud put full pot that

5. mè itàp muñ me lck and put water on body

6. mè iyik òtiñ cha mè ukañ and placed pot that on fire

7. mè ikitem and was-cooking

8. mè ikaan ǹkom òjôjọnọ̣ and have ladle long

9. mè ikitem mkpo yà and was-cooking thing that

10. ibat yà okêkiriak. mud that was-boiling 
This whole example can be freely translated, "He took the thing (drill) and put it in the canoe; and he put his hooks in; he put the mud in the pot in the canoe; he scooped the mud and filled the pot; he put water on himself; he put the pot on the fire-where it kept cooking-and he took his ladle while the thing cooked away; the mud kept boiling."

The preceding example is a very long chain within a sentence which describes the protagonist's preparations for revenge on his enemy. The initial clause 1 marks the whole chain as initiatory rather than pivotal or sequential. It has the characteristic $\hat{\imath}$-singular prefix and reduplicates neither the verb stem nor the auxiliary. Clause $\mathbf{1}$ also apparently contains a serial construction, îmọnnọ 'he took'...itàp 'he put'. The following clauses are all consecutive and marked with mè except that $\mathbf{4}$ also contains a serial construction ('scooped up...put'-I have omitted some extraneous explanatory material). Clauses 7 and 9 are not storyline; rather their verbs ( $i$ ki tem 'was cooking') contain $\mathrm{ki}$-continuative and indicate permissible digression from the storyline within the same sentence. Clause $\mathbf{1 0}$ is an amplification clause which does not have mè 'and' since it is essentially a kind of paraphrase, i.e. 'was boiling' paraphrases 'was cooking'. The verb of clause $\mathbf{1 0}$ is also continuative.

(16) 1 . ọmmộ onêni sibi ìjòn,

he came out land

2. mè imọmmọ mkpọ... ikaañ me ubọk

and took thing have in hand

isi iriak ibot kàñ me agba uji yà

go near head his at side canoe that

3. mè ilèt

and hide

4. mè isà itòoñ

and take place

5. mè iyaka edìm uji itibi.

and turn toil canoe bare

'He came out on land, took the drill, and went near the front at the side of the canoe; he hid, selected the place, and drilled into the canoe.'

In (16) the reduplication of the auxiliary 'come' 8 in clause 1 marks this sentence as sequential rather than initiatory, i.e. it does not occur at a break in the story but continues on in this paragraph or script span. Clause 2 is probably a long serial 
construction since it lacks a mè ('took...had///went'). Clause $\mathbf{5}$ is probably also a serial construction for 'to drill' ('turned... bore').

I do not include here a rank scheme diagram for Obolo. Aaron's scheme is comprehensive, detailed, and plausible. It deserves presentation and publication in its own light by Aaron himself. As already mentioned, there is a background activities band which has a variety of verb formations, all of which have in common the presence of ki-continuative. This is illustrated by clauses $\mathbf{7}, \mathbf{9}$, and $\mathbf{1 0}$ of (15). Other bands, i.e. flashback, setting, irrealis, author intrusions, and cohesion, are much as illustrated in other languages elsewhere in this volume.

\section{Tem, also called Kotokoli (Central Gur Niger-Congo)}

Tem (data from Bob De Craene) has a consecutive verb form which is somewhat more restricted in use than are the consecutive tenses in Mündü, Nzema, and Obolo. The rank scheme status of the consecutive verb form depends on the status of the initial verb which precedes it. In this respect the consecutive is potentially of general use. Its use is restricted by the fact that storyline occurrences of the consecutive verb form occur in sequence with the preceding verb (perfective) in ways more reminiscent of serial verb formation than of verbs in free sequence.?

4.1. The perfective and the consecutive. Thus, as in the following example, there can be a considerable stretch of text in which perfective forms succeed each other reinforced with nge 'and then'.

(17) 1.... máázín ứ naárv

I-met (per) man certain
2. nge méćzéć yl.
and-then I-greeted (per) him
3. nge $\quad$ sl:...
and-then he-said (per)
4. méégbédíná yı.
I-took (per) him
$\begin{array}{llll}\text { 5. nge } & \text { máázíl } & \text { yl } & \text { Yelívós. } \\ \text { and-then } & \text { I-put (per) } & \text { him } & \text { at-Yelivo }\end{array}$

'...I met a certain man and greeted him. Then he asked me [for a ride]. I took him along, then left him off at Yelivo.'

${ }^{9}$ I do not include here a summary of the morphological distinctions between the perfective and the imperfective in Tem. The formal patterns are distinct between the two aspects. Cf. De Craene [1986]. 
In (17) all the verbs are perfectives with frequent use of $n g \varepsilon$ 'and then'.

The following example, a composite one, gives several examples from the same text of perfectives followed by consecutive forms (which are underlined):

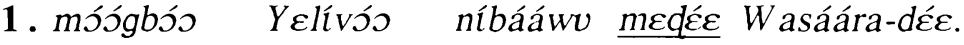
I-took (per) the Yelivo road I-went to Wasaara.

'I took the Yelivo road and went to Wasaara.'

$\begin{array}{llll}\text { 2. nge } & \text { móógbóo } & \text { megbená } \\ \text { and-then } & \text { I-took (it) (per) } & \text { I-went-with } & \text { home }\end{array}$

'And then I carried it home.'

3. máádásı mogódokl ki belé... hálı mogoná daána I-added (per) I-held it thus until I-came-with home

'I kept on pushing it (bicycle) all the way home.'

$\begin{array}{llll}\text { 4. bıdée wíre bıtbá } & \frac{\text { bıkánıl ma. }}{\text { its day it-certainly(per) }} \text { me }\end{array}$

'That day I certainly got tired out.'

In 1 above, 'to take a road' and to go somewhere on it seem to be closely associated. In 2, 'take' + 'go' patterns as the Tem equivalent of "to carry something" in English. In 3, the perfective form máádást 'I added', while grammatically dominant over the consecutive form mogódokl 'I held', seems to be lexically a qualifier of it, i.e. 'I added' + 'I held' = "I kept ahold of it"). In 4, again the perfective verb bubá functions much like a qualifier of the following consecutive. Notice also in $\mathbf{3}$ the modal use of the consecutive form in the clause 'until I reached home'.

4.2. Other uses of the consecutive tense. The same text illustrates the consecutive form used, after an exhortative form within a quotation:

(19) [He said that] tóo, mówo yúu ımú ge mogbóo

! I-should-roast rat the is I take

megégbéna cé mána menewáa ditóo.

I-go-home-with here me-and my-little-brothers we-eat 
'[He said that] I should roast it; I should take it home, and my little brother and I should eat it.'

Here, the initial verb is a special modal exhortative form mówo 'I should roast', and the following consecutives are also taken to have the same force. Notice that while 'take and go home' (= "carry") are closely associated semantically, the last clause involves a subject change and cannot therefore be so closely grouped with what precedes and may grade off into a purpose construction.

That the consecutive form is of quite general use is seen in De Craene's mentioning that the consecutive can follow the imperfective both in the background activities band and in subordinated clauses in the setting band (where $s l+$ the consecutive has a future reference, "when he was going/about to do X"). Here the consecutive very definitely grades off into future/modal uses.

4.3. Storyline scheme features. De Craene's salience scheme (which I do not reproduce here) is quite straightforward. It involves the following bands: Storyline, Background (activities), Flashback, Setting, Irrealis, Author Intrusion, and Cohesion. De Craene puts Setting and Cohesion as continuous since certain subordinate clauses seem to function in both bands. I feel that here, as in most languages embraced in this survey, a split is necessary as to whether a clause introduces new information, information that is script predictable from the last main clause, or is simply backreferential. At any rate, setting of a less ambiguous sort is given in what is simply a longer or shorter stretch of expository discourse with the typical use of 'be' verbs, statives, and verbless clauses that characterize the static quality of exposition in most languages.

\section{Yom or Pila-Pila (Gur Niger-Congo)}

Yom (data from Dorothy Forsberg) is spoken in the Benin Republic. This language has a consecutive tense (see end of footnote 10) with the following characteristics: (a) it occurs only when following an initial verb (most frequently the perfect) in serial constructions; (b) it is on the storyline when the verb which governs it is a storyline perfect. Since perfects occur in more than one function and in fact are scattered over several rank scheme bands, a focus of interest in Yom narrative discourse lies in distinguishing the various uses of the perfect. 10

${ }^{10}$ Forsberg, following Beacham [1968], gives the following summary of the most frequently occurring tense/aspect forms in Yom:

"The perfect shows completed action. Yom has several classes of verbs. So the perfect and other aspects are not readily recognizable by a single marker. Depending on the class, a verb in the perfect aspect will have the following suffixes: $-r,-\varnothing(),.-i i,-n$. The continuative or progressive aspect shows action that continues, and is marked by $\emptyset$, or - $a$.

"The consecutive or potential aspect is the basis for the primary classification of verbs in the 6 classes (these are further subdivided by tone pattern) having these suffixes: $\varnothing,-i,-a,-i i,-a a,-n a$. This aspect does 
5.1. The perfect and the consecutive as storyline tenses. The storyline perfect is characteristically preceded by a clause-initial time phrase or by a conjunction. The former regularly comes near or at the beginning of a story and the latter within the body of the discourse. The storyline perfect may be followed by one or more consecutive forms.

(20) [This sentence occurs after the stage of its story, i.e. after a paragraph whose verbs are continuative.]

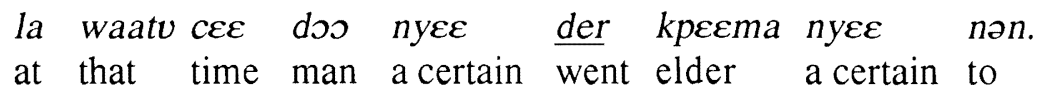

'At that time a certain man went to see a certain elder.'

Here the verb of the sentence der is perfect and is preceded by a time phrase.

(21) nonda a zendo a banya ka tusə da-jərya cəya

at-that he raised his spear and poked wood-piece that

'With that he took his spear and poked the piece of wood.'

Here the main verb, a perfect, is in a clause introduced with nonda 'at-that'. The consecutive form ka tusa 'and then he poked' is governed by the preceding perfect and both verbs are therefore storyline.

The conjunction $l \varepsilon$ 'and then' can likewise introduce a storyline perfect as in the following example.

(22) le a dan ka yer ka nyəgga.

then he came and saw one

'And then he came and saw one.'

not figure in [the framework of (REL)] narrative discourse, appearing only in quote material [and in awareness quotes, purpose clauses, and a few other sorts of verb complements (REL)]. A fourth aspect is the aorist or indefinite which, in itself, carries no particular reference to time or manner of action. It appears in verb serialization and takes on the time and manner of the first verb in the series and indicates successive actions or events... The form of the aorist again varies according to the verb class..."

For the purposes of this chapter, I refer to Beacham's "aorist" as the consecutive tense. What he terms "consecutive" is a construction which has special modal or quasi-modal usages. 
5.2. Storyline tenses at peak. In the peak region of a story (and perhaps in the inciting incident as well) the verb nyosa 'to see suddenly/unexpectedly' may occur as a perfect without a conjunction. But even here a conjunction-like backreference often occurs to give a backreferential contextual connection.

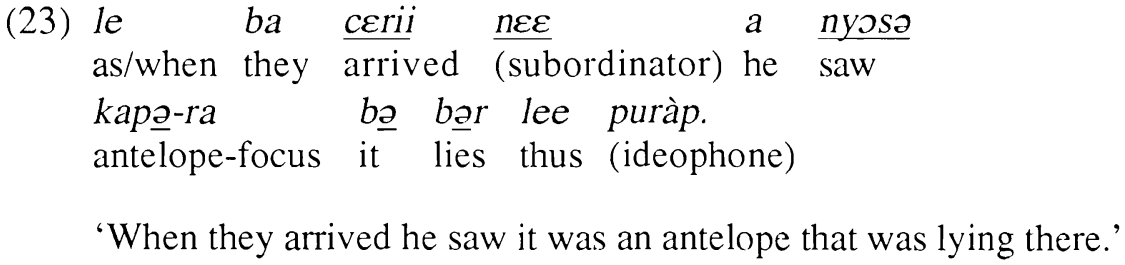

The peak of a story can also resort to the use of ideophones as seen in the use of puràp above (in a clause with a continuative verb). Compare also the use of an ideophone in the following.

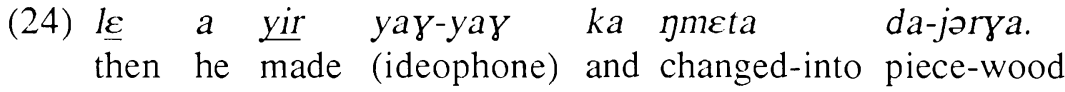

'And then he was frightened, and changed himself into a piece of wood.'

The peak of a story can also be indicated by a decided increase in the use of the consecutive tense.

I have illustrated in the above examples perfect and consecutive forms on the storyline plus some special structures which involve the verb 'see suddenly/unexpectedly', ideophones, and increased occurrence of the consecutive tense, with the latter features marking peak.

5.3. Perfect and consecutive off the storyline. Before proceeding on to illustrate other functions of perfects and the consecutives which depend on them, I submit the following summary of Forsberg's description of a rank scheme for Yom:

Taking the storyline-band as rank (1), there are (2) the background band with the perfect without a preceding conjunction (backgrounded event) and $k a$ ' while/as' + continuative, often with a durative adverb (backgrounded activities); (3) flashback, the clause la man it found/happened that' in the perfect followed by its own storyline verbs; (4) description/setting, with verbs of being and having (= 'to be with') and stative verbs; (5) irrealis, involving negative constructions and "if" clauses which usually take the perfect; (6) cohesion, with backreference by means of subordinated clauses ending with the particle nee and often introduced by le 'since/as' (this verb is in the perfect); and (7) evaluation/interaction with explanations, proverbs, and morals. 
It is evident that the perfect occurs in various places other than in the storyline band. When it occurs in any non-storyline situation, the consecutive clauses that it governs are also non-storyline. I proceed now to illustrate some of these possibilities.

(25) ba te on ba ne kpirwa-ra

their father and their mother died-focus

ka caa ba ba bali.

and left them they two

'Their father and mother had died leaving just the two of them.'

Here the non-occurrence of a conjunction in sentence initial marks this event-the death of the parents and the orphaning of the children-as background to what follows. The use of the focus particle presumably labels it, however, as highlighted background. The first verb kpirwa-ra 'died-focus' is perfect and the second verb caa 'left' is a consecutive form which depends on the perfect.

(26) la man Woru lor poya zandanga.

it found Woru finished wife taking

'It so happened that Woru had already taken a wife.'

Here the perfect, marked with la man, functions as a flashback.

kà a jir biroonga tiu a
if/when he ate disappearing medicine he kaa yakərən moska kpecn. will not be afraid of capturing again

'Whenever he takes the disappearing medicine he won't again need to fear capture.'

Here, with the kà 'if/when' structure in a conditional sentence (whose apodosis has the modal form yakərgon) the perfect is irrealis.

(28) le ka dan ka toka u ka as/when he came and approached him and guundii a non nee le a attack/pounce his place (sub) and/then he 
yir yay-yay ka jmeto da-jərya.

became frightened and changed-into wood-piece

'When he came and approached him and attacked him, then he jumped with fright and turned into a piece of wood.'

Here the particle nec subordinates the whole preceding string of clauses, i.e. the clause with the perfect dan 'came' and the clauses with toko and guundii, which are consecutive verb forms. The perfect is here demoted by grammatical subordination, as are also the consecutive forms which are governed by the initial perfect. Note also that $l e$ 'since/as' is distinct from the common conjunction $l \varepsilon$ 'and'. Forsberg considers that $l e$ 'since/as' is a further feature characteristic of the general region of the peak of a story. Elsewhere back references subordinated with clausefinal nec (no gloss-purely gramatical) occur without this clause-initial element.

The above examples illustrate how in some languages a given tense/aspect form does not in and of itself mark the storyline of narrative. Rather, a given tense/aspect plus the requisite conjunctions/particles is necessary to the marking of the storyline (cf. Murle in Chapter 2).

5.4. The continuative. Other aspects than the perfect do, however, occur in narratives as is seen above in (23) in the clause

bo bor lee puràp
it lies there (ideophone)

Here the verb is a continuative in the setting band. Consider the following extended example (the stage of a discourse):

(29) to teemba waat Zarmasa on Barwa yaa

our fathers' time Zermas and Baribas used-to

dana to tungu-ra on ba samso ka

come our town-focus with their horses and

jer bansə $k a$ cey norwa ka moy $k a$

hold spears and steal people and catch and

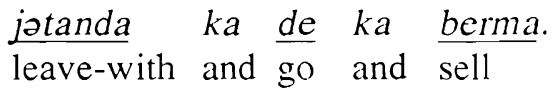

'In our father's time it was the Zermas and the Baribas that used to come to our town with their horses and spears to catch and steal people and take them away to sell.' 
Here all the underlined verbs are continuative and are joined by $k a$ into a serial construction. It is noteworthy that all the verbs are continuative rather than continuative plus consecutive. There is no rank shift of the consecutive tense as such in Yom. Rather, we find varying uses of the perfect which more than any other tense/aspect form governs the consecutive.

\section{Belanda Viri (Eastern Niger Congo)}

Belanda Viri (data from David Tani) like Mündü, is an Eastern Niger-Congo language. It has an elaborate tense/aspect system which is elaborated via auxiliary verbs and particles. Actually it has no simple unmarked form that could readily be called a special narrative tense nor a special consecutive tense. The primary storyline is marked by a form inflected with $t i$ 'be' plus 'dii 'come' that Tani calls a "present continuous" but which he recognizes as a "sequential" form in narrative. It seems reasonable to believe that this marks the primary storyline in the same way that historical present tenses mark the storyline in some types of narrative in IndoEuropean languages. Nevertheless, two Belanda Viri forms occur which are possible candidates for a consecutive tense or tenses.

6.1. Storyline form plus uninflected verb clause. (1) There is a close-knit combination of clauses, probably typical serial constructions, in which the storyline form ( $t i$ ' $d i i+$ verb) is followed by same subject clauses whose verbs are uninflected stems. This construction is sufficiently rare that it does not occur in the main text on which Tani based his write-up. He had to resort to a different text to exemplify it. Nevertheless, it illustrates a type of consecutive tense used in serialization.
(30) Kpere
ti'dii kara to
monitor (lizard) become turn itself
ro Uko'do jofo 'de.
bit beetle consumed-it up
'The monitor turned, bit the beetle, and ate it up.'

6.2. "Coordinated" clauses as consecutive. There is a more loosely-knit and generally used structure in which $t i$ ' $d i i$ + verb clauses are followed by 'dii + verb clauses. Two clauses or sentences thus juxtaposed are coordinated. Thus, in the "Hippo and Fire" story (from which Tani draws most of his examples) we have such coordinated sequences as the following:
(31)
$W i$
ti 'dii
'dai,
'dii
dii
suu suu
ti Firi.
fire be come
burned come came
very close
to Hippo 
'The fire burned and came very close to the hippo.'

Here the clauses with 'burned' ( $t i$ 'dii 'dai) and 'came' ('dii dii) are coordinated.

The preceding example is, however, approaching the peak of the story and the grammar becomes somewhat more involved than in routine narration. Correlating with this is the fact that still a further clause (in fact, the next sentence) is also coordinated with the sentence given in the above example.

(32) fofo Wi to 'dii yingi

heat of fire itself come began

a go lo ngooo Firi tanjo

to pain shank leg Hippo and

tìlì ndi ki.

face their has

'The heat of the fire began to affect the legs and the face of the hippo.'

The final particle, given the translation "has" in this text appears to mark pivotal events of the story.

The following example of coordination, also across sentence boundaries, involves the verbs 'send' (an invitation) and 'reach/arrive' (the message):

(33) tabiiwo, Firi ti 'dii yoro tu ndi Wi vee...

one day Hippo be come sent an invitation to Fire

tu ndi Firi 'dii yaa dii ti Wi ki.

the message Hippo come reached came the Fire has

'One day the hippo sent an invitation to the fire...The hippo's messages reached the fire.'

Note also, in the above, the occurrence of the tense particle $k i$ on a sentence (or on a coordination of sentences?) that marks a pivotal event early in the story.

It appears that, since clauses marked with 'dii + verb are coordinated with $t i$ ' $d i i+$ verb storyline forms, the former constitute a consecutive tense. They constitute, however, as already observed, a looser level of association than the tightly knit constructions with uninflected verbs as illustrated in (30). Probably, the latter are more properly viewed as serial verb constructions.

6.3. Non-storyline elements. Dissimilar to both the above constructions is a construction in which $t i+$ verb follows a clause with either a $t i$ ' $d i i+$ verb or a 'dii + 
verb. The $t i+$ verb construction does not appear to be storyline. Rather, it amplifies or is epexegetical of the preceding storyline form.

(34) Wi ti 'dii 'doo gu'du,

fire be come became surprised

ti jaagbinjoo ti teritei ta so vee.

be complaining be reckoning the fact that

'The fire became surprised, complaining and reckoning that fact.'

Here two $t i+$ verb clauses follow a $t i$ ' $d i i+$ verb construction.

$\begin{array}{llllll}\text { 'dii } & \text { katei } & \text { ti roo } & \text { ta njiii gbidifo ndoo. } \\ \text { (and he) come remained be standing in his courtyard }\end{array}$

'(And he) remained standing in his courtyard.'

Here the first verb given (a 'dii form) is coordinated with a $t i$ 'dii form in the previous sentence, while the clause beginning with ti roo amplifies and explains the coordinated verb which it follows.

Besides the storyline bands which are illustrated above and the $t i+$ verb construction (which is explanatory and therefore not storyline), Belanda Viri clearly has several further bands, e.g. setting, irrealis, evaluation, and cohesion, which I will not illustrate here. Possibly the $t i+$ verb construction would best fit into fit in a common expository band (setting, background, explanation).

6.4. Ideophones. Tani especially emphasizes the role of ideophones in text where they often substitute for inflected verbs. I can do no better than quote him here [personal correspondence]:

"Further, it seems to me that there is a great difference at the climax [Peak] when the story is told orally and when it is written down. In this [written], the form of the Sequential tense tends to prevail while in the other [spoken] the ideophone prevails. The ideophones convey the exact movements taking place. In other words, ideophones describe the events and render them as real and present in a vivid way, while the Sequential Tense at the climax narrates without color."

It is of interest, however, that while ideophones are more common in oral than in written text, they also figure seriously in the latter as well. Mr. Tani, as a translator of the Christian scriptures into Belanda Viri (his mother tongue) delighted me 
repeatedly with anecdotes as to how ideophones were being used effectively in his project. 


\section{CHAPTER IV}

\section{LANGUAGES WITHOUT \\ A CONSECUTIVE TENSE}

In this chapter we consider the question, "How is a story told in a language not characterized by any sort of chaining, whether right chaining towards a special final verb (in SOV languages) or left chaining away from a special initial verb (in VSO and SVO languages)?" Such non-chaining or co-ranking languages have neither the analytical complications nor the strategic advantages of chaining structures. The analytical complications entailed in evaluating the storyline status of the special final clause versus that of the medial clauses or the storyline status of the special initial clause versus the consecutive clauses are avoided. On the other hand, the strategic advantages of having either a special final clause or a special initial clause to which other forms can relate, whether storyline or downshifted, are not present in a co-ranking language.

Co-ranking languages mark their storyline by either a special unmarked ("neutral") narrative verb form or by some special tense/aspect form of the verb. Conjunctions, particles, or verb auxiliaries often play an important role either in distinguishing the storyline from other ranks or in setting up subranking within the storyline.

This chapter also illustrates (via Nawdm) a formal distinction within narrative discourse between the folktale, which is typically didactic, and history. While this formal distinction in narrative genre is apparently quite widespread it is represented only here in our data.

In the last language considered, Gangam, a paragraph analysis based on rank scheme analysis, is given as was done via Gimira (Chapter 1), Luwo (Chapter 2), and Mündü (Chapter 3).

I will not give storyline scheme diagrams for the languages of this chapter. There is a considerable range or variety of languages to cover, and the (unpublished) storyline schemes are in general similar to those which have been displayed in previous chapters.

\section{Izi (Kwa Niger-Congo)}

With Izi, we encounter another language (data from Reinier de Blois) where there is a complicated system of verb inflection in which tone plays no small part 
gè 'so that'

-rí 'to eat'

mu pronoun $1 \mathrm{ps}$

Base form A: $\quad$ Root + -á/-rú/Ø

Narrative past - Low-tone pronoun

e.g. mù ríá

Conditional - High-tone pronoun

e.g. mú ríá

Purpose

e.g. gè mú ríá

Base form AB: $\quad e-a^{*}+\operatorname{Root}+-a ́ /-r u ́ / \varnothing$

Sequential - High-tone pronoun + mid-tone prefix e.g. mú eríá

Conditional - High-tone pronoun + low-tone prefix e.g. mú èríá

Purpose

e.g. gè mú eríá

Base form B: $\quad e-a^{*}+$ Root

Present tense - High-tone pronoun + polar tone prefix e.g. mú $\hat{c} \vec{r}$

Future tense - High-tone pronoun + high-tone prefix + lowering of tone on the root

e.g. mú érĭ

Base form C: $\quad$ Root \pm -rù (root has low tone throughout)

Past tense - Active verbs (with -rù)

Present tense - Stative verbs (no -rù)

*The prefix is e before [+Advanced Tongue Root] vowels and a before [-Advanced Tongue Root] vowels.

Diagram I. Summary of Izi verbal forms 
(cf. Obolo in the previous chapter). I reproduce here de Blois' summary of Izi verb forms as Diagram I.

1.1. Grammaticalization of a former consecutive tense. The storyline is carried by two constructions: (1) a clause with the narrative past tense which may be preceded by a clause with an active past tense verb, i.e. A Narrative preceded by active $\mathbf{C}$; (2) the auxiliary verbs bya 'come' or jé 'go' in the narrative past plus further verb(s) in the Sequential tense (AB). It seems very plausible that $(2)$ is the historically older construction and that at one time the language had a special initial form followed by a consecutive tense-a pattern which is now preserved only in frozen sequences of AUX + main. Here, then, an old pattern has become grammaticalized, while the language has moved on to develop (1) as its characteristic storyline form.

Aside from storyline usage (2) above (the sequential tense after auxiliaries) the sequential tense ${ }^{1}$ figures in two other constructions: (a) in staging a story by means of reporting a series of habitual events, i.e. "Whenever he did X, Y would ensue" (here the construction is Past tense-de Blois' Base $\mathbf{C}$-plus the Sequential or A Conditional plus the Sequential); (b) in irrealis band (Purpose constructions). The Sequential, then, does not figure on the storyline except in its special construction after the auxiliaries 'come' and 'go'.

1.2. The narrative past on the storyline. The following example from a text analyzed by de Blois exemplifies the active past plus the narrative past as the storyline construction described above (de Blois' active $\mathbf{C}+\mathbf{A}$ Narrative). At the same time it exemplifies the construction described in (a) in the above paragraph, i.e. staging by means of a series of habitual events (de Blois' $\mathbf{C}+\mathbf{A B}$ or $\mathbf{A}$ Conditional $+\mathbf{A B}$ ).

(1) a. nwoke nwutaru unwegirima ishii

man got $(\mathbf{C}$-act $)$ children six

b. onye k'ikpazu wata eme ge onye eswe person of last began (A-narr) behaving like person fool

c. ephe dobesul (A-narr) lẹ o bu onye eswe they thought that he be person fool

d. teke o gbẹshiru obya eje l'ẹgbudu whenever he stood up (C) he came (AB) go to bush

1I have followed de Blois' usage in referring to this tense as "sequential" rather than "consecutive". Unlike contemporary consecutive tenses in certain other languages already described above (Chapters 2 and 3 ), this tense is on the storyline only in frozen combinations involving one of two auxiliaries; it is no longer freely consecutive. 

lẹ oogbua inongu ẹgu
and he killed (AB) rat field
$\begin{array}{llll}\text { e. oogbua } & \text { ya (lẹ) oowojeru } & \text { iya nwoke ono } \\ \text { he killed (A-cond) it (then) he bring (AB) it man that }\end{array}$

a. 'A certain man got six children. b. The youngest began to behave like a fool. c. They thought that he was a fool. d. Whenever he would go out he would go to the bush, and he would kill a field rat. e. Whenever he killed it he would bring it to that man.'

1.3. Auxiliaries plus the sequential as storyline. Having illustrated the storyline use of the narrative past, we must also consider the alternative storyline construction which employs the 'come' or 'go' auxiliaries plus the sequential. But why two alternative storyline constructions? The answer lies with the meaning and function of the two auxiliaries; they are used in Izi narrative in certain specifiable ways and when so used they entail the alternative storyline with the sequential.

In regard to the usage of bya 'come', de Blois reports its use after several sorts of constructions in which the item preceding the bya + Main is clearly of lesser rank:

(2) [Where a backgrounded activity precedes.]

ọcharu nọdu epheghata bya ahụma nwa.

bird (Aux) stay fly-around come saw child

'The bird was flying around and then she saw the child.'

(3) [Where a necessary preliminary event precedes.]

mbe numa iya bya enyizeta.

tortoise heard it came climbed-down

'The tortoise heard it and came down from the tree.'

(4) [Where a circumstantial clause precedes.]

mbe maenupho le... bya eshia uzo ntse...

tortoise knew $(\mathbf{C})+$ epho (Cir.) that came took road close

'When the tortoise knew that,... he took the shortcut and...' 
(5) [Where the preceding element is a clause containing a $\mathbf{C}$-active (past) form.]

nwanyi tsutaru ime bya anwụa ebo.

woman conceived stomach came delivered twins

'The woman conceived and gave birth.'

The last example, it might be argued, should be expected to involve an event of less rank followed by one of greater rank, judging by (1-3). It might represent conception as simply a necessarily preliminary event to the birth of the twins themselves. This suggests that $\mathbf{C}$-active (past) verbs instead of being storyline forms specialized for chain-initial, should be regarded as a secondary storyline, a category of backgrounded events.

Other usages of bya 'come' plus the sequential reflect a crowded action line or vigorous interaction.

(6) [This is a part of a story, preceding its peak, "where many events follow upon each other"; the example is abbreviated.]

nwanyi ono bya $\mathrm{V}$

bya $\mathrm{V}$

bya $\mathrm{V}$

bya $\mathrm{V}$

bya $\mathrm{V}$ '...the woman bought some eggs'

'...entered...'

'...took eggs...'

'...rubbed it on her body...'

'...rubbed it on the oke (personal god of her husband)'

[The peak itself has no bya: 'her child left her room and entered the belly of her husband.']

(7) [Here there is vigorous interaction between $m b e$ 'tortoise' and apya 'hornbill'.] mbe bya $\mathrm{V}$ 'Tortoise started to play the drum on the verandah.' apya bya $\mathrm{V}$ "Hornbill came down and started to dance.' mbe bya $\mathrm{V}$ apya bya $\mathrm{V}$ 'Tortoise went in the house and started drumming.' mbe bya $\mathrm{V}$ apya bya $\mathrm{V}$ 'Hornbill came down to the verandah and danced.' 'Tortoise went to the back of the house and drummed.' [Next the door is closed, and hornbill is caught and killed.] 
As for the other auxiliary je 'go', its functions are somewhat more restricted. It is used (1) after a preceding clause whose verb is a verb of motion and (2) to introduce a change of locale.

(8) bahụ l'ọma ụlo je awatakwa akụku.

entered inside house go started drumming

'He entered the house and started drumming.'

(9) o jịk eri nri je azẹe lę mgboru ọku. he refused to eat food go lay-down at near fire

'He refused to eat but went over and laid down by the fire.'

My summary here has meant to highlight a situation in which what was once undoubtedly a consecutive tense has become so restricted in use that it no longer is on the main storyline, except in combination with special auxiliaries. It also has been a part of this summary to present de Blois' provocative analysis of the auxiliaries themselves, an analysis which ranks alongside Dorothea Frank's analysis of Mündü auxiliaries as suggestive of the analytical gold that can be mined in this direction.

\section{Mumuye (Adamawa Niger-Congo)}

Mumuye (data from Danjuma N. Gambo) has a special storyline form, the neutral tense, which is unmarked for tense or mood. The role of the two auxiliaries 'come' and 'go' is of importance here.

$\begin{array}{lll} & \text { Verb } & \text { Auxiliary } \\ \text { 'come' } & \text { a } & \text { naa } \\ \text { 'go' } & \text { daa } & d i\end{array}$

Diagram II. Mumuye auxiliaries

A storyline form may be a single verb, auxiliary + verb, or verb + verb in serial construction. The following example is composite:

(10) 1 . basho daa nong soo.

hare go place woman

'The hare went to the woman's place.' 
2. sombo di woว 6asuba.

squirrel go wear (kind of leaf)

'The squirrel put on a leaf.'

3. sombo naa yii gong 6oding. squirrel come catch ridge another

'The squirrel then got as far as another ridge.'

4. a daa gaá kuru ki gbalang.

come go wait tortoise on road

'The squirrel proceeded to wait for him on the road.'

5. daa ii kuru doo ki gbalang. go find tortoise leg on road

'The tortoise found him still standing on the road.'

In $\mathbf{1}$ above the storyline form is a simply verb daa 'went'. In $\mathbf{2}$ the storyline form is di wos 'go wear', i.e. 'put on', auxiliary plus main. In $\mathbf{3}$ we likewise find an auxiliary plus main construction. Gambo states that 'come' as auxiliary has the force of "then". In 4 we have a serial construction with the verbs a 'come', daa 'go', and gaá 'wait'. In $\mathbf{5}$ we likewise have a serial verb construction 'go find'.2

The uses of the past perfective aspect (marked with to completive particle) is also of considerable importance in Mumuye narrative. Essentially, Gambo's description characterizes this tense form as having an initiatory or closing function in some unit ( a lexical script or a grammatical paragraph?):

"It signals the beginning of a new scene. In this function, there is often a sequence of two to clauses. It is also of ten accompanied by other signals which indicate a new scene, e.g. by temporal phrases or tos meaning 'then'... It also marks the completion of parallel actions."

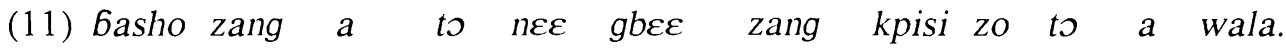
hare people came (pt) with leopard people meet self $(p t)$ in bush

'The hare people came along with the leopard. They met in the bush.'

Here the sequence of two past/perfective clauses introduces the new scene.

2The particular discourse (?) constraints that dictate the use of auxiliaries and in particular of aux + verb versus serial constructions await future research. 
(12) [Composite from several parallel episodes in the same story.]

21. sombo gbãa gong to squirrel dig ridge past)

'The squirrel dug a ridge.'

29. sombo hanse wuu gong to. squirrel finish him ridge (past)

'The squirrel finished another ridge.'

36. sombo hanse wuu vuu to. squirrel finish him thing (past)

'The squirrel finished another one.'

Here parallel episodes of the story end in parallel fashion and, again, have a special form in closure.

Analytically there are two possibilities here: (1) the initiatory and closing clauses with the past/perfective are of the same rank as the neutral tense (primary storyline), or (2) the past/perfective used in this function is a secondary storyline reserved for preparatory and resultant actions (as in several languages of Sudan). While the latter alternative seems to me to be the more probable, only the examination of a large number of narrative contexts and the consideration of the semantic classification of verbs that bear the past/perfective in narrative can resolve this question.

Gambo also mentions for possible storyline function a durative verb with the suffix -yi. He comments, "This suffix marks the fact that the action is non-punctiliar; that is, it went on for some time." Only certain verbs take this form; Gambo gives a list of 21 common verbs that take -yi but does not exclude the possibility of there being a few more which escaped his attention. He gives such examples as the following:

\section{(13) [Composite]}

1. kpanti nwang $\mathrm{kn}$ shayi. chief sat food eating

'The chief was sitting eating food.'

2. a sombo dayi di ya bii ka jaa gbaa.

? squirrel going go take (focus) child hoe

'The squirrel was going taking/to take a small hoe.' 
If the storyline in any language is by definition sequential and punctiliar then such forms as those just illustrated pertain not to the storyline as such but, taking Gambo's assessment of their importance, to a relatively high rank in the background activities band. Even more explicitly durative are past progressive forms formed with naa/kina progressive markers.

\section{(14) kura gbãa yuu naa.
tortoise
returning head (prog)}

'The tortoise was returning on the road.'

It would seem that the more explicitly progressive a verb form is the farther it is from the storyline. Hence, in Gambo's treatment the -yi suffixed forms rank above the forms with naa/kina progressive marker.

Further bands posited for the storyline rank scheme are Setting, Collateral, Author evaluation, and Cohesion.

In summary, higher ranking bands in Mumuye employ largely tense distinctions in which an unmarked or neutral tense ranks highest, in which the past/perfective has largely to do with matters of opening and closure within units of the story,and in which two degrees of durative/progressive figure.

\section{Jju or Kaje (Benue-Congo, Niger-Congo)}

Jju or Kaje (data from Martha Adive), like Mumuye, also has a special unmarked or neutral form on its storyline. The language is SVO except when the object is a pronoun, in which case SOV occurs.

$(15)$

na sook ryei
he took calabash

versus

cihywat u bu pyyem hunger it him caught
'He took a calabash.'

'He got hungry.'

Time is established in the setting of the story, e.g. yin past in a stative clause.
(16) ansom a yin
swat ba
ambrying $n i$
bu kawon nu.
rabbit he past(habitual) live with wife his and child his
'The rabbit lived/was living with his wife and his child.'

Serial verb constructions occur in which each verb refers to the same subject and the sequential pronoun precedes each verb. Neutral verbs in such serial constructions function on the storyline as in the example below: 
(17) agwam a pyyem ansom a yyik... chief he catch rabbit he locked (him up)

'The chief caught Rabbit and locked him up.'

On the other hand a serial construction which repeats the same pronoun + verb can turn what would have been storyline into a durative activity just below the storyline.

(18) ansom a pyyem bawop a wop a wop.

rabbit he catch netting he nets he nets

'The rabbit took ahold of netting material and spent some time making nets.'

The particle si 'and then' reinforces storyline movement and may on occasion introduce a new sequence of actions, i.e.a new script. Adive comments that use of $s i$ varies from storyteller to storyteller, since some use it more frequently than others in the course of a story.

(19) [Composite]

ba si kpang karyi.

they then reach home

'They then reached home.'

$\begin{array}{llllll}\text { ansom } & a & \text { si } & \text { hywa da ambrying } & n u . \\ \text { rabbit he } & \text { then said to wife } & \text { his }\end{array}$

'The rabbit then said to his wife.'

In both these instances new courses of action are inaugurated.

The possibility should be investigated that si, when occurring before the second of a sequence of two verbs, marks the latter as more crucial than the former:

(20) ba nat ba ansom a si tyyei agwam kankrang. they go with rabbit they then tell chief of (name of town)

'They went with the rabbit and then they told the chief of the town.'

Background activities may also be represented inceptively by nwwa meaning 'to start (and keep on doing)'.

(21) ba nwwa wwhut.

they started flying 
Background cognitive states are very similar to background activities as far as relation to the storyline.
(22) na bvo
di nkingya
na sshi
$u$ natung.
he knew(habitually) that food it is (habitually) at conferences
'He knew what the food was always like at conferences.'

Further bands of Martha Adive's scheme, Setting and Irrealis, are somewhat what we encounter in other languages. Some features deserve special mention. (1) There is no backreferential use of adverbial clauses in cohesive functions. (2) Initial dialogue between the storyteller and the audience is highly formalized in initiating a story, and the audience is expected to join in singing a song whenever the story involves a song. While interaction with the audience is the order of the day in storytelling in many African languages, Adive's description is especially detailed in this regard, and needs to be expanded and published in its own right.

\section{Ewe (standard dialect of Gbe, Kwa Niger-Congo)}

For Ewe Alan Duthie provides a storyline scheme organized according to "worlds": (1) "the world of the current text", i.e. as the story has developed up to that point; (2) "other worlds", i.e. either earlier or later than the current text [-world] or parallel to the text [-world]; (3) "real world" of the sender and the receiver(s) of the text. I will summarize somewhat quickly his (2) and (3) above, then consider more at length his (1).

Since Duthie's other worlds are earlier, later, or parallel to the current text world, this category subsumes Flashback (earlier than the current text-world), Preview (foreshading of a situation or "world" that is later than the current text world), and the content of speech or awareness quotes, which are parallel to the current text world. Duthie also subsumes under his second caption negatives, which, by virtue of being irrealis, imply an alternative world to that of the current text world.

Under his third category Duthie subsumes (a) the "evaluations" or morals which are often attached at the end of some types of narrative and thus reflect the sender's perception of what the receiver(s) should get out of the story and (b) indication of interaction in either story-initial or story-final.

Storyline schemes in this conceptual context reflect the world of the current text. Here Duthie distinguishes a Primary Storyline, a Secondary Storyline, Background activities, Setting, and Cohesion. I quote his indication of the first 4 categories:

1. "The Primary Story-line is carried by action verbs, unmarked grammatically, either singly or in series, e.g. efo, do go, daku te da $q u$ "he-rose went out to dig 
yam, cook, eat', or occasionally, with an intervening conjunction, e.g. eye 'and'. Occasionally, too, punctiliar aspect is marked with a verbal auxiliary va 'came-to' or with adverbs, e.g. gbe deka 'one day', enumake 'suddenly'.

2. "A Secondary Story-line seems to be carried by action verbs, occasionally marked for perfective aspect with vo 'finish', within subordinate clauses introduced by conjunctions like esi 'when, after', rarely si RELATIVE, and terminated by la. In all cases the Action is part of the story-line in normal sequence, but put off the primary line, e.g. esi wodii vo megbe la 'when-they-bury-him finish after'.

3. "Background activities or happenings are occasionally presented in action verbs marked for durative aspect, e.g. si no vu kum la 'who was car driv-ing.'). If verbs should express cognition, they remain semantically durative, but are grammatically unmarked, e.g. edi be... 'he-wish that...'; elabena esusu be... 'because he-think that...'.

4. "Setting of the story as it develops may be expressed by state verbs, e.g. bo "beplenty', no 'be-in-place', wo togbe 'be hilly', occasionally in relative clauses. Time may be expressed in a nominal phrase, e.g. le vemavi me la 'at that-time in', or more extensively, e.g. eva me gbadegbe bena do...to... 'it-came in some-day that famine...spread...'. Action verbs may appear marked for generic aspect, e.g. si woygna be... "which they-call-GENERIC say...'."

\section{Mwaghavul (Western Chadic)}

Like Mumuye and Jju, Mwaghavul (data from Stephen J. Niyang) has an unmarked neutral tense which carries the storyline. The tense is set by a time phrase at the beginning of the story. Furthermore, the great majority of storyline clauses are introduced by the connective $6 e^{\text {' }}$ and then'. 3

(23) [From the peak (resolution) of a story.]

be kaar wura met kaa ting.

then monkey she jumped up tree

be dafwan kwit del tughun.

then hare passed into hole

be dee duma wura milep yit di.

then left hyena she eye then there is

${ }^{3}$ In the two texts on which Nijang's study was based there were six examples of the nonoccurrence of be on what appeared to be storyline clauses. Resolution of this problem awaits the analysis of a greater corpus of texts. 
'Then the monkey jumped up into a tree. Then the hare went into his hole. And then the hyena was left looking around.'

Niyang notes that in Mwaghavul, as in some other languages, a verb of speech can be omitted in introducing a quotation. Thus, while be wuri sat nee... 'and then he said that...' is considered to be storyline, it is also assumed that be mo nee... 'and then that' is storyline as well. The precise conditions under which a verb of speech can be omitted in Mwaghavul and in other languages must await a careful analysis of the dynamics of dialogue in each language.

Niyang also mentions that while a verb may be accompanied by an ideophone, a storyline clause sometimes omits the verb and retains only the ideophone. Nevertheless the clause continues to be on the storyline. He cites the following:

\section{(24) be wuri viuu \\ and-then he (jumped) viuu}

[There is no verb 'jump', but the ideophone vilu remains.]

As in the case of quotation formulas, so here with ideophones, the particle be seems to be more diagnostic of the storyline than the occurrence of the neutral verb itself. And, again, it is not inappropriate to raise the question as to the nature of the constraints that cover retention or deletion of the verb. 4

Other conjunctions than be occur on the storyline. (1) dang be, a stronger 'and then', marks a major paragraph division. In this role it is neither introducing a higher nor a lower ranking clause than the clause with be. Rather dang be and be are both storyline but the former has the additional function of marking a division in the constituent structure. (2) yaksi 'and then, at that moment' occurs at the peak of a story (be yaksi can also occur). Several yaksi introduced clauses can occur in sequence at such a point in the narrative.

$\begin{array}{lllll}\text { (25) yaksi } & \text { wuri sham taa dighin kong ni. } \\ \text { at that moment he came down fell river it }\end{array}$

'At that very moment he fell down into the river.'

Other connectives than the above occur, but they are subordinating and therefore demote the neutral tense to some lower ranking in the rank scheme so that events are depicted as, for example, "resultant" rather than storyline in their own right. Two such connectives are $k u$ and peku 'so that'.

${ }^{4} \mathrm{Cf}$. Belanda-Viri (data from David Tani) where ideophones are endemic in folktales, with frequent omission of the verbs which can accompany them (Chapter $3 \$ 6$ ). 
Since the status of negatives (whether irrealis and off the storyline or on the storyline in some contextual circumstances) is of perennial interest to storyline analysts, it is noteworthy that Niyang states that the addition of be, storyline marker to a negative clause, promotes it to the storyline:

(26) [The negative construction ba...kas brackets the clause, aside from addition of an initial connective.]

be ba wuru mee bii kas.

then neg. she see nothing neg.

'Then she saw nothing at all.'

\section{Bassa (Kru Niger-Congo)}

In Bassa, (data from Donald Slager) the storyline concerns involve aspectual distinctions, word order variations, and the extensive use of conjunctions. The aspectual distinctions involve an unmarked form, a progressive aspect, and a perfective aspect. With the unmarked form the word order is SVO; with the two marked aspects the word order is SOV and the aspect particle occurs after the subject. 5 The progressive aspect has the aspect particle $n i$ 'be' and also takes a suffix $-n$ on the verb. The perfective aspect has the aspect particle dà. Most of this summary has to do with the role of conjunctions.

\subsection{Connectives as necessary to the storyline and background activi-} ties. Slager makes a convincing case for the thesis that if the unmarked form is storyline it must be preceded by a connective element, whether a conjunction or a subordinate (adverbial) clause. The conjunctions that he cites are the following:

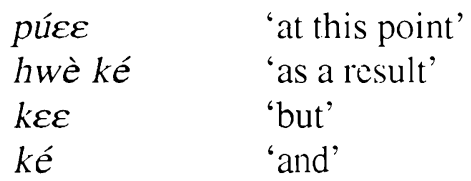

Slager comments that púce is essentially cataphoric, hwè ké is essentially anaphoric, and the other two connect in both directions. He believes that taking

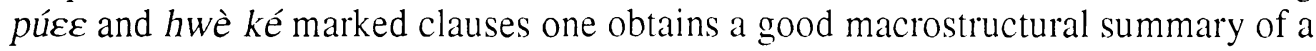

5 Notice here that the storyline form, which can be regarded as the least likely to be disturbed by focus permutations, is SVO while the off-the-line aspects are SOV. This is quite the opposite of Avokaya (see Chapter $2, \$ 6$ ) where the storyline forms are SOV and some of the off-the-line forms are SVO. Taking the storyline form as the more neutral and basic, Avokaya has been judged to be (weakly) SOV. By the same token, taking the storyline form as basic, Bassa is judged to be SVO. 
story. He therefore believes that these two conjunctives mark pivotal events. The more routine storyline is marked by the presence of a preposed subordinate clause or by ké 'but'. The lowest level in the storyline, perhaps a secondary storyline, is marked by ké 'and', since, according to Slager, "If the connective is ké 'and', a script-predictable event is in view."6

In contrast, background activities are marked by the progressive aspect (and, of course, the switch to SOV word order). Nevertheless, the same proviso holds here as that stated for the storyline, i.e. a connective must introduce such a clause with its verb in the progressive if it is to be considered to be indicating a background activity. Although Slager suspects that several connectives could figure here, his present examples of background activity clauses are introduced only by ké, which marks the lowest order on the storyline.

The importance of the presence of a connective in defining both the storyline and the background activities bands is seen by the inspection of clauses with the requisite aspectual forms but without a connective. Such clauses explain and amplify but neither move the storyline forward nor introduce a new background activity. They are in some ways similar to setting but distinctive enough that Slager separates Setting and Amplification as separate bands.

Subordinate clauses (whether relative or adverbial) can carry new information or information that is either old or script-predictable. In either case they may act as a connective in defining the storyline and background activities bands. Their own function is that of setting, where they carry new information, or cohesion, when the information is old or script-predictable. Slager comments, "These two types of subordinate/relative clauses differ in form. The former use the unmarked form or the progressive aspect without à 'so'. The latter use the perfect aspect or á on the unmarked form or on the progressive aspect."

6.2. Extended exemplification. Instead of submitting a rather extensive stretch of Bassa text to illustrate and support the preceding statement, I resort here to a translation of the Bassa with indication of relevant Bassa features:

(27) [ In this folktale, the Blackbird, disturbed that he is black and his eggs are white, goes to the "county doctor" who promises him that if he stops eating termites (his favorite food) his eggs will become black.]

1. When the next day came it was the time for termites to appear.

2. Púce-there at a cassava farm which they had recently burnt off, there on a branch near the edge of the field-Blackbird sat down(unmarked aspect).

6Slager also puts negated actions/events on the lowest level of the storyline: "The lowest event that can occur on the storyline is a negated event. It too must be preceded by a connective." 
3. Ké termites were coming towards him (progressive) buzz, buzz, buzz, buzz.

4. The termites were flying (progressive); they were falling down on each other (progressive); they were crossing each other's flight path (progressive).

5. They passed by, a lot of them (unmarked aspect).

6. When Blackbird smelled the termites (perfective) and had a desire to swallow them (progressive), he said (unmarked aspect), "Kebek won't see if I swallow a few termites."

7. Púce he really began to swallow them (unmarked aspect).

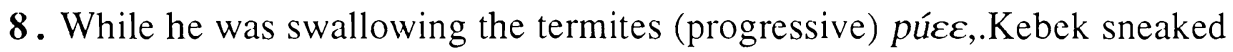
up (unmarked aspect) behind him there and saw him (unmarked).

9. Hwè ké he said, [in effect] "You couldn't do it, could you? Your eggs will remain white."

Notice in the above, the pivotal events in 2, 7, 8, and 9: Blackbird sat down [in the proper spot to be tempted and fall]; he began to eat the termites; Kebek caught him in the act; and he pronounced the doom, "Your eggs will have to be white." While

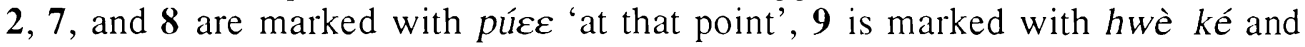
carries the force of "consequently". By contrast the action reported in $\mathbf{6}$, the Blackbird's decision to risk eating a few termites, is marked by an adverbial clause which functions as a connective. Here the action is pictured as somewhat more routine: the decision may be father of the act, but the act of eating was what got him in trouble.

Sentence 3, introduced by ké 'and' is from the background activities band and has, as expected, a progressive verb. Sentences $\mathbf{4}$ and $\mathbf{5}$ have no initial connective of any sort. They are amplificatory/explanatory of $\mathbf{3}$. Sentence $\mathbf{4}$, like what it amplifies, is also progressive. Sentence $\mathbf{5}$ is unmarked aspect but has no connective and must still be considered to amplify $\mathbf{3}$. Since $\mathbf{3}$ and $\mathbf{4}$ are both progressive and $\mathbf{5}$ is unmarked, this may indicate a constituency clustering of $\mathbf{3}$ and $\mathbf{4}$ over against $\mathbf{5}$. The same difference in aspect also appears in the long backreference (script predictable behavior on Blackbird's part) on sentence 6 . Here, the first clause in the backreference is perfective. Semantically, this could of course mean, "When he caught the smell of the termites and kept wishing to eat them." 7

${ }^{7}$ Slager's rule that adverbial clauses in the progressive convey new information while those in the perfective carry old or script-predictable information does not seem too applicable here-unless the smelling of the termites buzzing all around him is regarded as the script-predictable element, while his desire to eat them is presented as new information. 
This portion of the text does not illustrate too well the routine storyline, since we

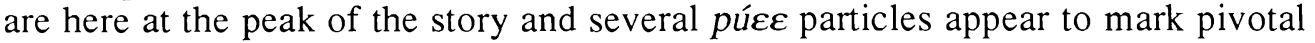
actions at this part of the story.

\section{Juba Arabic}

Juba Arabic is a creole spoken around Juba in South Sudan (data from Richard Watson). In that this language is creolized Arabic, the verbal and nominal inflections of contemporary standard Arabic are not employed. Instead, verbal distinctions are conveyed by particles and particle-like auxiliary verbs much in the manner of many surrounding Sudanic languages. A verb stem can be preceded by gum 'arise', can occur by itself, can take on inceptive auxiliary bada 'begin', or a continuative marker gi-.

The auxiliary particle gum is of such general use in narrative that Watson accords gum $+\mathrm{V}$ the highest rank on the storyline. Commenting on a clause towards the end of a folktale, u gum mutu hinaak 'and he arose and died', Watson notes,

"It is quite clear that the verb gum does not mean 'arose' as the elephant was on his feet wide awake all the time until his death, when he certainly did not 'arise and die'. Gum as an auxiliary clearly marks the storyline, and its repetition with several succeeding clauses marks the peak of a story, though peak can be marked in other ways as seen in the second episode. In the tape recorded first version of this story even kasuru adumaat 'broke his bones' was preceded by gum though it was later edited out as superfluous."

Unmarked verbs are considered to be storyline but of lesser rank, i.e. not as explicitly sequential as those with gum. Since forms with gum are too plentiful to fit well the rubric "pivotal events", maybe it would be better to regard the verbs with gum as primary storyline and the unmarked verbs as secondary. However, between gum $+\mathrm{V}$ and $\mathrm{V}$, Watson posits an intermediate ranking storyline form with bada 'begin'.8 He does not label the subdivisions within the storyline band. Finally, Watson considers the continuous particle gi- to mark a background activities band.

${ }^{8}$ This is a problem which is found in the bulk of the languages of this report. Since 'begin' is inceptive in reference to what then becomes an ongoing activity, some of my colleagues in this project have regarded it as storyline (since the inception is sequential and punctiliar), while others have regarded it as a background activity (because of the ongoing nature of the activity which is initiated at that point). I haven't included these varying points of view and who advocates what in this report. I lean to the side of those who regard the inception of an activity as a storyline action/event. Nevertheless, taking texts in which (1) unambiguous storyline forms, (2) inceptives, and (3) unambiguous continuatives (background activities) occur, it seems to me that the analysis of local spans (paragraphs) would proceed to plausible results in terms of which sentences emerge as more prominent if a (1), (2), (3) ranking is assumed. Whether we group (1) + (2) as storyline against (3) or group (1) as storyline against $(2)+(3)$ is a less pressing question. 
These various distinctions ranked in the order gum $+\mathrm{V}$, bada $+\mathrm{V}, \mathrm{V}$, and $g i^{-}+\mathrm{V}$ are illustrated in the following example:

(28) [The bad elephant has destroyed the bird's nest, killed her babies, and refused to listen to her complaint.]

1. fil gum zalaan ma huwo

elephant arose angry with her

2. wa sibu huwo gi kore.

and left her -ing cry

3. uma ta ter ruwa le reyiis ta gurabaat

mother of birds went to chief of hawks

4. u gum worii le huwo gisa...

and arose told to him the story

5. gurabaat ruwa le fil

hawks went to elephant

6. u bada dugu dugu fil.

and began peck peck elephant

7. fil ainu ze de

elephant saw like this

8. $u$ bada kore

and began cry

9. u gum jere

and arose ran

10. gi arfau adaan to kebiir

-ing raise ears his big

11. gi durubu kureen to fi wataa.

-ing pound feet his on earth

'The elephant got angry with her and left her crying. Then the mother bird went to the chief hawk and told him the story. . . The hawks went to the elephant and began pecking him. The elephant saw that, began to cry, and ran off, flapping his big ears and pounding the earth with his feet.'

In this passage clauses $\mathbf{1}, \mathbf{4}$, and $\mathbf{9}$ have gum $+\mathrm{V}$ and are primary storyline. Very probably the bada $+\mathrm{V}$ construction which are found in $\mathbf{6}$ and $\mathbf{8}$ are of much the same rank as gum $+\mathrm{V}$. Together they give us an outline of the event sequence: ]The elephant got angry. The mother bird told her story to the chief hawk. The hawks began to peck away at the elephant. He began to cry and ran off.' This leaves the 
unmarked verbs as preliminary or resultant: $\mathbf{2}$ the elephant left her crying (resultant on his anger); 3 mother bird went to the chief of the hawks (preliminary to telling him her story); 4 the hawks went to the elephant (preliminary to attacking him); 6 the elephant realized his peril (preliminary to flight). Notice that all but 7 , which is a cognitive event, are motion verbs. Motion verbs are suspect, in many languages, of having a secondary function relative to that of the active verbs, i.e. motion verbs take participants on and off the stage or move them across the stage so as to engage (or disengage) them in action sequences.

As for the gi V's, they are easily seen to involve background activities which are neither sequential nor punctiliar but rather overlap with one or more of the actions of the text (end of 2, 10, and 11).

\section{Nawdm (Gur Niger-Congo)}

In Nawdm (data from Marcel Gasser in an outline sketch of unusual value), there are storyline distinctions between two types of narrative: (1) folktale and (2) historical account. The former is considered to be the vehicle par excellence for conveying ethical and moral values and makes no claims to historicity; all takes place in a mythological never-never land. The latter is meant to be factual, but this does not exclude the possibility that it can convey ethical and moral values. This distinction in narrative text types is quite widespread in Africa (oral information from Jacob Loewen) but not well represented in this report.

Gasser summarizes the verb system of Nawdm much as follows:

(1) Aspect: "a very elaborate aspect system", which Gasser lists as containing completive versus incompletive, durative versus punctual, and ingressive versus terminative versus progressive, with the last two only when the verb depends on another ("begin X", "finish X", "keep on X").

(2) Time references: given in pre-verbal particles.

(3) Certain derivative suffixes, e.g. - I 'causative' and -d 'opposite', the contrary of the action indicated in the unsuffixed form.

(4) There is a further category of "subjoined verbs", which in folklore seem to be limited in function to verbal complements, purpose constructions, and descriptive participial-like usages, but which in historical narrative constitute the preferred encoding of background activities.

8.1. The folktale. In the Nawdm folktale, the storyline is carried by completive verb forms, and there is a background band with verbs in the incompletive. The background band with the incompletive can refer to backgrounded actions/events 
or to backgrounded activities. It, in effect, collapses into one a secondary storyline and background activities bands (cf. the French imparfait).

(29) [Completives are written in bold letters; incompletives have single underline.]

1. qigbama reda goore diire $n$ ka ked suunbe. hunter went-out day a certain and going the hunt

2. qa yum loku $n$ san luud $k u$ ni $n$ yum yuuga $n$ he saw a well and went to look it in and saw rat and waagbe ba lokun... snake are well-in

[wanting to get out and not able to do so.]

3. yuuga te yum qigbama $n$ boqoo-wu, rat the saw hunter and said-him

["Get me out of this well."]

4. qigbama te gbaam-ka na... hunter the asked-him that

["If I get you out then you won't steal my peanuts and my beans."'

5. yuuga te leed-wu na, "Qaay." rat the answered-him that no

'There was once a hunter who went out one day to hunt. He saw a well, went over to look in it, and found that a rat and a snake were down in the well, wanting to get out and unable to do so. The rat saw the hunter and asked him to get him out. The hunter asked him, "If I get you out will you stop stealing my peanuts and my beans?" The rat replied that he wouldn't steal them anymore."

Notice that in this example the more crucial actions and speech events are completives: the hunter went out to hunt, went to look into the well, proposed to free the rat conditioned on a promise of the latter's good behavior, and the rat agreed. Preliminary or resultant actions or activities are incompletive: the hunter saw the well (preliminary to going over to it), saw the rat and the snake down in the well (resultant on having gone over to it), the rat saw the hunter and requested help (preliminary as dialogue initiation).

Some other verb forms also occur in the above example. In $\mathbf{1}$ the form ka ked is a subjoined form in which $k a$ is the diagnostic functional particle. While $n$ 'and' is superficially a coordinator (cf. 2 where an incompletive and a completive are 
coordinated), here the use of the subjoined form of the verb gives a type of purpose construction (irrealis). In 2 ba 'are' occurs and is an element of the setting band.

8.2. The historical account. In the Nawdm historical text, matters are somewhat reversed. To begin with, while time particles are only rarely used in the folktale (where $d a$ "remote past" occurs chiefly in flashbacks), the particle da is used frequently on the storyline in historical narrative and occasionally in the background band as well. Also, the storyline verb form is the incompletive, although modified by the addition of $-m$ "terminative". There is a background action/activities band where the subjoined forms with ka figure prominently: either the completive or the incompletive can follow the ka. Furthermore, completives and duratives without $\mathrm{ka}$ also occur in what clearly seems to be background activities. While all this seems somewhat confusing, the focal distinction between the Nawdm folktale and the historical narratives seems essentially to cluster around the fact that while aspectual distinctions are focal in the folktale, temporal distinctions are focal in the historical narrative.

(30) [As before, completives are in bold face and incompletives and - $m$ terminatives are underlined. Here, however, the underlined forms rank higher than the bold forms. The past particle is bracketed. Underlined bold forms are subjoined forms.]

1. bermba-n [da] ba weem

lee,

le [da] sawlg ń

nidba long-ago-when past it before when it past started with persons bareq, fogwu ń daawa.

two woman and man

2. ba [dan] moqm raagun disaku kuyen, wu ń qa they past built in-the-forest hut one he and his fogwii ba ka go kan. wife they sleeping there

3. sajgbande te $[d a]$ gem, ba maadm buga, $n$ nan $\underline{k w e e m-k a}$ God the past made they bore child and later weaned-it n lilm volga and added another

4. hi [dan] yolm taa hiyen.

those past married reciprocal themselves 
'Long ago in old times, everything started with two people a woman and a man. They built a hut in the forest. God caused them to have a child. Later they weaned it and had another one. Those two married each other.'

Several things call for comment in the above example. (1) Notice first of all the use of the incompletive-terminative forms to mark the primary storyline: the couple built their house, had a child ('God made they bore...'), weaned it, added another child, and the two children married each other. (2) Notice also the frequency of the past tense $d a(n)$ which marks each sentence, including 1 where no storyline forms occurs, but rather a background/secondary form sowlg 'started'. (3) Besides this latter form, which seems to signal a preliminary statement, there is a subjoined clause $\mathbf{2}$ ba ka go kan 'they were sleeping/living there', which seems to signal a background activity.

For a rather extended example of subjoined forms used in portraying background activities, note the next example:

\section{(31) diite-n da kpaq na ba di lee, ba kalinta ń food-when past is-not that they eat when they wandering with kootií, ka yu tiibe gorona, ka lemaa be mag hom. fields seeing tree fruit tasting it suit well \\ 'As there was no food to eat they wandered around in the fields, seeing fruit in the trees, and tasting to see if it was good.'}

Here, the "subjoined" tense is not dependent on any prior element. The n...lee clause is a backreference to the preceding sentence. This goes on for a fairly long stretch of sentences in which $k a+\mathrm{V}$ and completives predominate. The whole thing signifies, 'This is what they did from time to time.' That is, in this historical text the primary storyline gives way at this point to the description of an ongoing situation. The completives, in particular, function typically in the consequents of conditional sentences.

(32) ka qa ba kpi, ba nan tiqd ba membee $n$ katoo, kaju.
if he not die they then assemble they all and picking eating
'If he did not die [the fruit taster] then they would assemble, all of them,
picking and eating [the fruit].'

Here, nan "future particle" has more of an 'and then' sense with the perfect. The use of the completive in conditionals is also found in reported speech in the folktale. The nan in the latter sense is, however, characteristic of the historical narrative as opposed to the folktale. 
We have tried to offer sufficient examples to illustrate the rather profound cleavage in the storyline devices between folktales and historical narrative. In the use of particles and in the use of aspects, the two types of narrative differ considerably.

\section{Gangam or Dye (Gur Niger-Congo)}

The storyline in Gangam narrative (data from Bonnie Walker and Jean Reimer) is carried by "realis perfective" verbs. The placement of this form of the Gangam verb among other verb forms of the language can be seen in Diagram III, supplied by Bonnie Walker. Notice that formal distinctions separate (1), (2), and (3) and (4) in the diagram, i.e. the realis versus the irrealis forms and the perfective versus the imperfective. On the other hand, functional distinctions just as clearly separate (3) from (4) as formal distinctions separate (1) from (2). The imperfective irrealis forms (4) are parallel with the perfective irrealis (2) except for the perfective/imperfective difference.

9.1. Storyline constructions. Realis perfectives, the storyline forms, may occur simply or in serial construction. Certain particles can occur with the storyline verb:

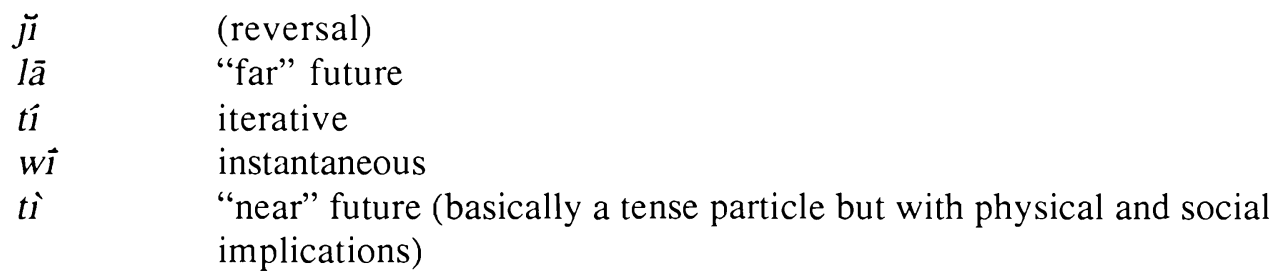

The latter particle is especially elusive in meaning. In some cases it clearly indicates physical removal ("over there"). In others, it refers to social distance (a man went to college and went on to become an important man, thus distancing himself socially from his former peers). In still other cases, ti seems to mark total affectedness of the object (cf. Hopper \& Thompson [1980], transitivity parameter I), i.e. 'to kill off'. Not all these particles are limited to occurrence with

storyline verbs but their occurrence is sufficiently frequent that it is difficult to cite examples that do not involve one or more of them.

(33) ipond ya cien ne $\underline{\text { kpo. }}$.

frogs poss. old off (?) died

'The oldest of the frogs died.' 


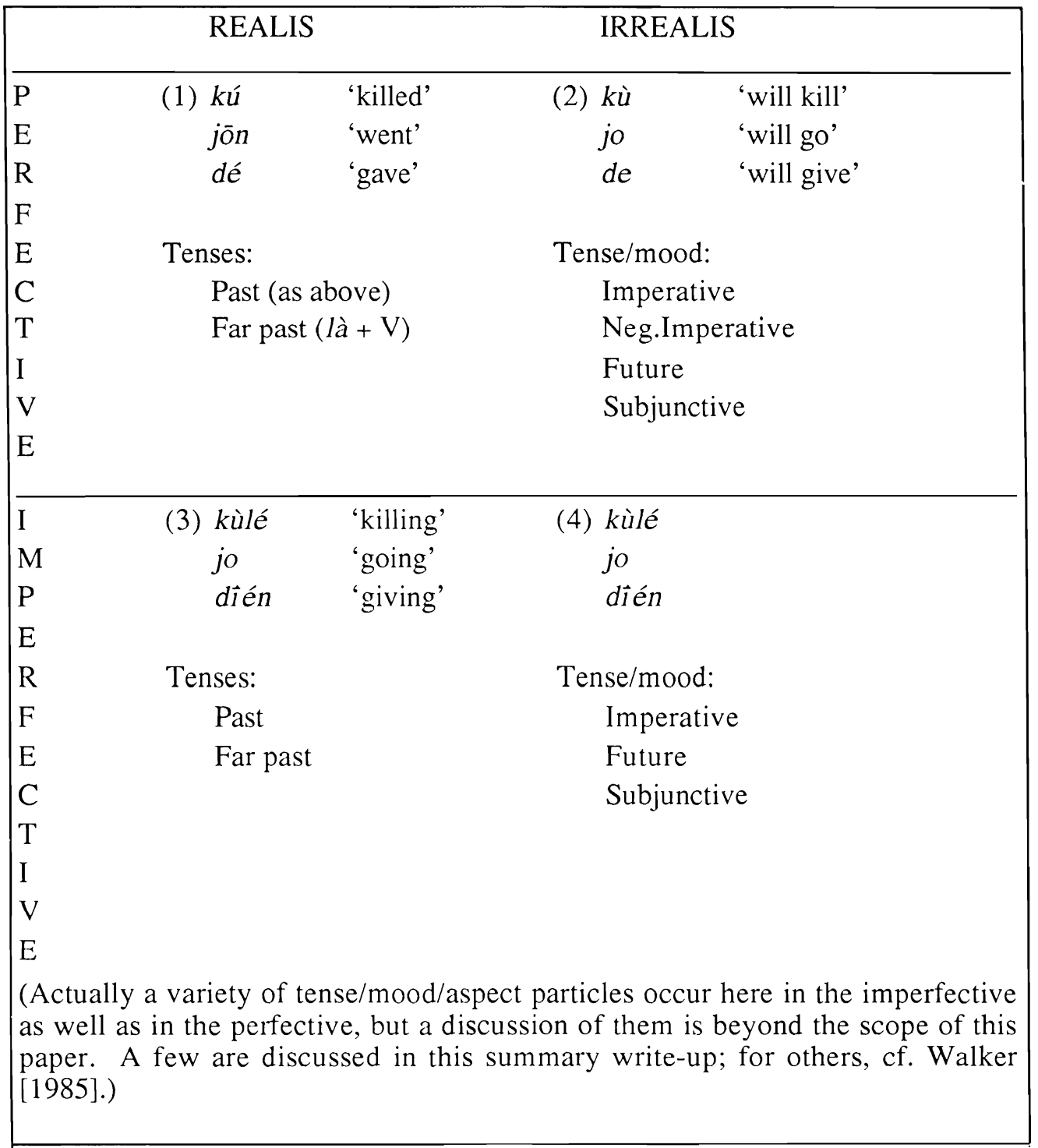

Diagram III. Gangam 
Here $k p o$ is storyline ${ }^{9}$ and occurs as the sole verb of its sentence.

(34) [This sentence follows the one above.]

u'bumu jon ki $\underline{d \varepsilon}$ un ben tucre u'kum. his children went and bought cow (that) they celebrate his death (irrealis perfective)

'His children went and bought a cow that they might celebrate his death.'

Here jon $k i d \varepsilon$ 'went and bought' is a serial construction both verbs of which are realis perfective. It is followed by a purpose construction whose verb is irrealis perfective.

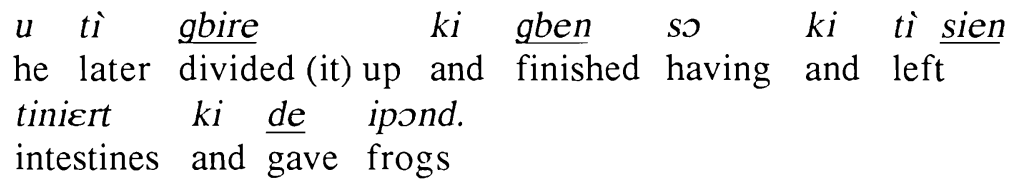

'He divided it all up, finished, left the intestines to one side, and gave them to the frogs.'

In this serial construction, $t i$ ' 'later' figures as a marker of total affectedness of the object of the first verb gbire 'divided' and possibly of the third verb sien 'left' (in the sense of 'left all the intestines' or, as I have translated here, in the sense of "placed to one side").
kperee wi
kon
kumuok ni.
hyena instantaneous went-home bush in

'The hyena suddenly struck out homeward for the bush.'

Here in this sentence there is one storyline verb accompanied by wi"instantaneously".
(37) unuon tí
gen iyuon.
bird iterative sang song
"The bird sang again."

\footnotetext{
${ }^{9}$ Walker prefers to assume here that the realis perfective form kpo 'died' is demoted from the storyline by virtue of its occurrence in setting. Since this is the opening setting of the narrative, it is assumed that it is setting and that the event of the old frog's death is an event which is backgrounded in reference to the storyline proper.
} 
In this example again there is but one storyline verb, in this case accompanied by $t \hat{i}$ "iterative".

9.2. Other storyline scheme bands. In Walker's salience scheme for Gangam narrative, realis imperfective forms, whether past or present, are in the Background band, which ranks just under the storyline.

(38)

ne $\quad k i$ fi paan ukpen bo ki ti ba and (he) conj. got up followed waterhole on and distance came

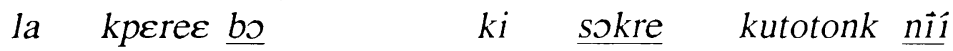
saw hyena bowing down conj. washing sweat sweating

'So he [rabbit] went to the waterhole and there he saw the hyena bowing down and washing [the intestines] with sweat pouring down him.'

This example illustrates realis imperfectives depicting background action. It also illustrates two common auxiliary verbs $f i$ 'get up' and ba 'come' whose precise discourse functions need to be studied. 10

Other bands of the Gangam salience scheme for narrative discourse are Setting, Collateral, Evaluation, and Backreference/Cohesion. Setting is characterized by nominal (verbless) clauses, existential clauses (with a 'be' verb te), and equational clauses (with a 'be' verb ye). The Collateral band is characterized by irrealis forms, especially the subjunctive and the future. Evaluation emerges in the conclusion of (explanatory) traditional stories in such forms as nen, saan, $+\mathrm{S}+$ $\mathrm{V}$... 'from then on he/they...'. Evaluation as author comment in the center of a narrative is given in a nominal (verbless) clause. Backreference is largely via connective phrases; backreferential clauses are apparently either infrequent or not used at all (cf. Kaje above).

9.3. Storyline rank and constituency structure. Some paragraph analysis of Gangam narrative was performed with Jean Reimer (co-worker with Bonnie Walker). While I do not reproduce the actual paragraph analysis, several things of interest emerged: (1) The verb ye 'said', although uninflected and therefore not formally a realis perfective, must be assumed to stand in for such a form (cf. such a verb as "questioned" which is inflected and has a realis perfective form).

${ }^{10}$ Admittedly, such verbs as 'get up' and 'go' and 'come' occur in serial verb constructions in many African languages where they apparently vary in status all the way from independent verbs to auxiliaries. Nevertheless, that their precise discourse functions must be traced out in particular for each language is evident, e.g. from the description of such verbs in Mündï, Jur-Mödö, Izi, and Mumuye in this volume. 
Therefore, in dialogue portions of narratives, speech acts introduced with ye are on the storyline much as in other languages (cf. the verb kob 'say' in Luwo, which is likewise uninflected). (2) In one narrative ("The Great Hunter") realis perfective verbs with subject as agent or experiencer clearly outrank realis perfective verbs with subject as patient. (cf. English as presented in the Introduction) This second concern is weighty enough to be developed more carefully below.

At one spot in the text the hunter is sitting alone in a tree over a waterhole. A variety of animals has come by, but in each case he has refrained from shooting the animal on the grounds that an even larger animal was coming. Eventually the presence of some great bird-like creature makes itself manifest. At this point I present this part of the text in translation (by Jean Reimer). For convenience of reference I number the sentences:

(39) 1. And he stayed sitting, sitting, sitting in the tree.

2. Then perceived something flying in, noise.

3. Trees split and fell.

4. He then came, tried to sit on a tree.

5. Aaa! That tree broke and fell.

6. He went sat on the water and covered all the water, all all all the surface.

7. The great hunter sitting in the tree shook with fear.

8. His skin clothing fell off, bow fell, rifle slipped and fell.

All the underlined forms represent Gangam realis perfective verbs. In 2 the subject of the verb perceived is experiencer. In numbers $\mathbf{4}$ and $\mathbf{6}$ the subject of the verbs is agent. In numbers $\mathbf{3}, \mathbf{5}, \mathbf{7}$, and $\mathbf{8}$ the subject of the verb is patient. While this paragraph could be analyzed as a simple sequence of events, this analysis seems to deny something almost strophic in the structure of the passage. We seem, in fact, to have a series of perceptions/actions each of which has certain results, either in the environment or on the psyche of the hunter himself. Regarded this way, $\mathbf{3}$ is resultant on 2, 5 is resultant on 4 , and 7 and 8 are resultant on 6 .

Since result paragraphs occur in languages around the world, we can construe this paragraph as a series of chronologically arranged result paragraphs. This means, therefore, that we considered 2 to dominate over 3, 4 to dominate over 5, and 6 to dominate over 7 and 8 . The dominant sentences expound theses and the ancillary sentences expound results. Sentence 1 with an off the line verb is simply setting. This yields the following tree diagram: 


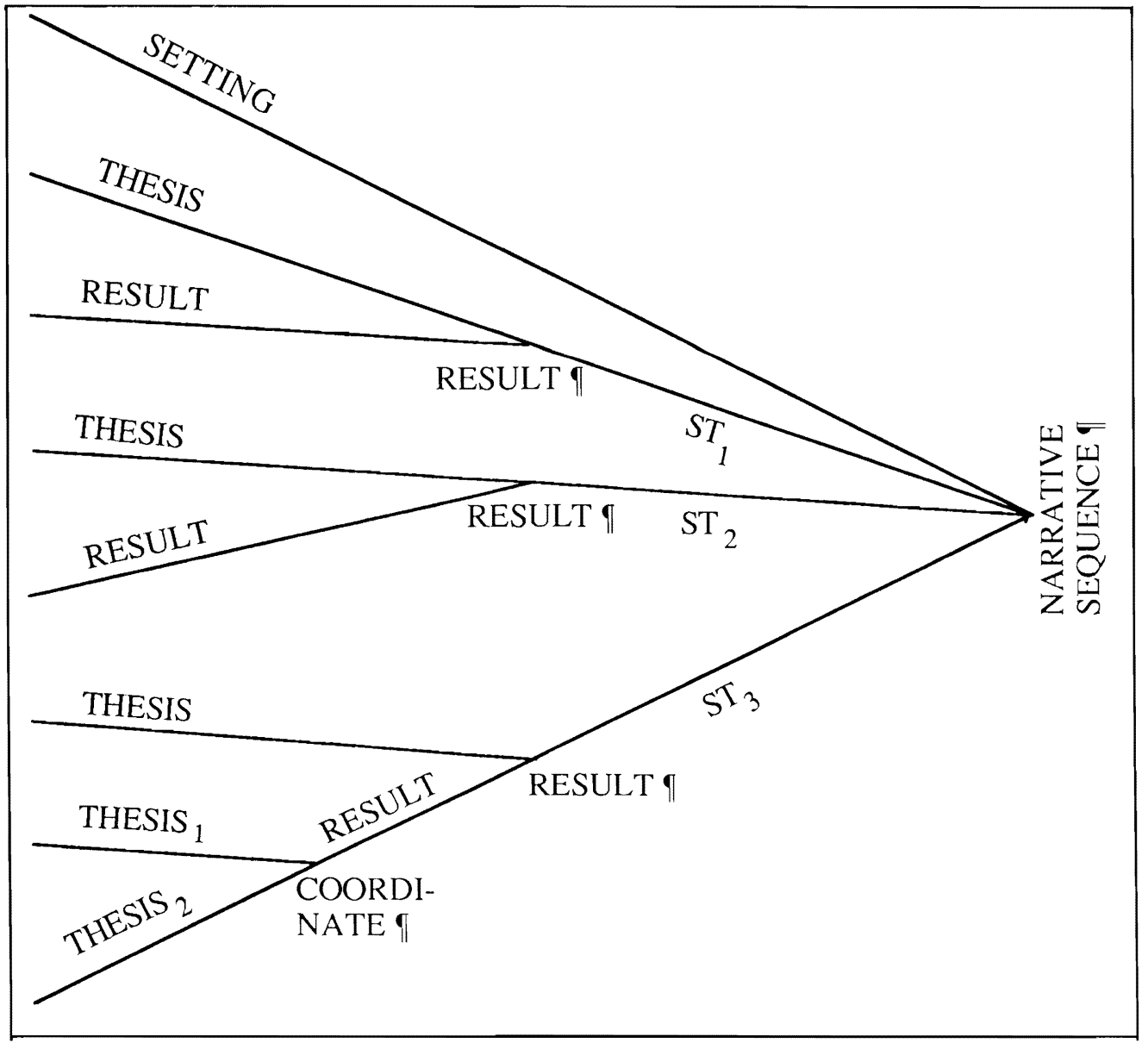

Diagram IV. A Gangam narrative sequence paragraph

The whole is a Narrative Sequence Paragraph which has a Setting and three Sequential Theses (ST's consisting of $2+3,4+5$, and $6+7 \& 8$ ). The embedded Result Paragraph consists of Thesis and Result in each case. The third Result Paragraph has a coordinate Paragraph embedded in its Result.

In this analaysis the agents are animate and voluntary; the patients are inanimate in $\mathbf{3}, \mathbf{4}$, and $\mathbf{8}$ and animate in $\mathbf{7}$. Instead of an agent we find an experiencer in $\mathbf{2}$; here, sentence 3 portrays the result of the being he perceived as coming.

I suspect that an in-depth analysis of storyline elements in languages the world over might well reveal some such subranking as that suggested here, i.e. a 
subranking within the storyline itself. This is propounded in the introduction but was not (because of time limitations) vigorously pursued as a research goal in the present project. 


\section{SOME CONCLUSIONS AND COMPARISONS}

There have been occasions in Chapters 2 and 3 to compare the surface structure chaining mechanisms of chaining languages which have medial verbs dependent upon a special final verb (Chapter 1) with chaining languages which have a special initial verb upon which depends the following consecutive verbs. I want here to examine and expand this comparison, then in turn to compare these chaining languages with such co-ranking (non-chaining) structures as those which are mentioned in Chapter 4.

Please note Diagram I. In this diagram MV, FV, IV, and CV symbolize medial verb, final verb, initial verb, and consecutive verb respectively. The left hand column is schematic of chaining languages of SOV structure which have a special fully inflected final verb preceded by medial verbs which are of simpler structure. These are dealt with in Chapter 1. The right hand column is schematic of chaining languages which have a more fully inflected initial form followed by consecutive forms which are of simpler (often unmarked) structure. Underlining, which is explained below, refers to storyline dominance.

\begin{tabular}{llll} 
Right-Chaining & \multicolumn{2}{l}{ Left-Chaining } \\
MV & $\underline{\text { FV }}$ & $\underline{\text { IV }}$ & CV \\
$\underline{\text { MV }}$ & FV & IV & $\underline{\text { CV }}$ \\
$\underline{\text { MV }}$ & $\underline{\text { FV }}$ & $\underline{\text { IV }}$ & $\underline{\text { CV }}$
\end{tabular}

Diagram I. Mirror image relationships in Right Chaining and in Left Chaining Languages 
A mirror-image relationship between the two types of structure is patently evident. Furthermore, it is of considerable interest that such a display as Diagram I reinforces against the background of discourse concerns the contention [Lehmann 1978] that the most profound and relevant typological cleavage is between OV languages (on the left hand side of diagram) and VO languages, whether VSO or SVO (on the right hand side of the diagram).

In considering various storyline weightings of parts of the medial-final chain in languages considered in Chapter 1, we found Koorete representative of languages in which the final verb outweighs the medial in terms of primary storyline versus secondary storyline. This is represented in the left column top row by underlining FV. We also found that Afar approximates a situation where the medials outweigh the final. Here, grammaticalization of certain finals has gone so far that in some case the medials have higher storyline rank. This is symbolized in the left column center row by underlining MV. For most Ethiopian chaining structures, however, the (unmarked) medial and the final on which it depends are of equal storyline status. This holds true of the other languages which are mentioned in Chapter 1 (Gimira, Kambaata, Haddiyyah, Amharic, and Silti). This third and more prevalent sort of storyline weighting is symbolized in Diagram I by underlining both MV and FV.

It was noted, moreover, in Chapter 1 that the degree of downward rank-shifting of medials (unmarked gerunds) differs considerably from language to language. In Gimira, although unmarked gerunds are storyline when they precede storyline finals, unmarked gerunds are downshifted to the rank of any non-storyline final that they precede. In Silti, on the other hand, downward rank-shifting does not occur at all. This probably correlates with the fact that true medials do not occur in Silti but rather modified finals.

All of this invites comparison with the right side of the diagram. To begin with, however, it should be noted that IV in the diagram indicates two differing constructions. (1) In some languages (Obolo, Anywak, Tem, Yom, Belanda-Viri and Jur-Mödö) there is an obligatory initial verb in storyline constructions. Some of these (noticably Tem) are also characterized by downward rank-shifting of the consecutive form (which may continue other, non-storyline, constructions). (2) In other language (Mündü, Sabaot, Luwo, and Nzema) there is no obligatory initial which preceeds consecutive forms when they are on the storyline. In a word, the consecutive form is autonomous when on the storyline. Nevertheless, all the latter languages permit the consecutive form to be used in at least some lower bands of the storyline rank scheme, i.e. downward rank-shifting occurs more or less freely, so that the consecutive form depends for rank on the non-storyline initial that it follows.

The question as to the relative dominance of initial verbs vis-a-vis consecutives is a bit more difficult. Dorothea Jeffrey has produced convincing evidence that in Mündü rank-shifted consecutive forms are not as dominant in paragraph structures 
as the marked forms on which they depend. This illustrates well the top row second column of Diagram I, where $\underline{\mathrm{IV}}$ is underlined.

Nawdm may represent a historical development where a consecutive tense has largely been relegated to the status of a complement or quasi-modal construction, as seems to be true of the "subjoined" structures which are described by Gasser. In fact, in historical narrative they still pattern somewhat similar to a consecutive tense on the lower bands of the storyline scheme. Here may possibly be an instance where a former consecutive tense has survived only in specialized uses. Such a development would most logically come about if the original situation was one in which the IV outweighed in storyline value the CV.

In most languages, it is probable that the IV and the $\mathrm{CV}$ are of equal storyline rank as is represented in the bottom row, second column. Here the comparison of the bulk of the languages described in Chapter 1 with some of the languages of Chapters 2 and 3 is closest. In right-chaining languages the most probable situation is that a medial verb will be of the same storyline rank as the final on which it depends. Similarly, in a left-chaining language the most probable situation is that a consecutive tense will be of the same storyline rank as the initial form on which it depends. This is represented in the diagram second column, bottom row as IV and $\underline{\mathrm{CV}}$ (where both are underlined).

But what of column two, middle row, where I represented a situation (IV $\underline{\mathrm{CV}}$ ) in which the consecutive form outranks the initial form? Here we would have to assume something on the order of grammaticalization of the initials (as auxiliary or aspect particles) with the disappearance of the consecutive form as such in favor of a particular marked form with a characteristic place in the storyline scheme. This, I suspect is what has happened in Izi, where 'go' and 'come' auxiliaries plus the sequential tense may reflect the collapse of a former initial verb and consecutive into an auxiliary-main construction.

Before terminating this discussion of MV + FV vis-a-vis IV + CV, it snould be mentioned that in approaching either sort of language we should not make the a priori assumption that the chain will be coextensive with the sentence; it may have a larger domain. In some Papua New Guinea chaining languages [Longacre 1972] and in some South American languages of similar structure [Longacre 1983b], the $(\mathrm{MV})_{\mathrm{n}}+\mathrm{FV}$ chain clearly outruns the sentence and may equal a paragraph or some larger span. In two of the IV $+(\mathrm{CV})_{\mathrm{n}}$ situations which are described in Chapter 3 we see that the chain can outrun the sentence: (a) in Belanda-Viri, where such a chain can cross sentence boundaries, and (b) in Jur-Mödö, where the chain relates to participant spans which can include a number of sentences.

A further MV + FV and IV + CV parallel has to do with the characteristic occurrence of longer chains at peak of a narrative discourse. Thus, for example, for Haddiyah, Korhonen reports long $(\mathrm{MV})_{\mathrm{n}}+\mathrm{FV}$ chains at peak, while for Mündü, Jeffrey reports a long IV $+(\mathrm{CV})_{\mathrm{n}}$ at the peak of at least one discourse. 
Turning now to other languages which are reported on in this study, we note the similarity of a neutral unmarked "narrative" tense to a consecutive tense without an obligatory initial form. Unlike a consecutive tense the neutral narrative tense does not undergo downward rank-shifting. We have mentioned such neutral and relatively unmarked narrative tenses for Mumuye, Jju, Ewe, Bassa, Mwaghavul, and Toposa. The neutral tense as a storyline form resembles, then, a consecutive tense without an IV and without rank shifting.

To show this similarity, note Diagram II, where four situations are schematically compared in relation to the occurrence of (a), an initial marked verb which must precede (b); (b) represents the occurrence of an unmarked verb; and (c) represents rank-shifting after non-storyline initial verbs. ("Verb" in all the above is to be construed as the verb plus other elements of the clause that it entails.) Rows 1-3 represent languages where it seems reasonable to speak of consecutive tense, i.e. a relatively unmarked verb form which entails either an obligatory preceding marked initial and/or rank-shifting of the unmarked form. Line 4 represents a narrative tense, which, like a consecutive tense, is relatively unmarked but entails neither a preceding marked form nor downward rank-shifting.

(a) (b) (c)

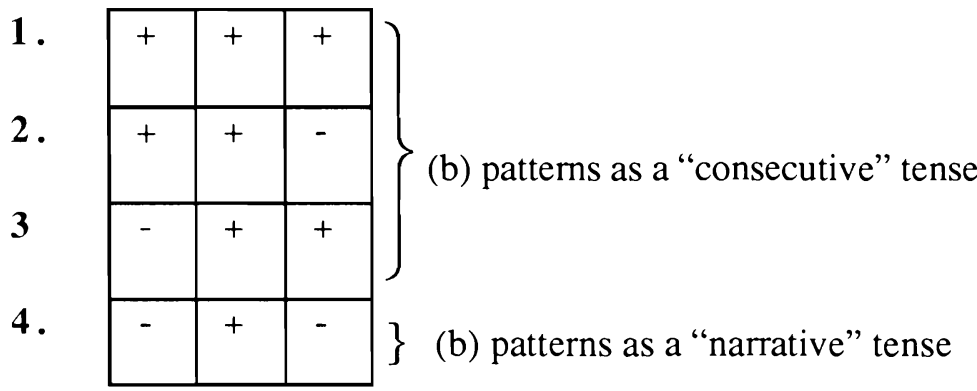

(a) = an initial marked verb which must precede (b); (b) = a relatively unmarked storyline form; $(\mathbf{c})=$ downward rank-shifting after non-storyline initials

\section{Diagram II}

Languages with a neutral form on the storyline may reinforce the storyline force of the verb with conjunctions. Thus, in Bassa, without a conjunction or backreferential clause, the unmarked form is not storyline but constitutes some sort of amplification or comment on a previous storyline verb. This is true also of Yom which I have listed above as having a consecutive tense. But the situation in Yom is peculiar and illustrates row 2 in Diagram II: (1) a consecutive form must be preceded by a perfect; (2) consecutive forms do not downshift-they never follow anything except a perfect; and (3) the perfect and the consecutive(s) which depend upon it are storyline if and only if preceded by a conjunction or clausal 
backreference (reminiscent of Bassa). In Mwaghavul, a language with a neutral narrative tense, the narrative particle $6 e$ 'and then' regularly precedes the neutral form as reinforcing the storyline. But this is also true of Mündü (which has a freely rank-shifting consecutive tense), where fü similarly reinforces the consecutive form and stays with it even when the latter is downshifted. Such languages typically plague the analyst with a small residue of neutral or consecutive forms where the all but diagnostic conjunction does not occur.

It is of some interest that Bassa is SVO in storyline clauses (with unmarked aspect) but SOV in non-storyline clauses with other aspects. Perhaps it is significant in the latter that the aspect particle follows the subject? A tempting but incomplete parallel is Avokaya where storyline clauses are SOV and have an aspect particle after the subject, while the secondary storyline is SVO and has no such particle. Has the interpositon of the aspect particle (a former verb?) in Bassa and Avokaya disturbed a SVO former order? (Avokaya has, however, a few other SOV forms in which no aspect particle intervenes.)

An outstanding feature in some languages of Sudan is the very large role given to the secondary storyline. This is evident in the frequent use of a "perfect" as secondary storyline in both Luwo and Avokaya. (The former has a consecutive tense, the latter does not). In texts in both languages the primary or the secondary storyline can prevail for extensive sections of narrative, or they can alternate with each other in a fashion that is bewildering in initial stages of analysis.

While I have not made much of the VSO versus SVO typological distinction in these comments, one important feature of VSO deserves comment, i.e. the focustopicalization slot available by left shifting the $\mathrm{S}$ or the $\mathrm{O}$ to the fore of the verb. This is not used at all (or negligibly) in Toposa but is structurally exploited in both Sabaot and Luwo. Use or non-use of such left shifting can also serve to distinguish a storyline (VSO) from non-storyline or secondary storyline (SVO) forms as in Luwo and in Biblical Hebrew. Such left-shifting is also is broadly characteristic of the many VSO languages of Mesoamerica. VSO languages do, then, provide some storyline strategies that are distinct from those of SVO languages, although the cleavage is not as great as of SOV versus VSO and SVO.

The two-fold assumption of this volume has been that (1) the various verb forms/clause structures of a language can be arranged in a structured cline from the most dynamic element, the storyline, on down and (2) that such a the scheme can be used to guide constituency analysis in the local span (the paragraph) by leading us to recognize dominant sentences versus sentences that are ancillary to them. In each of the substantive chapters of this book I have reported on the application of the latter to one language in each chapter. I have endeavored to show that rank scheme analysis can instruct paragraph analysis and that both can guide the interpretation of a discourse. It is the belief of the writer that careful discourse analysis can constain our interpretations of text so as to guide us to a kind of probability hermeneutics. 


\section{BIBLIOGRAPHY}

Bach, Emmon. 1970. "Is Amharic an SOV language?" Journal of Ethiopian Studies 8.1:9-20.

Beacham, C. Gordon. 1968. "The phonology and morphology of Yom." Doctoral dissertation, Hartford Theological Seminary.

Bender, M. Lionel (ed.). 1976. The Non-Semitic Languages of Ethiopia. Monograph No. 5, Occasional Papers Series, Committee on Ethiopian Studies. East Lansing, MI: The African Studies Center, Michigan State University.

Bender, M. Lionel, J.D. Bowen, R. L. Cooper, and C.A. Ferguson (eds.). 1976. Language in Ethiopia. London: Oxford University Press.

Bliese, Loren F. 1981. A Generative Grammar of Afar. SIL Publications in Linguistics 65. Arlington, TX: University of Texas at Arlington.

Bliese, Loren F. 1984. "On discourse analysis of Amharic narrative." Paper presented at the Eighth International Congress of Ethiopian Studies.

Chafe, Wallace. 1970. Meaning and the Structure of Language. Chicago: University of Chicago Press.

Creider, Chet A. and Jane. T. Creider. 1983. "Topic-comment relations in a verbinitial language." Journal of African Languages and Linguistics. 5:1-15.

De Craene, Robert. 1986. "Le verbe conjugué en tem." Studies in African Linguistics 17:1-38.

Dik, Simon. 1978. Functional Grammar. Amsterdam: Elsevier.

Ferguson, Charles. 1976. "The Ethiopian linguistic area." In M. Lionel Bender et al.(eds.), Language in Ethiopia, pp. 63-76. London: Oxford University Press. 
Givón, Talmy. 1975. "Serial verbs and semantic change: Niger-Congo." In C. Li (ed), Word Order and Word Order Change, pp. 47-112 Austin: University of Texas Press.

Hetzron, Robert. 1972. Ethiopian Semitic. Journal of Semitic Studies, Monograph No. 2. Manchester: Manchester University Press.

Hopper, Paul J. and Sandra A. Thompson. 1980. "Transitivity in grammar and discourse." Language 56:251-299.

Hudson, Grover. 1972. "Why Amharic is not a VSO language." Studies in African Linguistics 3:127-165.

James, Dorothy J. 1970. "Embedding and coordinating transforms in Siane." In Stephen A. Wurm and D.C. Laycock (eds.), Pacific Linguistic Studies in Honour of Arthur Capell, pp. 1095-1125. Sydney: Australian National University.

Jeffrey, Dorothea. 1983. "Third person identification and reference in Mündü narrative." To appear in the Proceedings of the Second Nilo-Saharan Colloquium at the New University of Ulster, Colerdine, Co. Derry, N. Ireland, July 1983.

Jones, Larry and Linda K. Jones. 1979. "Multiple levels of information in discourse." In L. K. Jones (ed), Discourse Studies in Mesoamerican Languages, Vol. I, pp. 3-33. SIL Publications in Linguistics 58. Arlington: University of Texas at Arlington.

Lehmann, Winfred P. (ed). 1978. Syntactic Typology: Studies in the Phenomenology of Language. Austin: University of Texas Press.

Longacre, Robert E. 1972. Hierarchy and Universality of Discourse Constituents, Vol. I, discussion. Washington: Georgetown University Press.

Longacre, Robert E. 1981. "A spectrum and profile approach to discourse analysis." Text 1:337-360.

Longacre, Robert E. 1982a. "Discourse typology in relation to language typology." In Sture Allén (ed.), Text Processing, pp. 457-486. Nobel Symposum 81. Stockholm: Almquits and Wyksell.

Longacre, Robert E. 1982b. "Verb ranking and the constituent structure of discourse." Journal of the Linguistic Association of the Southwest 5:177-202. 
Longacre, Robert E. 1983a. The Grammar of Discourse. New York: Plenum Press.

Longacre, Robert E. 1983b. "Switch-reference systems in two distinct linguistic areas: Wojokeso (Papua New Guinea) and Guanano (Northern South America)." In John Haiman and Pamela Munro (eds.), Switch-Reference and Universal Grammar, pp. 185-207. Amsterdam/Philadelphia: John Benjamins Publishing Co.

Longacre, Robert E. 1985. "Discourse peak, as zone of turbulence." In J.R. Wirth (ed.), Beyond the Sentence: Discourse and Sentential Form, pp. 81-98. Ann Arbor: Karoma Publishers.

Longacre, Robert E. 1989a. Joseph, a Story of Divine Providence: a Text Theoretical and Textlinguistic Analysis of Gen. 37 and 39-48. Winona Lake: Eisenbrauns.

Longacre, Robert E. 1989b. "Two hypotheses regarding text generation and Analysis." Discourse Processes 12:413-460.

Lusted, Marie. 1976. “Anywa." In M. Lionel Bender (ed.), The Non-Semitic Languages of Ethiopia, pp. 495-512. Monograph No. 5, Occasional Papers Series, Committee on Ethiopian Studies. East Lansing: African Studies Center of Michigan State University.,

Popovich, Harold. 1985. "A discourse phonology of Maxacali." Master's thesis, University of Texas at Arlington.

Walker, Bonnie. 1985. "Aspect, mode and viewpoint in Gangam narrative." Unpublished ms., Lome, Togo.

Wiebe, Neil. 1977. "The structure of events and participants in Cayapa narrative discourse." In R.E. Longacre and Frances Woods (eds.), Discourse Grammar: Studies in Indigenous Languages of Colombia, Panama, and Ecuador, Vol. 2, pp. 191-228. Summer Institute of Linguistics Publications in Linguistics and Related Fields 52. Arlington: University of Texas at Arlington. 
